\title{
LES VÉGÉTAUX AQUATIQUES Données biologiques et écologiques Clés de détermination des macrophytes de France
}

\author{
J. BARBE *
}

\section{AVANT-PROPOS}

Les ouvrages en langue française pouvant fournir des renseignements sur la végétation aquatique sont rares. Seu/s les travaux d'ACTA (1973) étaient susceptibles de remplir ce rôle, mais leur épuisement pose de nouveau le problème. Les flores générales ne manquent pas : COSTE (1937), BONNIER et DELAYENS (1974), FOURNIER (1961). MCLINTOCK et coll. (1964) mais leur utilisation. dans le cas qui nous préoccupe, est peu aisée pour les 2 raisons suivantes:

- les deux cents plantes aquatiques sont disséminées parmi les 4500 especes recensées :

- la systématique de ces ouvrages est essentiellement basée sur des caractères floraux; or, la floraison en milieu aquatique est loin d'être indispensable à la reproduction et surtout pas fréquente pour certaines espèces. Le meilleur exemple est celuide l'élodée (Holodea canadensis) dont seuls les pieds femelles ont été introduits en France vers 1870 . Combien ont déjà vu les fleurs de cette plante? Néanmoins, elle a colonisé tous les systèmes aquatiques.

Afin de pallier cette lacune et ces difficultés et, grâce au concours du Conseil Supérieur de la Pêche qui en assure la publication et la diffusion, jairassemblé dans ce document des éléments sur la systématique, la reproduction, la dissémination mais également des données écologiques sur la distribution et les rôles des végétaux aquatiques. Ce travail se termine par une clé originale de détermination des macrophytes, basée essentiellement sur les caractères morphologiques des tiges et des feuilles; lorsque cela n'a pu se faire, la clé s'arréte au genre (famille des JONCACEES et CYPERACEES). Elle est construite en trois étapes:

- une clé des embranchements et des classes,

- à l'intérieur de ceux-ci une clé des familles.

- puis chacune d'entre elles est reprise séparément pour aller, selon le cas, jusqu'au genre ou à lespece.

La nomenclature est celle utilisée par la Flore de France de FOURNIER(1961). Les planches ont été réalisées par A. MONNIER d'après nature, le cas échéant, d'aprés FOURNIER (1961).

Ce document doit répondre aux préoccupations, à la fois des personnels techniques des services d"application (services régionaux de l'aménagement des eaux, techniciens du Conseil Supérieur de la Pêchelet de tous ceux qui cherchent à connaître les végétaux aquatiques pour le rôle qu'ils peuvent avoir au sein des écosystèmes (habitats ou nuisances).

\footnotetext{
* Ministère de l'Agriculture, Laboratoire d'Hydroécologie du C.E.M.A.G.R.E.F., Division Qualité des Eaux, Pêche et Pisciculture, 3, quai Chauveau, 69009 LYON.
} 
SOMMAIRE

I. DONNEES BIOLOGIQUES

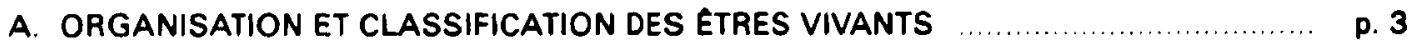

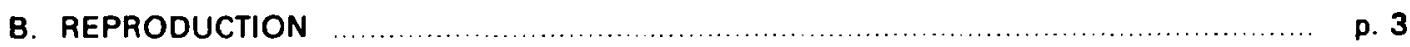

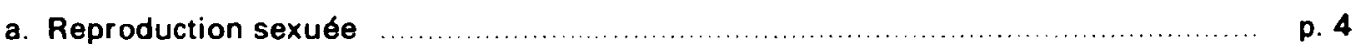

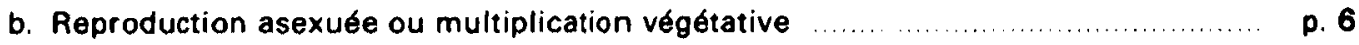

c. Dissémination des végétaux aquatiques …............................................ p. 6

II. DONNEES ECOLOGIQUES

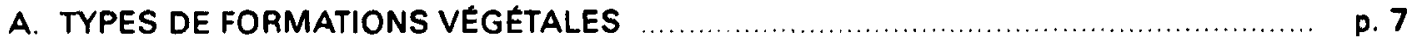

a. Les végétaux libres flottants - pleustophytes ou phytoneuston $\ldots \ldots \ldots \ldots \ldots \ldots \ldots \ldots$ p. 7

$\begin{array}{ll}\text { b. Les végétaux microscopiques de pleine eau : phytoplancton } \ldots \ldots \ldots \ldots \ldots \ldots \ldots \ldots \ldots \ldots & \text { p. } 7\end{array}$

c. Les végétaux benthiques ou phytobenthos .......................................... p. 7

d. Les groupements végétaux aquatiques …............................................. p. 10

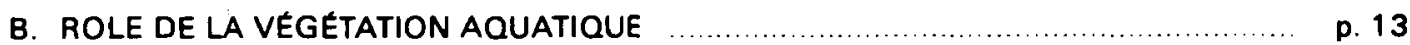

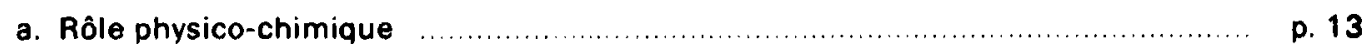

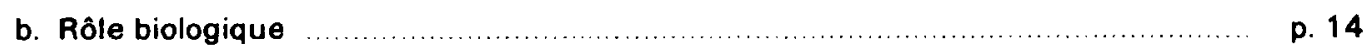

c. Rôle mécanique

III. CLE DE DETERMINATION

A. CRYPTOGAMES VASCULAIRES OU PTERIDOPHYTES (FOUGËRES) $\ldots \ldots \ldots \ldots \ldots \ldots \ldots$ p. 16

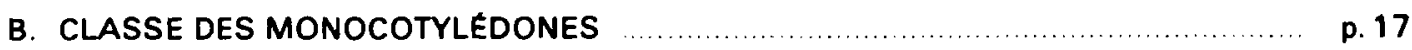

C. CLASSE DES DICOTYLEDONES …............................................................ p. 21

GLOSSAIRE

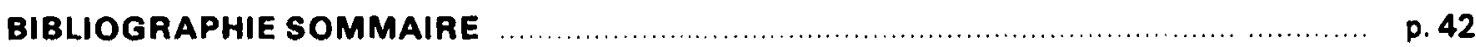




\section{INTRODUCTION}

C'est à partir d'organismes unicellulaires dotés de propriétés photosynthétiques vivant au sein d'un système aquatique que s'est développée la vie à la surface de notre planète. En effet, ces êtres chlorophylliens dérivés des bactéries (hétérotrophes) sont ainsi devenus autotrophes. Ce changement a permis l'apparition de l'oxygène dans l'eau par photosynthèse, puis progressivement la création d'une atmosphère d'oxygène faisant écran aux rayonnements ultraviolets et rendant possible la vie en dehors de l'eau. L'origine de ces organismes simples et primitifs, dont subsistent encore actuellement de nombreux représentants de la classe des cyanophycées, remonte à environ 3 milliards d'années. C'est donc l'évolution et l'adaptation de ces individus au cours des temps géologiques qui ont permis la complexité et la diversité du monde vivant actuel.

Les végétaux sont des êtres vivants généralement verts (pigments chlorophylliens) qui se nourrissent principalement, grâce à la photosynthèse, des sels minéraux et du gaz carbonique (autotrophie). La réaction globale de la photosynthèse peut se résumer comme ceci : d'une part, des molécules d'eau et de gaz carbonique constituent la matière première ; d'autre part, des molécules glucidiques sont les produits finis et l'oxygène est un sous-produit. L'énergie nécessaire à cette réaction est fournie par la lumière reçue, traitée et transmise par les molécules de chlorophylle et toute une chaîne de transporteurs. Ils les transforment en matière organique par fixation de l'énergie lumineuse ou chimique exogène.

En outre, les végétaux se caractérisent par rapport aux animaux par une mobilité généralement moindre, une sensibilité et des réactions plus faibles, une composition particulière de la membrane cellulaire (pecto-cellulosique, absence d'azote) et une nutrition à partir d'éléments simples. Ce sont des êtres sans orifice buccal et incapables d'ingérer des proies solides. La distinction des végétaux et des animaux est d'autant plus simple que les organismes sont plus différenciés. Certains groupes systématiques (bactéries, champignons) sans chlorophylle sont cependant rangés parmi les végétaux (hétérotrophes).

\section{DONNEES BIOLOGIQUES}

\section{A. ORGANISATION ET CLASSIFICATON DES ETRES VIVANTS}

L'unité d'organisation de tous les êtres vivants est la cellule. Animales ou végétales, isolées ou assemblées, les cellules ont un certain nombre de caractères communs.

Cependant leur nombre, leur forme, leur dimension varient selon les organismes. Mais pourtant, leur dimension ne varie pas en fonction du développement de l'organisme. Chacune des cellules remplit un certain nombre de fonctions vitales : elle respire, elle assimile les éléments nutrit ifs, elle excrète et, dans le cas de certaines cellules isolées, elle est très douée de mobilité.

Les animaux et les végétaux ont des degrés d'organisation variés : les plus simples d'entre eux sont les êtres unicellulaires. La complexité augmente avec le nombre de cellules en même temps que les cellules se spécialisent en vue de certaines fonctions.

Les végétaux pluricellulaires se rencontrent, soit sous forme de colonies de cellules, toutes semblables, soit à des niveaux divers de complexité jusqu'à atteindre les formes de végétaux supérieurs où les cellules sont assemblées en tissus remplissant certaines fonctions.

Le règne végétal est divisé en 2 sous-règnes :

- les protocaryotes possédant un noyau rudimentaire et comprenant les bactéries, les champignons et les algues bleues (cyanophytes).

- les eucaryotes comportant un noyau vrai sont constitués des algues (autres que les bleues), des bryophytes (mousses + hépatiques), des ptéridophytes (fougères) et des angiospermes (plantes à fleurs) (cf. tableau ci-après).

Dans les eaux douces on dénombre environ 15000 especes d'algues, une centaine de bryophytes et 150 à 200 angiospermes.

\section{B. REPRODUCTION}

Il existe, chez les végétaux, parmi les êtres vivants, deux manières fondamentales d'assurer par la reproduction la pérennité de l'espèce.

Tantôt le nouvel individu prend naissance à partir d'une cellule unique, l'œuf, généralement formé par la conjonction de deux cellules spécialisées : les gamètes (gamos = mariage) qui proviennent soit de deux parents différents ( $\delta$ et $q$ ), soit de deux organes différenciés sur un même individu. Ce type de multiplication par fusion nécessite l'existence de conditions ambiantes particulières (maturation, humidité, température, vent, présence d'un hôte transporteur de gamètes) et, de ce fait, la réussite est aléatoire : c'est la reproduction sexuée. 
CLASSIFICATION DU KICNI: VEGITAL

\begin{tabular}{|c|c|c|c|c|}
\hline SOUS-REGNE & & SUPER EMBRANCHEMLNT & EMBKANCHEMENT & CLASSES \\
\hline PROTOCARYOTES & & SCHIZOPHYTLS & $\begin{array}{l}\text { BACTEKIOSCHIZOPHYTES } \\
\text { CYANOSCHIZOPHYTES }\end{array}$ & $\begin{array}{l}\text { BACTERIES } \\
\text { CYANOPHYCEES }\end{array}$ \\
\hline \multirow{10}{*}{ Eucaryotes } & \multirow{9}{*}{ Cryptogames } & \multirow{7}{*}{ Thal lophytes } & $\begin{array}{c}\text { Mycophytes } \\
\text { (Champignons) }\end{array}$ & \\
\hline & & & Pyrrophytes & $\begin{array}{l}\text { Cryptophycées } \\
\text { Di nophycées }\end{array}$ \\
\hline & & & Chromophytes & $\begin{array}{l}\text { Chrysophycées } \\
\text { Dia tomophycées } \\
\text { Phéophycées } \\
\text { Xantophycées }\end{array}$ \\
\hline & & & Euglénophytes & Eug lênophycēes \\
\hline & & & Rhodophytes & Rodophy cées \\
\hline & & & Raphidophytes & Raphidophycées \\
\hline & & & Chlorophytes & $\begin{array}{l}\text { Chlorophycées } \\
\text { Prasi nophycées } \\
\text { Zygophycées } \\
\text { Cha rophycées }\end{array}$ \\
\hline & & $\begin{array}{l}\text { Cryptogames } \\
\text { cellulaires }\end{array}$ & Bryophytes & $\begin{array}{l}\text { Hépathiques } \\
\text { Muscinées }\end{array}$ \\
\hline & & $\begin{array}{l}\text { Cryptogames } \\
\text { vasculaires }\end{array}$ & Ptériduphytes & \\
\hline & Phanérogames & Spermaphytes & Angiospermes & $\begin{array}{l}\text { Monocotylëdones } \\
\text { Di cotylédones }\end{array}$ \\
\hline
\end{tabular}

Tantôt les individus fils prennent naissance directement à partir du parent par division, segmen. tation, bourgeonnement, production des stolons, sans l'intervention des gamètes. Ces éléments (unités de dispersion : diaspores) formeront immédiatement des organismes identiques à ceux dont ils proviennent. C'est la reproduction asexuée ou végétative.

\section{a. Reproduction sexuée}

La fécondation de 2 gamètes de sexes différents fait doubler le stock chromosomique. La méiose est le mécanisme compensateur qui ramène l'équipement en chromosomes à son niveau initial. Au cours du cycle sexué alternent ainsi une phase haploïde (à $n$ chromosomes) et une phase diploïde (à 2 n chromosomes).

Nous allons maintenant voir successivement comment se déroulent ces 2 phases chez les différents groupes du règne végétal.

\section{a.1. Les Algues}

Chez les algues, la méiose se produit à des moments variés et ne précède pas nécessairement la gamétogenèse. Lorsque la réduction chromatique intervient dès la germination du zygote, celui-ci constitue à lui seul la diplophase et le thalle est haploïde (cycle haplophasique).

Si le zygote est à l'origine du thalle diploide, qui produit par méiose des spores haploides, ces dernières engendrent un thalle haploïde portant les gamètes ; il y a aussi alternance de 2 générations : l'une haploïde, l'autre diploïde (cycle haplodiphasique). ou les spores

On appelie gamétophyte ou sporophyte la génération produisant respectivement les gamètes

L'importance relative des phases est variable selon les espèces. Trois grands types de cycles de développement (fig. 1) ont été distingués :

- cycle haplophasique,

- cycle haplodiplophasique,

- cycle diplophasique. 


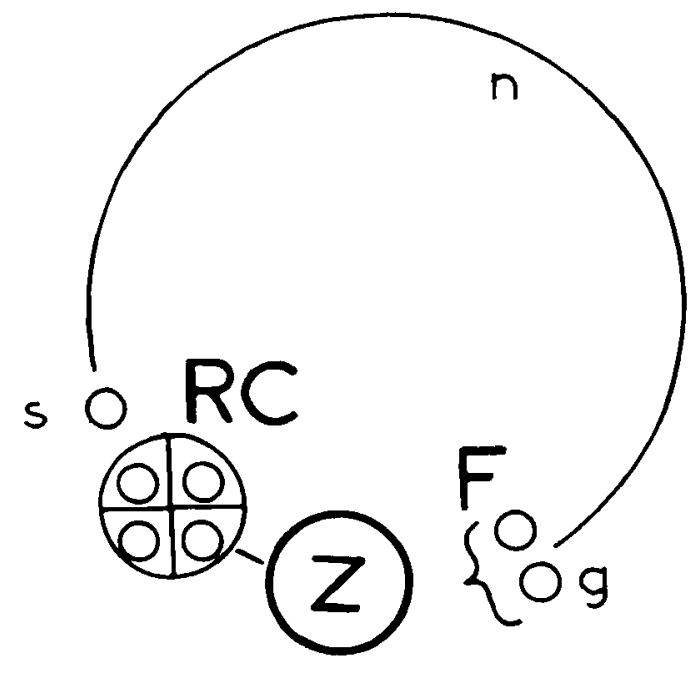

a

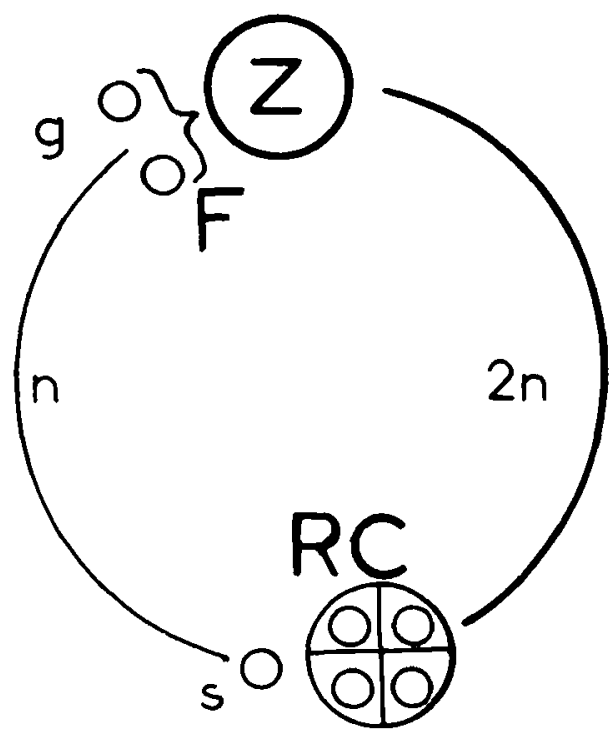

C

FIGURE 1. CYCLES DE DEVELOPPEMENT. DES ALGUES

g. gamètes a. cycle haplophasique

b. cycle diplophasique

c. cycle haplo-ciplophasique

F. Fêcondation

RC.reduction chromatique

s. spore

Z. zygote

\section{a. 2. Les Bryophytes}

L'appareil végétatif feuillé des mousses ne s'édifie pas d’emblée lors de la germination des spores, mais après la formation d'un élément d'apparence algoide, le protonéma (protos = primitif, nema $=$ filament) . La plante feuillée se forme ensuite sur le protonéma.

Ce protonéma et cette plante (feuillée ou à thalle) constituent le gamétcphyte, porteur des organes sexuels. Selon les espèces, les gamètes des 2 sexes sont issus soit du même pied soit des pieds différents. Cette phase gamétophytique est haploïde. Le sporophyte, diploïde, résulte de la fécondation et se développe sur le gamétophyte : on dit qu'il est parasite du gamétophyte. Par méiose. le sporophyte produira des spores haploides. Il y a alternance de 2 phases avec dominance de la phase haploide.

\section{a.3. Les Ptéridophytes}

Le sporophyte est ici plus développé que le gamétophyte qui, lui, est microscopique. Par rapport aux bryophytes, il y a inversion de l'importance des phases haploides et diploides. 
La tige feuillée représente donc le sporophyte qui libère les spores produites à l'intérieur des sporanges.

La germination de la spore conduit à l'édification du gamétophyte ou prothalle qui reste microscopique $(<1 \mathrm{~cm})$, chlorophyllien et fixé au substrat. Les gamètes se forment sur la face inférieure du prothalle. Les 2 sexes peuvent être sur le même pied ou sur des pieds différents. La fécondation donne naissance à un zygote $(2 \mathrm{n})$ qui engendre le sporophyte

a.4. Les Phanérogames (de phaneros = apparent et gamos = union)

IIs représentent le niveau d'organisation le plus évolué. La division du travail physiologique y est très marquée et l'organisme comporte plusieurs parties distinctes ou organes ayant chacun une structure et des fonctions propres.

L'appareil végétatif est typiquement constitué de racines et tiges femelles ; les organes reproducteurs sont groupés en rameaux très modifiés. Ils sont généralement bien apparents et colorés; ils sont regroupés dans la flaur. Les étamines correspondent aux sporanges ót produisent les grains de polten dont le contenu correspond au gamétophyte $O$. Le sporange $q$, ou ovule. renferme les oosphères ou gamète femelle. L'ovule fécondé se développe en fruit qui, après maturation, donnera les graines.

\section{b. Reproduction asexuée ou multiplication végétative}

Ce moyen de reproduction ne fait pas intervenir d'organes sexuels. II permet, en outre, la propagation de l'espece dans des conditions non favorables à la reproduction sexuée. Le milieu aquatique est particulièrement propice à l'installation de tout fragment de végétal détaché volontairement ou accidentellement d'une souche originelle : c'est le bouturage.

Ce mode est même obligatoire pour certains végétaux, soit parce qu'ils fleurissent rarement, soit parce qu'ils possèdent un seul type de fleurs. Helodea canadensis, en Europe, ne produit que des pieds portant des fleurs femelles.

Quelques plantes immergées (nénuphars, myriophylles, potamots, élodée, utriculaires), produisent des " hibernacles", sortes de "bourgeons dormants " qui passent l'hiver au fond.

La plupart des hélophytes (Phragmites, Scirpus, Typha) présentent un apparail radiculaire très développé et produisent de la même manière que le fraisier, des stolons permettant à une population de s'étendre progressivement si les conditions sont favorables.

Chez les algues également, la multiplication végétative est courante ; les organismes microscopiques sont capables de se scinder par scissiparité en 2,4 , n cellules-filles.

\section{c. Dissémination des végétaux aquatiques}

Les produits résultant des reproductions sexuées et asexuées parcourent parfois des distances importantes avant de donner naissance à de nouveaux individus. Ils sont transportés par des agents de dispersion divers.

\section{c. 1. Anémochorie ou dispersion par le vent}

II peut intervenir directement en transportant les éléments dans l'air ou indirectement en les accumulant à la surface de l'eau sur la rive exposée au vent.

Seules les graines des hélophytes (Phragmites, Typha) sont suffisamment légères pour être emportées par voie aérienne.

\section{c. 2. Hydrochorie ou dispersion par l'eau}

En eau courante, l'entraînement vers l'aval constitue une potentialité de colonisation à l'occasion de tout arrêt de transport. En eau stagnante, du temps de flottaison et des conditions d'accueil sur le substrat, dépend la réussite de la dissémination.

\section{c.3. Zoochorie ou dispersion par les animaux}

Il faut distinguer l'endozoochorie ou transport à l'intérieur de l'animal après ingestion et l'épizoochorie ou le transport à l'extérieur de l'animal.

L'action des sucs digest ifs, par destruction partielle des tissus des enveloppes de graines, aurait tendance à augmenter le taux germination

Les poissons peuvent ingérer les graines des genres Naias. Nuphar. Aponogeton.

La consommation des graines et des fruits par les oiseaux semble la plus fréquente, mais elles ne sont pas toutes digérées (Cypéracées, Nuphar, Nymphaea, Potamogeton).C'est également par les oiseaux que se fait l'épizoochorie : les fragments de plantes sont accrochés au bec, aux pattes et aux plumes. Toutefois, la conservation de l'échantillon dans une atmosphère suffisamment humide est le facteur de réussite de la transplantation. 


\section{c.4. Anthropozoochorie ou dispersion par l'homme}

MITCHELL (1974) signale que l'examen des exemples d'introduction de plantes aquatiques indique quatre catégories de personnes responsables: les aquariophiles, les pisciculteurs, les botanistes et les horticulteurs.

Le nombre de plantes proposées aux aquariophiles est relativement important (400 espèces) ; leur dispersion, à partir de la vidange d'aquariums ou l'enlèvement du surplus de plantes sans aucune précaution, est fréquente.

Les travaux de récupération des poissons dans le milieu naturel ou en pisciculture arrachent des fragments de plantes qui sont déversés sur les lieux d'exportation.

Botanistes et horticulteurs ont contribué à la dissémination pour des raisons esthétiques.

Eichhornia crassipes (jacinthe d'eau), considérée comme la peste d'eau sur le plan mondial, a été introduite aux États-Unis au siècle dernier pour la beauté de ses fleurs.

\section{DONNÉES ÉCOLOGIQUES}

\section{A. TYPES DE FORMATIONS VEGETALES}

\section{a. Les végétaux libres flottants - pleustophytes ou phytoneuston}

L'appareil radiculaire est peu développé, en l'absence de rôle de fixation : il s'agit de végétaux de petite taille $(1 \mathrm{~mm}$ à $5 \mathrm{~cm}$ ) spécialement adaptés à la flottaison grâce à la structure aérée de leurs tissus. Ils se développent exclusivement en faciès lénitique.

- Ptéridophytes (fougères) : ex : Azolla sp., Salvinia natans.

- Spermaphytes (ou phanérogames) : ex : Lemna sp., Spirodela sp., Hydrocharis sp., Wolffia arrhiza.

Cette espèce est la plus petite plante à fleur du monde.

\section{b. Les végétaux microscopiques de pleine eau : phytoplancton}

Le phytoplancton est composé d'algues unicellulaires ou coloniales vivant librement au sein du volume d'eau. leur mobilité relative étant due à l'existence de flagelles ou le plus souvent à des échanges gazeux avec le milieu ambiant.

Ces algues se développent dans les eaux calmes : lacs, étangs, noues et bras morts des granđs cours d'eau de plaine; dans les lacs profonds, elles se tiennent dans les couches superficielles où la lumière pénètre suffisamment pour permettre la photosynthèse.

La prolifération de certaines espèces donne diverses colorations au volume d'eau et peut même constituer des masses importantes a la surface ou en se déposant sur les berges; on parle alors de "fleurs d'eau". On observe une couleur lie de vin pour Oscillatoria rubescens, bleue ou verte pour certaines cyanophycées (comme Aphanizomenon) ou chlorophycées (comme Pediastrum - Scenedesmus).

Tous ces organismes font partie des producteurs primaires qui élaborent leur propre matière à partir des sels dissous, du gaz carbonique et de l'énergie lumineuse ; ils servent de nourriture aux petits invertébrés (rotifères, cladocères, copépodes...) et à certains poissons planctonophages (coré. gone, gardon, vandoise...)

\section{c. Végéteux benthiques ou phytobenthos}

\section{c. 1. Champignons et bacteries}

Ce sont des organismes dépourvus de chlorophylle qui, contrairement à tous les autres végétaux, sont hétérotrophes ; ils peuvent vivre à l'obscurité et synthétiser leur propre matière à partir de substances organiques dissoutes ou en cours de transformation. Cette particularité explique le fait qu'ils se développent parfois massivement au niveau des effluents résiduaires ou dans lés systèmes à forte charge organique. Certaines espèces sont spécialisées dans la transformation de substances particulières comme la cellulose (cellulo-bactéries), le fer (ferro-bactéries), le soufre (sulfo-bactéries). mais les formes les plus facilement observables dans les systèmes aquatiques pollués constituent des colonies macroscopiques. Ces dernières prennent l'aspect de flocons, de coton hydrophile, de filaments duveteux appelés "queues de mouton " ou "queues d'agneau " ou encore " glu ". Ces formations colonisent tous les substrats en formant des masses plus ou moins filamenteuses. généralement blanchâtres ou grisâtres, visqueuses au toucher. Les groupes les plus fréquents sont : 
- parmi les champignons

- Leptomitus de couleur laiteuse

- Fusarium aquaeductum de couleur rouge brique garnissant les canalisations et les crêtes de barrages (préférence pour les fortes vitesses d'écoulement) :

- parmi les bactéries

- Beggiatoa, Sphaerotilus, Cladothrix, Leptothrix, Crenothrix, Zoogloea.

Partant de la constatation qu'un certain nombre d'organismes se développent électivement dans les eaux polluées par des matières organiques, on peut proposer une gamme d'espèces considérées comme indicatrices de certains degrés de pollution organique.

Parmi ces indicateurs, diversement saprobiontes, figurent des algues filamenteuses formant des colonies macroscopiques, des bactéries et des champignons dont le développement correspond à des teneurs excédentaires en matières organiques, azote ou phosphore.

\section{c. 2. Algues épibenthiques constituant la couverture biologique primaire des supports immer-} gés.

Dans les eaux courantes et les bordures lacustres, ces algues, parmi lesquelles de nombreuses diatomées, colonisent tous les supports : elles forment une pellicule brunâtre $(e \leqslant 1 \mathrm{~mm})$ glissante à la surface des pierres et des galets. Certaines, entourant les macrophytes d'une sorte de gaine, font partie du périphyton.

Les diatomées sont des algues unicellulaires ou coloniales, solitaires ou filamenteuses, formées d'un squelette siliceux finement orné, constitué de deux valves emboîtées renfermant l'individu. Les groupements d'espèces peuvent être utilisés pour l'évaluation de la qualité biologique des eaux courantes.

\section{c.3. Algues constituant des colonies macroscopiques non filamenteuses}

Ce type de formation regroupe des algues coloniales appartenant à différents groupes :

- des chlorophycées comme Palmella,

- des rhodophycées comme Batrachospermum,

- des cyanophycées comme Nostoc.

- des chrysophycées comme Hydrurus foetidus.

Dans tous les cas, le thalle forme des masses gélatineuses, lâches ou globuleuses, fixées sur les supports benthiques.

Hydrurus foetidus se développe surtout dans les cours d'eau à salmonidés, le front de la population se déplaçant vers l'aval en période froide, pour se limiter à des secteurs de plus en plus apicaux lorsque les eaux s'échauffent.

Certaines colonies constituent des masses gélatineuses vertes ou bleutées, irrégulièrement lobées (Palmella) ou globuleuses (Nostoc); d'autres sont plus ou moins irrégulièrement ramifiées en forme de doigts (Hydrurus) ou en chapelets à l'image des pontes de batraciens (Batrachospermum).

Toutes ces formes se développent généralement dans les eaux froides ou fraîches.

\section{c.4. Algues constituant des colonies macroscopiques filamenteuses.} variables

Les filaments ramifiés ou non constituent des colonies de forme, de couleur et de texture

- filaments rassemblés en coussinets à la surface des pierres et galets - toucher rugueux - fréquente alternance d'auréoles vertes, claires et foncées (Vaucheria),

- filaments longs $(5-40 \mathrm{~cm})$, couleur verte.

- non ramifiés, toucher visqueux)(Spirogyra),

- irrégulièrement ramifiés (Cladophora),

- ramifiés dichotomiquement (Dichotomosiphon)

couleur violacée, noirâtre ou brunâtre, rude au toucher (Lemanea),

- filaments courts et colonies de petite taille $(2.5 \mathrm{~cm})$

- ramifiés, de couleur rouge ou violette (Audouine/la)

- ramifiés, de couleur verte (Stigeoclonium)

non ramifiés, de couleur vert pâle (Ulothrix).

lacs).

\section{c.5. Algues macroscopiques imprégnées de calcium tapissant le fond des eaux calmes létangs,}

Ces algues rappellent par leur morphologie extérieure et leur taille des plantes plus évoluées comme les cératophylles ou les prêles.

La plante est formée d'une" tige " principale portant des verticilles réguliers de " rameaux "et 
de "feuilles". Par contre, la structure de ces éléments figurés, très simple, n'est pas comparable à celle des plantes supérieures.

L'incrustation de toutes les parties végétatives donne un toucher rugueux et rigide, parfois cassant ; ces algues benthiques appartiennent à la famille des Characées.

La profondeur, liée à la transparence à laquelle ces algues se développent, constitue une indication synthétique de la qualité de l'eau, d'autant meilleure que la profondeur de récolte est grande.

\section{c.6. Les Hépatiques}

L'appareil végétatif se présente sous la forme d'une lame verte (hépatiques à thalle) plus ou moins large ou possédant une" tige "et des" feuilles "en deux rangées (sauf Fissidens - muscinée).

Hépatique à thalle :

- thalle en forme de lame bifide - plante flottant librement (Riccia fluitans),

- thalle rampant sur les pierres ou sur la vase exondée,

- face supérieure du thalle sans stomate ni cavité aérienne - plante souvent submergée (Pellia)

- face supérieure du thalle avec stomates et cavités aériennes - plante rarement submergée,

- stomates visibles à l'ceil nu (Fegatella conica)

- stomates visibles seulement à un fort grossissement (Marchantia polymorpha).

Hépatique à feuilles:

- feuilles bilobées - lobe dorsal plus petit que le ventral (Scapania)

- feuilles non lobées (Chilosciphus polyanthus)

Cette espèce des sources et des ruisseaux est indicatrice de la fraîcheur de l'eau lespèce sténotherme d'eau froide).

\section{c.7. Mousses (plus les sphaignes)}

Les mousses possèdent une tige et des feuilles disposées en 3 rangées au moins (sauf Fissidens) et sont fixées au substrat par des rhizoïdes (crampons) qui leur permettent de résister à de fortes vitesses de courant.

Pendant les périodes de basses eaux, elles se dessèchent et reprennent leur activité en période plus favorable. Généralement groupées en peuplements très denses, elles gardent ainsi la légère humidité nécessaire à leur survie. Elles constituent l'habitat préféré d'un grand nombre d'invertébrés benthiques.

Certaines especces forment des brosses (de quelques $\mathrm{cm}$ ) a la surface des roches, alors que d'autres laissent onduler leurs rubans (quelques $\mathrm{cm}$ ) dans les courants (mousses fluicoles comme Fontinalis).

Dans les marais, les milieux tourbeux, prospèrent des peuplements très denses de sphaignes, éléments à croissance continue participant à la formation de la tourbe.

Au niveau des suintements, des milieux humides et ombragés, des sources, se développent sur les dalles et les blocs des mousses appartenant aux genres Cratoneurum ou Cinclidotus.

Dans les courants croissent des mousses constamment immergées comme Fontinalis, Lepdodyctium ou Plathypnidium.

\section{c.8. Phanérogames fixés radicants, à feuilles immergées : hydrophytes submergés.}

II s'agit de végétaux aquatiques au sens strict dont l'existence est liée à la permanence d'une couche d'eau ; ils sont fixés au substrat et la totalité de leur appareil végétatif est immergé ; $n$ 'apparaissent à la surface de l'eau que les parties reproductrices (reproduction sexuée, fleurs).

De nombreux représentants de cette catégorie présentent des tiges grêles et des feuilles filiformes ou laciniées offrant peu de résistance; c'est le cas par exemple de Ranunculus fluitans, Potamogeton pectinatus ou Potamogeton mucronatus, Potamogeton trichoides capables de se développer dans tout le volume d'un étang, Ranunculus aquatilis ou Myriophyllum spicatum.

Parmi les formes à feuilles étalées ou bien développées, figurent de nombreuses espèces du genre Potamogeton comme $P$. densus, $P$. crispus, $P$. lucens, $P$. perfoliatus, ainsi que de nombreux autres végétaux surtout lacustres comme Elodea canadensis ou de cours d'eau comme Callitriche obtusangula.

\section{c.9. Phanérogames fixés à feuilles flottantes: hydrophytes flottants}

Ces végétaux sont fixés sur le substrat et étalent à la surface de l'eau le limbe de leur feuille, ils se rencontrent en faciès lénitique en des profondeurs pouvant être assez grandes $(1 \mathrm{à} 7 \mathrm{~m})$.

Les feuilles sont généralement de grande taille et présentent stomates et lacunes aérifères sur la face supérieure, ex. : Nuphar luteum. Nymphaea alba, Potamogeton natans, Polygonum amphibium. 


\section{c. 10 Phanérogames de bordure : amphiphytes ou hélophytes.}

Ce sont des espèces dont l'appareil racinaire se trouve dans un milieu constamment gorgé d'eau mais dont les parties végétatives se développent plus ou moins hors de l'eau. Ce sont des espèces semi-aquatiques ou amphibies, ex. : parmi les espèces communes : Phragmites communis, Typha latifolia, Carex riparia, Equisetum limosum, Ranunculus lingua, Helosciadium nodiflorum. Menyanthes trifoliata, Denanthe.

\section{d. Les groupements végétaux aquatiques}

Les plantes ne sont pas réparties au hasard dans les écosystèmes aquatiques mais groupées en associations dont les éléments présentent sensiblement les mêmes exigences écologiques.

L'association végétale, expression d'un ensemble de caractéristiques écologiques, constitue une unité de base en Phytosociologie.

Bien qu'ils renferment certaines espèces communes, les groupements végétaux sont différents dans les systèmes d'eau calme et les systèmes d'eau courante.

\section{d. 1. Dans l'écosystème d'eau courante (fig. 2)}

Suivant le mode d'écoulement et les variations de certains paramètres corrélés comme la pente, la vitesse du courant, ou la granulométrie des fonds, les végétaux se distribuent longitudinalement, une flore des fonds déposés se substituant progressivement à celle des fonds érodés.

- Les émergences rhéocrènes :

Elles sont peuplées d'hépatiques comme Fegatella conica ou Marchantia polymorpha et de muscinées incrustantes à l'origine de la formation des tufs (Cratoneuron).

- Les sources limnocrènes :

Elles sont situées dans des dépressions formant des flaques ou des plans d'eau de petites dimensions. Ces sources sont peuplées d'espèces lénitophiles d'eau fraîche comme Nasturtium officinale, Helosciadium nodiflorum. Mentha aquatica, Veronica anagallis, Veronica beccabunga et les lentilles d'eau (Lemna).

- Les secteurs torrentiels et les surfaces hygropétriques :

Les dalles et blocs hébergent une flore souvent réduite à des algues benthiques (diatomées) généralement sténothermes d'eau froide; dans les secteurs les moins turbulents, s'installent quelques mousses comme Plathypnidium.

- Les secteurs d'eau vive (cours d'eau à Salmonidés dominants - Rhithron) :

lls sont caractérisés par une alternance d'habitats en faciès lotique (radiers) et lénitiques (profonds, mouilles, "pools ").

Les forts courants sur un substrat de blocs et de cailloux sont colonisés par des bryophytes rhéophiles : Cinclidotus aquaticus, Cinclidotus fontinaloides, Fontinalis antipyretica, Calliergon giganteum, Leptodyctium riparium...

Les éléments sablonneux ou limoneux en courant plus faible sont peuplés de phanérogames d'eau vive : Ranunculus fluitans, Potamogeton crispus, Potamogeton perfoliatus, Helosciadium nodiflofum, callitriches...

- Les secteurs inférieurs des cours d'eau (à Cyprinidés dominants - Potamon) :

Dans ces secteurs à pente et vitesse de courant faibles, les sédiments permettent le développement des végétaux du faciès lénitique. Les hydrophytes fixés affleurant (Nuphar. Nymphaea, Potamogeton natans, Polygonum amphibium...) colonisent les zones rivulaires et lorsque les berges sont en pente douce, on observe une succession d'espèces identique à celle des écosystèmes d'eau calme, (" herbiers "des grands cours d'eau de plaine comme la Saône ou le Doubs inférieur)

\section{đ. 2. Dans l'écosystème d'eau dormante (fig. 3)}

On distingue trois zones nettement différenciées par la nature et la taille des peuplements végétaux

- une zone littorale colonisée par des macrophytes disposés en ceintures plus ou moins nettes, pouvant d'ailleurs se rejoindre dans les étangs peu profonds.

- une zone pélagique, bien éclairée, domaine du phytoplancton,

- une zone profonde, obscure, où ne subsiste qu'une flore achlorique (bactéries et champignons) et quelques cyanophycées.

- La zone littorale abrite des végétaux de types biologiques différents définis suivant leur position par rapport à la surface de l'eau ; les espèces se répartissent en fonction de la profondeur en une distribution plus ou moins concentrique (ceintures végétales). 


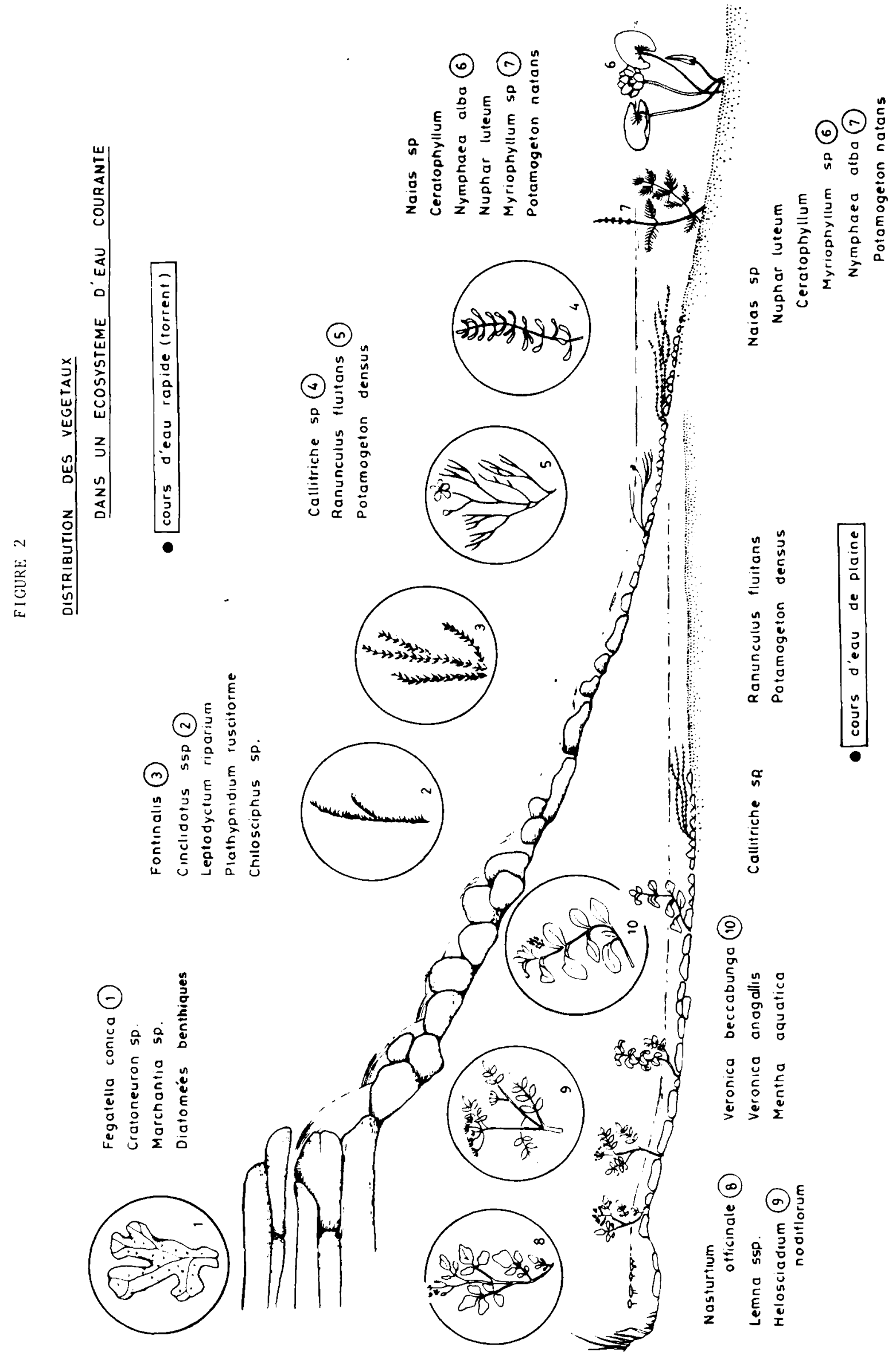




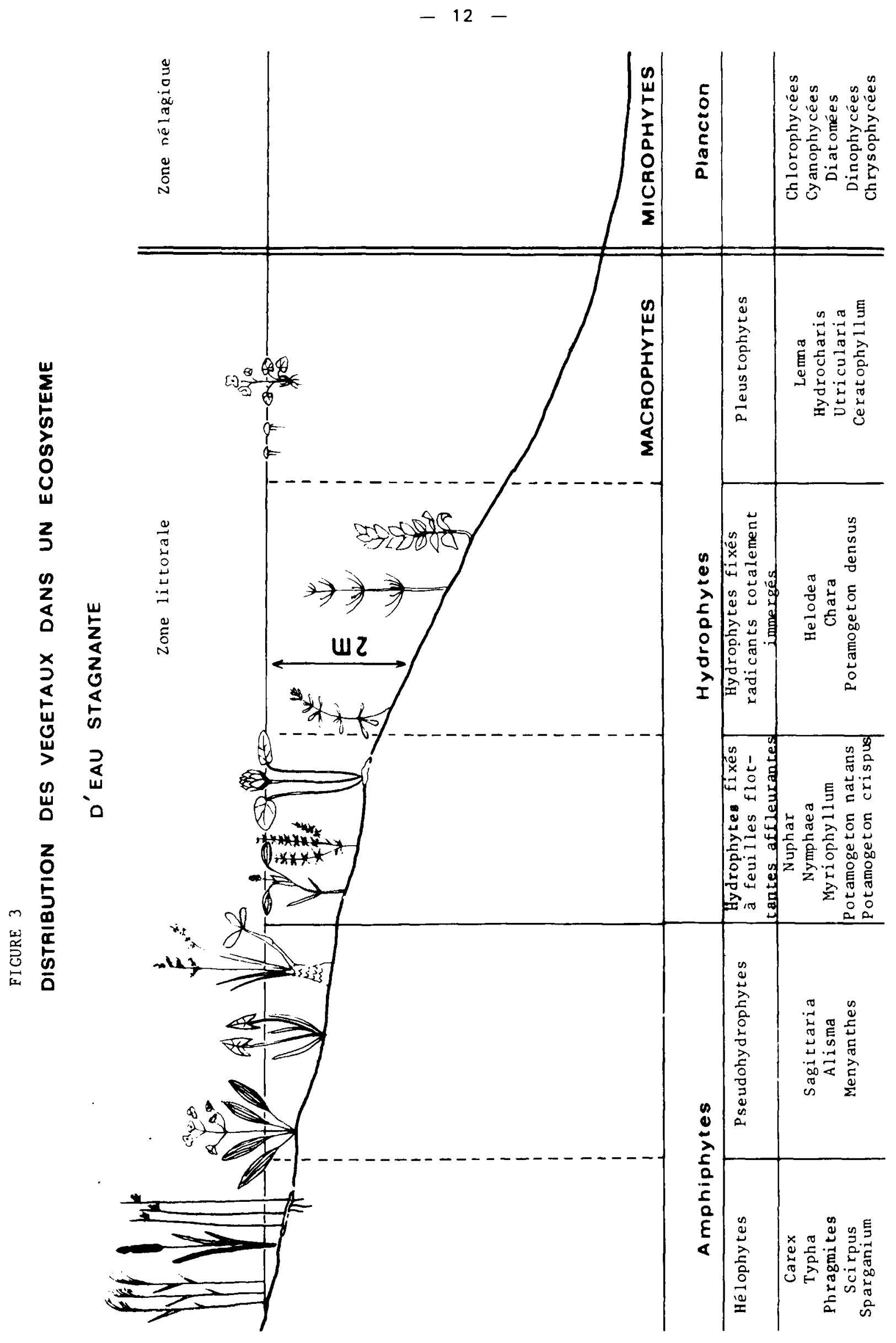


- Les amphiphytes ou hélophytes : ce sont des plantes amphibies dont la base est normalement dans l'eau et dont le développement des parties reproductrices nécessite le contact avec l'atmosphère (elles peuvent avoir des formes aquatiques mais elles restent alors stériles). Parmi ces espèces de l'extérieur vers l'intérieur, se rencontrent successivement : Phragmites communis, Typha sp.. Equisetum limosum, Scirpus lacustris.

- Les hydrophytes fixés à feuilles flottantes affleurantes possèdent un appareil radiculaire, leurs parties végétatives traversent la colonne d'eau par les tiges ou les pétioles et viennent s'étaler à la surface de l'eau (feuilles).

C'est le cas de Nuphar luteum, Nymphaea alba, Potamogeton natans, Polygonum amphibium

- Les hydrophytes fixés radicants totalement immergés développent leurs parties végétatives au sein de la masse d'eau sans contact avec l'atmosphère. Parmi ce groupe on rencontre des espèces formant de véritables prairies sur le fond des plans d'eau (Helodea canadensis, Potamogeton densus, Hippuris vulgaris, Chara $s p$.

- Les hydrophytes libres ou pleustophytes ne possèdent aucun système de fixation sur le substrat, ils peuvent être soit flottants comme les Lemnacées (lentilles). Salvinia natans, Azol/a sp., soit nageants en pleine eau comme Utricularia sp.

- La zone pélagique est la zone préférentielle du développement des organismes microscopiques libres constituant le plancton.

Les peuplements planctoniques beaucoup plus complexes dans leur composition et dans leur succession que les groupements végétaux font l'objet d'une double distribution à la fois dans l'espace et dans le temps.

\section{Distribution verticale :}

La quasi-totalité des peuplements est localisée dans les dix premiers mètres : zone trophogène où les processus métaboliques l'emportent sur le catabolisme. En dessous de cette zone, la quantité d'énergie lumineuse incidente est très faible et ne permet pas le développement des organismes photosynthétiques, c'est la zone tropholytique ou zone profonde.

\section{Distribution temporelle :}

De par leur taille, leur structure, les organismes planctoniques sont très sensibles aux variations de certaines composantes du milieu (température. sels nutritifs...) et ont de ce fait une existence très éphémère, aboutissant à une succession de peuplements différents au cours d'un cycle annuel.

Ces variations saisonnières ont des effets immédiats sur la transparence et la couleur de l'eau. la prolifération de certaines algues pouvant entrainer une coloration rapide et intense de la masse d'eau ; elles se traduisent également par une biomasse hivernale minimale à diatomées dominantes. les "fleurs d'eau" se succédant du réchauffement printanier jusqu'en automne.

\section{B. Role de la vegetation aquatique}

\section{a. Rôle physico-chimique}

L'activité photosynthétique diurne des végétaux chlorophylliens produit de l'oxygène et absorbe le gaz carbonique.

Quelles que soient leurs formes et leurs dimensions, les plantes sont indispensables dans tout écosystème aquatique.

Durant la période nocturne, la fonction chlorophyllienne ne s'effectue pas, les végétaux, comme les animaux, utilisent l'oxygène dissous dans l'eau.

La quantité d'oxygène produite pendant le jour dépend des caractéristiques de la plante (état physiologique) et des paramètres propres au substrat aqueux (insolation, température, pourcentage de saturation du milieu).

L'oxygène libéré, outre de permettre la respiration des animaux, a pour rôle essentiel de favoriser les oxydations (nitrifications). La fixation du carbone du gaz carbonique ou des bicarbonates affecte leurs teneurs dans les eaux et s'accompagne d'une élévation du $\mathrm{pH}$. En période de végétation importante, on assiste à des cycles journaliers de l'oxygène, $\mathrm{du} \mathrm{pH}$, des carbonates et bicarbonates. Les concentrations en oxygène sont maximales en fin de journée (19 h) et minimales en fin de nuit ( $6 \mathrm{~h}$ ). Des concentrations variant de $25 \mathrm{mg} /$ / (200\% de saturation) à $3 \mathrm{mg} /$ I peuvent se rencontrer sur un cycle de $24 \mathrm{~h}$ dans des milieux très chargés en phytoplancton.

L'écran que constituent les pleustophytes (Lemna sp.) ou les hydrophytes fixées à feuilles flottantes (Nymphéacées, Trapa natans) limite la pénétration du rayonnement lu mineux et le développement de la végétation sous-jacente (hydrophytes immergés, phytoplancton). Simultanément ce tapis végétal joue un rôle de barrière entre l'eau et l'atmosphère, limitant les échanges thermiques et engendre ainsi une stratification thermique estivale peu marquée (JUGET, ROSTAN, 1973). 
La nutrition azotée et phosphorée des plantes s'effectue par absorption directe des substances nutritives dans l'eau ou dans les sédiments. Dans le cas des macrophytes, la consommation des nutriments a lieu essentiellement au cours de la période végétative (mai-octobre).

Jusqu'à une époque relativement récente, il était admis que la nutrition s'effectuait seulement par diffusion des éléments à travers les membranes cellulaires des tiges et des feuilles. Diverses expérimentations récentes (HUTCHINSON, 1975) ont montré que certains végétaux enracinés pouvaient également puiser leur nourriture dans le sédiment de la même façon que les plantes terrestres. Toutefois, la majeure partie de leur nutrition est extraite du milieu ambiant permettant ainsi une amélioration de la qualité de l'eau. Selon divers auteurs (SYMOËNS et coll., 1982) les populations de végétaux vasculaires peuvent contenir 0,2 à $16 \%$ de l'azote et 1 à $37 \%$ du phosphore des apports annuels. Ces résultats ont conduit à estimer que la récolte des plantes pouvait être un moyen de lutte contre l'eutrophisation des milieux (CARPENTER et ADAMS, 1977).

Les végétaux libèrent dans l'eau des substances organiques selon deux processus

- I'un est continu, il s'agit de produits d'excrétion sous forme de matières organiques dissoutes par les tiges feuillées. Ce phénomène dépend des divers facteurs (WETZEL, 1969) dont les concentrations en cations des eaux ( calcium, magnésium, sodium, fer, etc.). Ce relargage peut atteindre $20 \%$ de la quantité de carbone fixé par photosynthèse :

- l'autre est lié à la décomposition de la matière organique des tissus végétaux. Il peut se produire naturellement au cours d'un cycle annuel ou être le résultat de certaines actions anthropogènes (faucardage, traitement chimique). A terme, ces produits viennent s'ajouter aux sédiments superficiels et rentrent dans le cycle de la matière par l'intermédiaire des décomposeurs.

Les échanges entre le milieu aquatique et l'atmosphère se font directement au niveau de leur surface de contact, l'évapo-transpiration des végétaux à feuilles flottantes est supérieure à l'évaporation de la surface libre. Cette évapo-transpiration revêt une importance particulière dans les systèmes à faible taux de renouvellement.

\section{b. Rôle biologique}

\section{b. 1. Production primaire}

Les végétaux constituent l'élément de base des chaînes alimentaires des biocénoses aquatiques. La production de matière organique à partir de substances dissoutes ou colloïdales dans l'eau est l'expression de la synthèse du vivant à partir des composés élémentaires.

Les végétaux vasculaires peuvent représenter 0,7 à $5,1 \%$ de la production primaire totale des écosystèmes stagnants. Cette production annuelle peut paraître relativement faible vis-à-vis de celle des algues planctoniques ou périphytiques, mais si elle est rapportée uniquement à la période de croissance, elle devient nettement plus importante : cf. le tableau comparatif ci-dessous, d'après WETZEL, 1964

Phvtoplancton (année) Périphyton (année) Macrophytes (année) Macrophytes (période de croissance : 75 j)

\begin{tabular}{l|l}
\begin{tabular}{l|l} 
Production movenne \\
$\mathrm{mgC} / \mathrm{m}^{2} / \mathrm{j}$
\end{tabular} & $\begin{array}{l}\text { Valeurs } \\
\mathrm{mgC} / \mathrm{m}^{2} / \mathrm{j}\end{array}$ \\
\hline 249,3 & $\begin{array}{r}10,4-524,5 \\
731,5\end{array}$ \\
76,5 & $0.0-5760,0$ \\
372,3 & $0.0-982,2$
\end{tabular}

La part de production primaire des macrophytes dans la production totale d'un lac dépend essentiellement de la hauteur d'eau.

Les concentrations des eaux et des sédiments en substances nutritives ont également une influence sur la biomasse produite: WESTLAKE (1963) estime que les productions primaires nettes annuelles des plantes immergées dans des lacs fertiles varient de 4 à 7 tonnes par ha, alors qu'en milieu pauvre elles sont seulement de 1 à 2,5 tonnes à l'ha. La production des végétaux émergés (hélophytes) peut atteindre 20 à $46 \mathrm{t} / \mathrm{ha}$ avec la valeur extrême de l'ordre de $75 \mathrm{t} / \mathrm{h}$ a pour la graminée Arundo donax.

La biomasse des plantes immergées (hydrophytes au sens large) dépasse rarement $1 \mathrm{~kg}$ de matière sèche au $\mathrm{m}^{2}$, alors que les macrophytes émergés (hélophytes) peuvent atteindre $4.5 \mathrm{~kg}$ de matière sèche au $\mathrm{m}^{2}$.

Dans les lacs, cette matière végétale est décomposée, stockée au niveau des sédiments et recyclée plus ou moins rapidement selon l'activité des organismes décomposeurs.

$\mathrm{RICH}(1970)$ estime que pour le lac Lawrence (Michigan) la quantité de carbone organique accumulée est de l'ordre de $2 \mathrm{t} / \mathrm{m}^{2}$.

Dans les eaux courantes, cette matière organique est entraînée par le courant, déposée et décomposée en des lieux plus calmes puis parfois transportée vers l'aval à l'occasion d'une crue ultérieure. 


\section{b.2. Diversification des habitats}

Les peuplements végétaux et animaux au sein du milieu aquatique sont liés les uns aux autres non seulement par la nourriture que les premiers fournissent aux seconds mais également par les supports et les abris qu'ils leur procurent.

En effet, beaucoup d'algues benthiques microscopiques (diatomées) sont fixées sur la tige ou les feuilles des macrophytes (épiphytes).

La production d'oxygène par les plantes pouvant varier de 0.13 à $7,36 \mathrm{~g} / \mathrm{m}^{2} / \mathrm{jour}$ (SCULTHORPE, 1967) permet l'installation d'espèces très exigeantes vis-à-vis de ce paramètre.

La densité des peuplements de macroinvertébrés augmente considérablement en présence de végétaux. GAUDET (1974) signale en Angleterre que dans les rivières à fond caillouteux la densité des organismes est de 3 a $4.10^{3} / \mathrm{m}^{2}$, dans les mousses et autres végétaux elle peut atteindre $40.10^{4} / \mathrm{m}^{2}$.

La présence de plantes contribue à l'augmentation de la surface d'accueil potentiel du milieu pour la faune benthique : a $1 \mathrm{~m}^{2}$ de sédiment peuvent, selon la nature de la végétation, correspondre plus de $20 \mathrm{~m}^{2}$ de surface foliaire. Les végétaux servent en outre de lieux de ponte et de frayère pour invertébrés et poissons. Ils sont utilisés également en tant que matériaux de construction pour les fourreaux larvaires de certains trichoptères ou les cocons de nymphoses de certains lépidoptères.

Il faut signaler enfin leur rôle d'abri pour les organismes qui viennent se cacher parmi la masse végétale de la vue de leurs prédateurs ou également y trouvent une protection contre l'ardeur du soleil estival.

Parmi le monde végétal, il existe une compétition interspécifique. Les plantes à feuilles flottantes et les plantes émergées sont favorisées vis-à-vis de la lumière qui peut devenir un facteur limitant de la croissance des espèces immergées. PHILLIPS et coll. (1978) ont montré à l'aide d'expériences en milieux contrôlés et naturels que la disparition des hydrophytes dans les milieux riches en substances nutritives était à rapprocher du développement important d'algues épiphytiques, qui, à la suite de la destruction de leurs supports, disparaissent également.

Les peuplements végétaux de tels milieux sont alors constitués essentiellement du phytoplancton.

\section{b.3. Source de nourriture}

Les végétaux peuvent être consommés directement par les organismes phytophages ou indirectement par des prédateurs du deuxième ou troisième ordre. Les algues planctoniques ou benthiques servent de nourriture à tous les alevins et à quelques poissons adultes (hotu, gardon, corégone). Leurs principaux consommateurs sont les petits invertébrés (rotifères, cladocères, copépodes) qui constituent la masse essentielle de la chaine alimentaire des poissons. Certaines espèces de poissons (brêmes, carpes, cyprinidés asiatiques) sont herbivores et consomment feuilles ou tiges de phanérogames. Les mollusques, les crustacés et les larves d'insectes se nourrissent des plantes aquatiques. Le ragondin (Myocastor eoypu) mange de préférence les rhizomes des nymphéacées ou de certains hélophytes.

\section{c. Rôle mécanique}

\section{c. 1. Entrave à l'écoulement}

Le volume occupé par les végétaux peut atteindre des proportions importantes dans certains cours d'eau. En réduisant la valeur de la section mouillée originelle, les plantes font diminuer la vitesse d'écoulement et augmenter la hauteur d'eau. En Angleterre, DAWSON (1978) indique une baisse de la vitesse d'écoulement de 0.3 a $0.1 \mathrm{~m} / \mathrm{s}$ environ et une augmentation de la hauteur d'eau de 0.2 à $0,4 \mathrm{~m}$. Le coefficient de CHEZY-MANNING qui rend compte de la rugosité du substrat et des obstacles à l'écoulement était passé de 0,03 à 0,3 . Les variations de ce coefficient sont en relation directe avec la biomasse végétale.

L'existence d'herbiers fixateurs des substrats meubles en période d'étiage peut engendrer des modifications des fonds et des rives en créant des turbulences érosives au moment des crues.

La végétation dense favorise la sédimentation des particules en suspension. Les débris organiques ou minéraux ainsi piégés contribuent à la formation d'embâcles préjudiciables à l'écoulement des eaux (DAWSON et coll., 1978).

\section{c. 2. Consolidation des éléments meubles et fixation des berges.}

Les sédiments déposés peuvent être ultérieurement fixés, les plantes s'y installent et les stabilisent. Racines et rhizomes consolident efficacement des bancs de matériaux fins qui, dans des conditions normales d'écoulement, seraient entraînés vers l'aval.

En bordure des eaux stagnantes les hélophytes s'opposent à l'action érosive des vagues à la fois en les affaiblissant et en fixant les éléments du substrat (WETZEL et HOUGH, 1973). 


\section{CLÉ DE DETERMINATION}

\section{Détermination des embranchements (d'après FOURNIER, 1961)}

1(4) : plante dépourvue de véritables fleurs et de graines, se reproduisant par une poussière fine contenue dans des sporanges

CRYPTOGAMES

2(3) : plante composée de cellules toutes identiques sans vaisseaux ni racines

CRYPTOGAMES CELLULAIRES (algues, bactéries, mousses)

3(2) : plante possédant un tissu vasculaire et de véritables racines

CRYPTOGAMES VASCULAIRES (A) (fougères)

4(1): plante possédant des fleurs et se reproduisant par graine

PHANEROGAMES (B et $C)$

$5(6)$ : feuille à nervures principales parallèles ou arquées, non réunies entre elles par des ramifications. 1 seul cotylédon

MONOCOTYLEDONES (B)

6(5) : feuille à nervures ramifiées ou anastomosées. 2 cotylédons

DICOTYLEDONES (C)

\section{A. CRYPTOGAMES VASCULAIRES OU PTERIDOPHYTES (FOUGERES)}

\section{Clé des familles}

1(2): plantes sans tiges ni feuilles distinctes - formées de tubes emboités bout à bout

EQUISETACÉES

$2(1)$ : tiges et rameaux construits autrement

3(4) : feuilles cylindriques en forme de joncs, réunies en rosette et épaissies en bulbe à la base

ISOETACÉES

4(3) : feuilles élargies nullement jonciformes

5(6): plantes flottantes non enracinées à feuilles ovales

SALVINIACÉES

6(5) : plantes enracinées dans le sol, feuilles flottantes en trèfle à quatre feuilles

MARSILIACÉES

\section{Famille des EQUISETACEES}

1(6) : tiges portant des verticilles réguliers, se desséchant en hiver.

2(3) : rameaux de verticilles creux (loupe) tiges de 2 sortes, les stériles vertes, les fertiles sans chlorophylle Equisetum maximum Lmk. (fig. 1, pl. 1)

$3(2)$ : rameaux pleins, un seul type de tige

$4(5)$ : tiges grêles, $6-8$ sillons profonds, $25.60 \mathrm{~cm}$

E. palustre L. (fig. 2, pl. 1)

$5(4)$ : tiges épaisses, $8 \mathrm{~mm}, 10-20$ cannelures peu apparentes, 0,5-1,5 m

E. limosum (L.) Wild. (fig. 3, pl. 1)

6(1) : tiges simples ou avec quelques rameaux latéraux, pas de verticilles réguliers, persistant l'hiver gaines entourées de noir, aussi larges que longues, tiges robustes $(6 \mathrm{~mm})$

E. hiemale L. (fig. 4, pl.1)

\section{Famille des ISOETACEES}

1(6) : bulbe à contour bilobé

2(3) : plante robuste $(8-18 \mathrm{~cm})$, racines noires, macrospores couvertes de protubérances irrégulières, altongées en bandelettes - feuilles demi-cylindriques

Isoetes lacustris L. (fig. 5, pl. 1)

$3(2)$ : plante moins robuste $(4-10 \mathrm{~cm})$ - racines ferrugineuses - macrospores hérissées de tubercules ou d'aiguillons.

$4(5)$ : feuilles cylindriques, vert foncé, roses à la base, dressées, opaques, cassantes

Isoetes brochoni Motelay

5(4): feuilles comprimées sur les côtés, vert tendre, flexibles, transparentes 
6(1): bulbe à contour trilobé

$7(8)$ : ligule allongée, pas de voile - macrospore finement rugueuse

Isoetes setaceum Bosc.

$8(7)$ : ligule courte, voile développé, macrospore fortement tuberculeuse

Isoetes variabile Rouy

\section{Famille des SALVINIACEES}

1(4): feuilles de $1 \mathrm{~mm}$ de long, imbriquées, sessiles (aspect d'un brin de thuya)

2(3) : feuilles vert pâle, rosées aux bords, les supérieures subaiguës de moins de $1 \mathrm{~mm}, 1-3 \mathrm{~cm}$ Azolla caroliniana Willd.

3(2) : feuilles luisantes, souvent rouge brunâtre, de $1 \mathrm{~mm}$, obtuses $(2-5 \mathrm{~cm})$

Azolla filiculoides Lmk. (fig. 7, pl. 1)

4(1) : feuilles de $1 \mathrm{~cm}$ de long, pliées, hérissées, pétiolées (aspect de folioles de robinier)

Salvinia natans (L.) All. (fig. 8, pl. 1).

\section{Famille des MARSILIACEES}

1(4): limbe flottant en trèfle à 4 feuilles.

$2(3)$ : plante glabre, fructifications pédicellées, insérées vers la base des pétales $(5-15 \mathrm{~cm})$

Marsilia quadrifolia L. (fig. 9, pl. 2)

3(2) : plante pubescente, fructifications sessiles accolées au rhizome $(5-15 \mathrm{~cm})$

Marsilia pubescens Ten. (fig. 10, pl. 2)

4(1): limbe nul, feuilles filiformes

$5(6)$ : feuilles de $4-10 \mathrm{~cm}, 1 \mathrm{~mm}$ d'épaisseur - fruit gros $(3-4 \mathrm{~mm})$

Pilularia globulifera L.

(fig. 11, pl. 2)

6(5) : feuilles de $2-4 \mathrm{~cm}$, grêles, fruits petits $(1 \mathrm{~mm})$ longuement pédonculés

Pilularia minuta Durieu (fig. 12, pl. 2).

\section{B. CLASSE DES MONOCOTYLEDONES}

\section{Clé des familles}

$1(2)$ : plante flottant librement à la surface, de petite taille $(5 \mathrm{~cm})$

LEMNACEES

2(1): plante généralement enracinée et de taille plus importante

3(22) : feuilles de longueur supérieure à 10 fois la largeur

4(13): feuilles épaisses en forme de lame de sabre, rigides, longues de $40 \mathrm{~cm}$ à $1 \mathrm{~m}$

$5(10)$ : feuilles identiques de la base au sommet

6(7) : feuille plane sur toute sa longueur

TYPHACEES

$7(6)$ : feuille non plane

8(9) : feuille trigone sur toute sa longueur .. BUTOMACEES (Butomus umbe//atus L.)

$9(8)$ : feuille pliée en $V$
(fig. 21, pl. 3)

$10(5)$ : feuille non identique de la base au sommet

$11(12)$ : feuille trigone dans le tiers inférieur-nervures délimitant des carrés

$12(11)$ : feuille tétragonale au milieu - plante aromatique ..... (ARACEES) Acorus $13(4)$ : feuilles minces, non rigides

$14(21)$ : feuilles plates alternées, ou opposées, rubanées d’un seul type

$15(18)$ : tige creuse cylindrique

16(17): tige creuse cylindrique, interrompue par des nœuds GRAMINACEES

17(16) : tige creuse cylindrique, sans nœud - feuilles tubulaires ou réduites à des gaines

JONCACEES

(Juncus sp.) (fig. 48, pl. 5, Scirpus) (CYPERACEES)

18(15) : tige pleine

19(20): tige cylindrique ou comprimée ou ailée ou capillaire

POTAMOGETONACEES 
20(19) : tige pleine, souvent triangulaire sans nœuds (sauf Scirpus)

CYPERACEES

$21(14)$ : feuilles plates, rubanées en rosette

Vallisneria, Stratiotes

(HYDROCHARIDACEES)

22(3): feuilles de longueur inférieure à 10 fois la largeur

23(26) : feuilles opposées, alternées ou ternées

24(25) : feuilles sinuées, dentées à dents épineuses, opposées ou ternées NAIADACEES

25(24) : feuilles à bord entier ou imperceptiblement denté opposées ou alternées

POTAMOGETONACÉES

26(23) : feuilles ternées ou en rosette

$27(28)$ : deux types de feuilles, les submergées rubanées, les flottantes ovales lancéolées

28(27): un seul type de feuille

ALISMACEES

$29(30)$ : feuilles cordiformes pétiolées ou ovales, lancéolées sessiles

HYDROCHARIDACEES + Cal/a (ARACEES)

30(29) : feuilles ovales pétiolées, en rosette à la base

APONOGETONACEES

Aponogeton distachyonThunb. (fig. 80, pl. 6)

\section{Famille des LEMNACEES}

1(2): plante sans racines, $1 \mathrm{~mm}$ de diamètre

2(1): plante munie de racines

Wolffia arrhiza (L.) Wimm. (fig. 13, pl, 2)

$3(4)$ : un faisceau de racines par fronde, d'un brun rougeâtre en dessous

Spirodela polyrrhiza (L.) Sch. (fig. 14, pl. 2)

4(3): une seule racine par fronde

$5(6)$ : frondes lancéolées - aiguès $(1 / 2-1 \mathrm{~cm})$ pétiolées, réunies en croix Lemna trisulca $\mathrm{L}$.

6(5): frondes ovales, non pétiolées, non réunies en croix

$7(8)$ : lentille plane sur les 2 faces

8(7) : lentille très convexe au moins face inférieure

(fig. 15, pl. 2)

Lemna minor L. (fig. 16, pl, 2)

Lemna gibba L. (fig. 17, pl. 2)

\section{Famille des TYPHACEES}

$1(2)$ : feuilles larges (1 à $2,5 \mathrm{~cm}$ ) glauques, planes, épis de 8 à $15 \mathrm{~cm}$ chacun, épi mâle blanchâtre, épi femelle noirâtre sans bractéole

2(1): feuilles plus étroites (1 à $8 \mathrm{~mm}$ )

3(4) : feuilles linéaires, larges de 1 à $4 \mathrm{~mm}$, épi femelle plus court

Typha latifolia L. (fig. 18, pl. 2) (fig. 20. pl. 2)
$4(3)$ : feuilles plus larges ( 4 à $8 \mathrm{~mm}$ ), épis espacés de 2 a $4 \mathrm{~cm}$, feuilles glauques, convexes d'un côté - présence de bractéoles

Typha angustifolia L. (fig. 19, pl. 2)

\section{Famille des SPARGANIACÉS}

1(4) : feuilles inférieures triquètres, tige dressée

2(3): feuilles larges de 6 à $16 \mathrm{~mm}$, acuminées

$3(2)$ : feuilles larges de 4 à $6 \mathrm{~mm}$

Sparganium ramosum Curt. (fig. 23, pl. 3) Sparganium simplex Huds.

$4(1)$ : feuilies toutes planes, minces et flexibles flottantes, larges de 2 a $3 \mathrm{~mm}$ 5(6) : feuilles vert pâle, non dilatées à la base Sparganium minimum Fries. (fig. 24, pl. 3) sommet

6(5) : feuilles vert foncé, très dilatées à la base, diminuant régulièrement de largeur de la base au Sparganium affine Schnitzlein

\section{Famille des ARACEES}

$1(2)$ : feuilles en glaive, souche rampante très aromatique Acorus calamus L. (fig. 25, pl. 3)

2(1): feuilles cordiformes ou sagittées $(15 \mathrm{~cm})$ - partant toutes de la souche

Calla palustris L. (fig. 26, pl. 3)

\section{Famille des GRAMINÉES}

$1(6)$ : ligule ovale-allongée

2(3): feuilles longues, rudes, rhizome traçant

Phalaris arundinacea L. (fig. 27, pl. 3)

$3(2)$ : feuilles courtes, lisses

4(5) : tige genouillée, radicante, feuille glauque

$5(4)$ : stolons radicants, feuille verte 
6(1) : ligule ovale-laciniée, feuille rude, tige rude au sommet, panicule contracté

$7(12)$ : ligule tronquée-apiculée, tige et feuille rudes - stolons radicants

Calamagrostis epigeios (L.) Roth (fig. 30, pl. 4)

$8(9)$ : nœud hérissé de poils - ligule tronquée - feuille très rude (large de 0.4 à $1 \mathrm{~cm}$ ), panicule lâche, filamenteuse

$9(8)$ : nœud glabre, ligule tronquée-apiculée

10(11): feuille large, 0,5 à $1 \mathrm{~cm}$ - tige aplatie de 50 à $100 \mathrm{~cm} \quad$ Glyceria fluitans (L.) $\mathrm{R}$. Br.

11(10): feuille large de 1 à $1,8 \mathrm{~cm}$, tige plus ou moins cylindrique

(fig 32, pl. 4)

12(7): ligule remplacée par des poils

Glyceria aquatica Walbg. (fig. 33 et 34 , pl. 4)

13(14) : tiges ligneuses, plus grosses que le doigt - feuilles lisses aux bords - limbe à oreillettes

Arundo donax L. (fig. 35, pl. 4) oreillettes

14(13) : tiges non ligneuses, moins grosses que le doigt - feuilles rudes aux bords - limbe sans Phragmites communis Trin. (Arundo phragmites L.)(fig. 36, pl. 4)

\section{Famille des CYPERACEES}

1(2): étamines et pistils sur des fleurs différentes

Carex sp. (fig. $37, \mathrm{pl} .4$ )

2(1) : étamines et pistils sur la même fleur

3(4) : tige terminée par un seul épillet

$4(3)$ : tige terminée par plusieurs épillets ou par des feuilles

5(6) : écailles en 2 rangées, épillets aplatis latéralement

6(5) : écailles naissant tout autour de l'épillet, épillet cylindrique

$7(8)$ : ovaire surmonté d'un tubercule résultant de la persistance de la base du pistil

Rhynchospora sp. (fig. 40 et 41, pl. 4)

8(7) : ovaire non surmonté d'un tubercule $9(10)$ : épillets dont les écailles cachent les fleurs

10(9) : épillets dont seulement l'écaille supérieure cache la fleur

Scirpus $s \rho$

Cladium mariscus (L.) R. Br.

\section{Famille des HYDROCHARIDACEES}

1(2) : feuilles flottantes, en cœur à la base, longuement pétiolées, entières

2(1): feuilles submergées, lancéolées, linéaires sessiles

Hydrocharis morsus ranae L. (fig. 42, pl. 4)

$3(8)$ : feuilles courtes $(5 \mathrm{~cm})$ en verticilles ou alternées le long d'une tige allongée à entre-nœuds à peu près égaux sans stolons

$4(7)$ : feuilles disposées en verticilles

5(6) : feuilles (1-2 cm sur 1,5 mm) fortement denticulées, spinuleuses, terminées en pointes presques piquantes, verticilles de 2 a 8

Hydrilla verticillata Caspary (fig. 43, pl. 4)

$6(5)$ : feuilles faiblement denticulées oblongues, obtuses, ondulées en verticilles de 3

Helodea canadensis Rich. (fig. 44, pl 4)

$7(4)$ : feuilles alternes, enroulées vers le bas, linéaires-acuminées (10-15 $\mathrm{mm}$ sur 2-3 $\mathrm{mm}$ )

Lagarosiphon major (Ridley) Mose (fig. 45, pl. 4)

$8(3)$ : feuilles allongées, toutes radicales, en rosette, en forme de rubans ou de poignard

9 (10): feuilles minces, en rubans (30-80 cm de long, $5-12 \mathrm{~mm}$ de large), obtuses, denticulées au sommet

Vallisneria spiralis L. (fig. 46, , pl. 4)

10(9) : feuilles épaisses, raides, épineuses, en forme de lame de poignard (15-40 cm sur $2-4 \mathrm{~cm})$ souche stolonifère

Stratiotes aloides L. (fig. 47, pl. 4)

\section{Famille des NAIADACEES}

Feuilles sessiles, opposées ou verticillées par 3, engainantes, lancéolées, linéaires

1 : tiges et dos des feuilles portant de petits aiguillons

Feuilles larges de $2-4 \mathrm{~mm}$

Naias major All. (fig. 49, pl. 5)

2 : Tiges et dos des feuilles lisses

Feuilles larges de moins de $1 \mathrm{~mm}$

Naias minor All. (fig. 50, pl. 5).

\section{Famille des POTAMOGETONACEES}

1(20): feuilles toutes étroitement linéaires (filiformes ou rubanées) et submergées sessiles, pourvues de 2 glandes à leur base. 
2(15): base des feuilles non ou à peine engainante

Zannichellia palustris L. (fig. 51, pl. 5)

$3(6)$ : tige aplatie comme une feuille; feuille à 3-7 nervures plus fortes, avec de nombreuses autres plus fines, longitudinales

4(5) : feuilles de $10-20 \mathrm{~cm}$ sur $2-4 \mathrm{~mm}$, subarrondies, sous une pointe courte

Potamogeton compressus L. (fig. 52, pl. 5)

5(4) : feuilles munies de 2 glandes noires à la base, rétrécies brusquement en pointe

$P$. acutifolius Link (fig. 53, pl. 5)

6(3) : tige cylindrique ou légèrement comprimées (dans ce cas à 2 angles arrondis), nervures peu nombreuses

$7(8)$ : feuilles larges de $2.5 \mathrm{~mm}$, minces, planes de $2.8 \mathrm{~cm}$ très obtuses à 3.5 nervures dont 2 peu apparentes - tigge presque filiforme, légèrement comprimée $(0,5-1 \mathrm{~mm})$

$P$. obtusifolius Mert. et K. (fig. 54, pl. 5)

$8(7)$ : feuilles larges de $1,2.2 \mathrm{~mm}$; tige de moins de $1 \mathrm{~mm}$ de diamètre

9(14) : feuilles à plusieurs nervures (3-5) - tige légèrement comprimée.

10(13): feuilles subobtuses mucronées

$11(12)$ : feuilles de $3-5 \mathrm{~cm}$ sur $2.5 \mathrm{~mm}$ à $3-5$ nervures, anastomosées

P. mucronatus Schr. (fig. 55, pl. 5)

$12(11)$ : feuilles de $1,5-3 \mathrm{~cm}$ sur $1,5 \mathrm{~mm}$, trinervées, sans réseau d'anastomoses

P. pusillus L. (fig. 56, pl. 5)

$13(10)$ : feuilles très aiguës, à 3 nervures, rétrécies à la base, persistant sur la tige, tiges rameuses à la base, de $20-40 \mathrm{~cm}$, souvent rougeâtres

P. rutilus Wolfg. (fig. 57. pl. 5) rameaux courts

14(9): feuilles à une seule nervure, filiformes de $2.4 \mathrm{~cm}$, aiguës - tige filiforme à subfiliformes, canalicules, apaques

16(19) : tige subcylindrique, très ramifiée, dichotome atteignant $2-3 \mathrm{~m}-$ feuilles $2-15 \mathrm{~cm}$ sur $2,5 \mathrm{~mm}$, acuminées ou obtuses - gaine de $5 \mathrm{~m}$ - ligule obtuse

$17(18)$ : gaine mince, membraneuse, munie d'un limbe, non renflée à ligule libre

$P$. pectinatus L. (fig. 59 . pl. 5)

18(17): gaines inférieures très rigides et renflées, 2 à 3 fois plus épaisses que la tige $-2-4$ rameaux à chacune

$P$. vaginatus Turcz. (fig. 60 . pl. 5 )

$19(16)$ : tige comprimée, ne dépassant guère $20-30 \mathrm{~cm}$, ramifiée seulement à la base - feuilles

filiformes universées .............................................. P. filiformis Pers. (fig. 61, pl. 5)

$20(1)$ : feuilles, au moins les supérieures à limbe large, ovale ou lancéolé, sans glande à la base

21(38): feuilles toutes sessiles ou atténuées en très court pétiole $(1 \mathrm{~cm})$ ailé, généralement submergées

22(23) : feuilles toutes opposées par paires, toutes semblables, rapprochées, semi-embrassantes, lancéolées, souvent arquées, $1,5-3 \mathrm{~cm}$

23(22) : feuilles toutes alternes (sauf aux ramifications et à l'inflorescence)

$24(25)$ : tige à 4 angles arrondis, un peu comprimée - feuilles oblongues de $4-6 \mathrm{~cm} \mathrm{sur} 1,5 \mathrm{~cm}$, sessiles à bord parallèles dentées; généralement ondulées

25(24): tige cylindrique - feuilles non crépues

26(31): feuilles submergées à base arrondie embrassant la tige (à demi ou complètement)

$27(28)$ : feuilles très entières aux bords (loupe), grandes $(6-13 \mathrm{~cm}$ sur $4,5 \mathrm{~cm}$ ) obtuses . tige zigzaguant à chaque nceud P. praelongus Wulf. (fig. 64, pl. 5)

28(27) : feuilles denticulées, scabres aux bords (loupe), planes au sommet

$29(30)$ : feuilles en cœur embrassant complètement la tige $(1,6 \mathrm{~cm}$ sur $0,5-3 \mathrm{~cm})$

$30(29)$ : feuilles non en cœur à la base

P. perfoliatus L. (fig. 65, pl. 6)

31(26) : feuilles rétrécies à la base, $n$ 'embrassant nullement la tige

32(35): feuilles submergées non terminées en pointe fine, souvent obtuses, étroites et allongées à anastomoses bien marquées

33(34) : feuilles submergées sessiles (sauf les supérieures) ou rétrécies en court pétiole ailé, courtes et arquées en faucille sur les tiges stériles ; les florifères avec quelques feuilles flottantes coriaces elliptiques de $5.7 \mathrm{~cm}$ sur $2.3 \mathrm{~cm}$

P. gramineus L. (fig. 67. pl. 6)

$34(33)$ : feuilles rétrécies en pétiole ailé, les submergées sessiles de $25 \mathrm{~cm}$ sur $25 \mathrm{~mm}$. obtuses. les flottentes ovales-oblongues (courtement pétiolées) P. rufescens Schrad. (fig. 68, pl. 6)

35(32) : feuilles submergées terminées en pointe fine, denticulées rudes aux bords : a anastomoses peu marquées, rétrécies en pétiole ailé

$36(37)$ : feuilles toutes submergées et courtement pétiolées, atténuées aux 2 extrémités, grandes $(15-30 \mathrm{~cm}$ sur 4-6 cm), 5-11 nervures saillantes P. lucens L. (fig. 69, pl. 6)

$37(36)$ : feuilles inférieures sessiles ou subsessiles de $10-14 \mathrm{~cm}$ sur $2 \mathrm{~cm}$, les supérieures longuement pétiolées souvent flottantes et plus larges $P$. zizi Mert. et K. (fig. 70-71, pl. 6)

$38(21)$ : feuilles toutes plus ou moins longuement pétiolées

$39(4,2)$ : feuilles flottantes coriaces à limbe formant deux plis saillants au point de jonction avec le pétiole 
40(41) : feuilles flottantes ovales $(5-12 \mathrm{~cm}$ sur $3.5 \mathrm{~cm}$ ) à nervures transparentes, les submergées réduites à un pétiole très long $(50 \mathrm{~cm})$ canaliculé

P. natans L. (fig. 72, pl. 6)

$41(40)$ : feuilles flottantes elliptiques $(3.9 \mathrm{~cm}$ sur $2.3 \mathrm{~cm})$ à plis peu perceptibles à nervures peu transparentes - pétioles plans ou convexes - feuilles inférieures à limbe allongé lancéolé

42(39) : feuilles flottantes sans plis au point de jonction

P. polygonifolius Pourret (fig. 73, pl. 6)

43(44) : feuilles supérieures coriaces, les autres minces et transparentes, ovales ou

lancéolées

P. fluitans Roth (fig. 74, pl. 6)

44(43): feuilles toutes minces et transparentes, munies de limbes, arrondies à la base, souvent rougeâtres, nervures secondaires saillantes en dessous

P. coloratus Vahl (fig. 75, pl. 6)

\section{Famille des ALISMACEES}

1(2): présence de feuilles radicales et de feuilles caulinaires - feuilles submergées linéaires en rosette, les flottantes caulinaires, elliptiques, arrondies

Alisma natans L. (fig. 76, pl. 6)

2(1) : feuilles uniquement radicales en rosette

3(4) : 2 types de feuilles : les submergées rubannées, les flottantes en fer de lance

4(3): 1 seul type de feuilles (aériennes) les submergées petites, linéaires

Sagittaria sagittifolia L. (fig. 77, pl. 6)

5(6) : feuilles ovales, cordiformes, à nombreuses nervures arquées - parallèles, atténuées à la base

6(5) : feuilles lancéolées, étroites à 3 nervures

Alisma plantago L. (fig. 78, pl. 6)

Alisma ranunculoides $\mathrm{L}$. (fig. 79, pl. 6).

\section{CLASSE DES DICOTYLÉDONES}

\section{Clé des familles}

$1(2)$ : tige de section carrée

LABIÉES, SCROPHULARIACÉES

$2(1)$ : tige de section ronde

3(6) : tige ou feuilles portant des vésicules servant de flotteurs (renflements remplis de gaz) ; plante normalement flottante, sans racines, feuilles découpées en lanières

4(5) : feuilles filiformes

5(4) : feuilles triangulaires dentées, aussi longués que larges

UTRICULARIACEES

Trapa natans

(OENOTHERACEES)

6(3) : pas de vésicules

$7(8)$ : tige sans ramifications

HIPPURIDACEES

8(7) : tiges ramifiées

9(12): feuilles entières grandes (15 a $40 \mathrm{~cm}$ ) - elliptiques ou cordiformes

$10(11)$ : feuilles elliptiques, lisses, brillantes, non dentées (flottantes)

NYMPHÉACÉES

Nymphoides peltata (MENYANTHACEES)

$11(10)$ : feuilles cordiformes, velues, dentées, nervures saillantes sur la face inférieure

Petasites, Tussilago (COMPOSÉES)

Caltha palustris (RENONCULACÉES)

12(9): feuilles de plus petite taille et non entieres

13(28): feuilles divisées

14(23): divisions de largeur $>$ à $0,5 \mathrm{~cm}$

15(16): feuilles palmatilobées (les flottantes au moins) ou laciniées

16(15): composées - pennées

17(18): folioles (trois) distinctes non dentées

RENONCULACÉES

$18(17)$ : folioles dentées

$19(22)$ :folioles échelonnées le long du pétiole

20(21) : pétiole engainant

$21(20)$ : pétiole non engainant

OMBELLIFERES (sauf hydrocotyle) CRUCIFERES

$22(19)$ : folioles rapprochées semblant diverger à partir d’un même point Bidens

23(14): divisions de largeur $<0.5 \mathrm{~cm}$ : feuilles laciniées simples

(COMPOSÉES)

24(25): feuilles alternées

Hottonia palustris L. (fig. 140, pl. 11) (PRIMULACÉES)

25(24): feuilles en verticilles par quatre ou plus

26(27) : par quatre ou cinq

plus RENONCULACEES

27(26) : par plus de 5 et dentées sur un bord 
28(13) : feuilles simples, entières

29(30): feuilles verticillées

ELATINACEES

30(29) : feuilles opposées ou alternées

$31(34)$ : feuilles alternées grandes

32(33) : feuilles sessiles, linéaires, hérissées, vert clair

BORRAGINACEEES

Myosotis palustris L. Horm (fig. 150, pl. 12)

33(32) : feuilles pétiolées ou limbe amenuisé en pétiole, stipule, soudées en gaine

POLYGONACEES

34(31); feuilles opposées

35(36) : feuille charnue, nervures non visibles, lancéolées, amenuisées en pétiole

PORTULACACÉES

$36(35)$ : feuille non charnue

$37(38)$ : plus ou moins longuement pétiolée

Montia rivularis Gmel. (fig. 160. pl. 12)

38(37) : sessile

$39(40)$ : feuilles supérieures disposées en verticilles ou en rosette

CALLITRICHACÉES

40(39) : feuilles supérieures non disposées en rosette ou en verticille

CARYOPHYLLACEES, SCROFULARIACEES

\section{Famille des LABIEES - SCROFULARIACÉS}

LABIEES : Mentha, Stachys, Lycopus, Scutellaria

SCROF ULARIACEES : Veronica, Scrofularia, Pedicularis, Gratiola, Mimulus

$1(8)$ : feuilles opposées sessiles

2(3) : feuilles ovales lancéolées à pointe obtuse - tige creuse de section carrée

3(2) : feuilles lancéolées, linéaires : tige pleine de section carrée

Veronica anagallis L. (fig. 81, pl. 7)

$4(7)$ : feuilles dentées sur tout le contour - grappes de fleurs

$5(6)$ : dents des feuilles dirigées vers le bas - grappes alternées ... ... Veronica scutellata $L$.

6(5) : dents des feuilles dressées - grappes opposées

(fig. 82, pl. 7)

7(4) : feuilles dentées seulement au sommet - fleurs isolées

Veronica anagalloides Gussone (fig. 83, pl. 7)

Gratiola officinalis L.

(fig. 84, pl. 7)

$8(1)$ : feuilles opposées courtement pétiolées

$9(10)$ : tige ronde pleine - feuille ovale, dentée, fleurs en grappes opposées

10(9) : tige quadrangulaire

$11(16)$ : feuille ovale : lancéolée, régulièrement dentée

12(13) : feuille obtuse, en cœur à la base, 4-8 dents petites de chaque côté

Scutellaria galericulata L. (fig. 86, pl. 7)

13(12) : feuille obtuse non en cœur à la base, fortement dentée

14(15) : feville obtuse, triangulaire, avec une ou deux fortes dents de chaque côté à la base Scutellaria minor L. (fig. 87, pl. 7)

15(14) : feuille aiguë, arrondie à la base, fortement dentée, plante velue

16(11): feuille ovale, large inégalement dentée

Stachys palustris L. (fig. 88, pl. 7)

$17(24)$ : dents peu profondes

$18(21)$ : plante glabre

$19(20)$ : feuille obtuse, arrondie au sommet - tige ailée, creuse

20(19) : feuille aiguë, cordiforme - tige non ailée, pleine

Scrofularia aquatica L. (fig. 89, pl. 7)

Scrofularia nodosa L.

(fig. 90, pl. 7)

21(18): plante tres velue

22(23) : odeur mentholée

$23(22)$ : odeur de musc

Mentha aquatica L. (fig. 91, pl. 7)

$24(17)$ : dents profondes

Mimulus moschatus Douglas

Lycopus europaeus L.

\section{Famillo des UTRICULARIACEES}

1(4) : rameaux identiques portant de nombreuses vésicules - subdivision des feuilles bordées de fines épines (à la loupe) - espèces montant à la surface de l'eau pour fleurir. 
2(3) : pédoncule floral 2 a 3 fois plus long que la feuille la plus proche

3(2): pédoncule floral 4 à 5 fois plus long que la feuille la plus proche

Utricularia. vulgaris L. (fig. 92, pl. 7) Utricularia major Schmidel (fig. 93, pl. 8)

4(1): rameaux et feuilles de deux types, les uns verts, flottants, vésicules peu nombreuses ou absentes, les autres diaphanes, fixés sur la base et portant des vésicules nombreuses

$5(8)$ : lanières des feuilles bordées de cils ou d'épines

6(7) : lanières des feuilles brusquement rétrécies à l'extrémité et possédant une petite pointe terminale ; épines latérales découpées dans la feuille Utricularia intermedia Hayne (fig. 94, pl. 8)

$7(6)$ : lanières des feuilles progressivement et régulièrement rétrécies - épines insérées sur un court pédoncule Utricularia ochroleuca Hartman (fig. 95, pl. 8)

8(5) : lanières des feuilles sans cils ni épines

9(10): éperon de la fleur plus long que large, plus long que les sépales

Utricularia bremii Heer (fig. 96, pl. 8)

10(9) : éperon aussi long que large, réduit à une bosse, plus court que les sépales

Utricularia minor L. (fig. 97, pl. 8).

\section{Famille des OENOTHERACEES}

1(4) : feuilles toutes ovales, lancéolées

2(3) : tige quadrangulaire rougeâtre

$3(2)$ : tige ronde pubescente

Ludwigia palustris L. Elliot (fig. 98, pl. 8) Jussieua repens L. (fig. 99, pl. 8)

$4(1)$ : feuilles flottantes losangiques, pennivervées, dentées, en rosace, pétiole flottant, feuilles submergées laciniées

Trapa natans L. (fig. 100-101, pl. 8).

\section{Famille des CERATOPHYLLACEES}

$1(2)$ : feuilles trois fois fourchues, a lanières denticulées capillaires, fruit sans épines

Ceratophyllum submersum L. (fig. 102, pl. 8)

2(1) : feuilles seulement 1 \ 2 fois fourchues, a lanières fortement dentées - épineuses

Ceratophyllum demersum L. (fig. 103, pl. 8).

\section{Famille des NYMPHEACEES}

1(2) : pétiole à section circulaire - feuille orbiculaire - fleurs blanches

Nymphaea alba L. (fig. 105, pl. 8)

2(1) : pétiole à section triangulaire - feuille ovale - fleurs jaunes

$3(4)$ : fleurs petites $(2-3 \mathrm{~cm})$, disque des stigmates portant $8-10$ rayons - feuilles petites $(5-15 \mathrm{~cm}$ sur 4-11) Nuphar pumilum DC. (fig. 106, pl. 9) 10-20)

$4(3)$ : fleurs grandes $(4-5 \mathrm{~cm})$, disque portant $15-20$ rayons - feuilles grandes $(15-30 \mathrm{~cm}$ sur

\section{Famille des RENONCULACEES}

$1(18)$ : feuilles plus ou moins profondément divisées, lobées, laciniées

2(11): feuilles flottantes palmatilobées ou dentées

3(6) : feuilles submergées, absentes ou non laciniées

$4(5)$ : feuilles a 3-5 lobes, arrondis, peu profonds

Ranunculus hederaceus $\mathrm{L}$.

(fig. 108, pl. 9)

5(4) : feuilles à 3-5 lobes, assez profonds, aigus

6(3) : feuilles submergées présentes, laciniées

R. Ienormandi Schultz (fig. 109, pl. 9)

$7(10)$ : feuilles flottantes a 3 lobes - stipules presque libres

$8(9)$ : fleur blanche

(fig. 110 , pl. 9)

$9(8)$ : fleur jaune

10(7): feuilles flottantes à 5 lobes - stipules adhérentes

$11(2)$ : feuilles submergées et découpées en lanières filiformes

$12(13)$ : feuilles toutes submergés et découpées en lanières très longues $(7-16 \mathrm{~cm})$ parallèles contour général dans l'eau et hors de l'eau en long pinceau

R. fluitans Lmk. (fig. 112 , pl. 9)

13(12): feuilles submergées beaucoup plus courtes $(5 \mathrm{~cm})$ en lanières écartées à contour orbiculaire dans l'eau

(fig. 113 , pl. 9)

$14(15)$ : feuilles à lanières raides, courtes $(1-2 \mathrm{~cm})$ disposées en cercle et ne formant pas un pinceau lorsqu'on les retire de l'eau, plus courtes que les entre-nœuds

R. circinatus (divaricatus) Sibth. 
15(14): feuilles à lanières molles, se réunissant en pinceau lorsqu'on les retire de l'eau

16(17) : feuilles submergées plus courtes que les entre-nœuds

$R$. trichophyllus Chaix

$17(16)$ : feuilles submergées plus longues que les entre-nœuds

R. aquatilis L.

(fig. 111, pl. 9)

18(1): feuilles toutes entières, non divisées, dentées sur les bords

$19(22)$ : feuilles radicales différentes des caulinaires

20(21) : feuilles supérieures (caulinaires) lancéolées, atténuées en pétiole, jamais en cœur plante de taille médiocre (crayon, $20-40 \mathrm{~cm}$ )

R. flammula L. (fig. 114, pl. 9)

21(20) : feuilles supérieures (caulinaires) lancéolées-linéaires, les inférieures parfois submergées-cordiformes - plante de grande taille (grosseur du pouce, $1 \mathrm{~m}$ de haut)

R. lingua $\mathrm{L}$

(fig. 115, pl. 9)

22(19): feuilles toutes de même type (arrondies)

Caltha palustris L. (fig. 116. pl. 9).

\section{Famille des MENYANTHACEES}

1(2) : plante flottante à feuilles arrondies (petits nénuphars), luisantes, tuberculeuses en dessous fleur jaune assez grande $(2-3 \mathrm{~cm})$ Nymphoides peltata (Gmel.) Kuntze (fig. 117, pl. 9) 2(1): plante non flottante, feuille à trois grandes folioles (trèfle d'eau) - fleur blanc-rosé, en grappe dressée Menvanthes trifoliata L. (fig. 118, pl. 9).

\section{Famille des OMBELLIFERES}

$1(8)$ : feuilles composées, folioles distinctes

2(5) : folioles à dents arrondies, plus ou moins régulières, brusquement mucronées

$3(4)$ : feuilles toutes aériennes à folioles ovales - ombelles de 3-12 rayons - folioles presque aussi larges que longues - dents grossières inégales Apium nodiflorum (L.) Lag. (fig. 119, pl. 9) 4(3) : feuilles de 2 sortes, les submergées découpées en lanières très étroites, les aériennes à folioles ovales en coin

$5(2)$ : folioles à dents effilées en mucron Apium inundatum L. (fig. 120, pl. 9)

$6(7)$ : folioles à dents irrégulières, peu nombreuses, foliole à base dissymétrique - base de la tige finement striée Sium angustifolium L. (fig. 121, pl. 10)

7(6) : folioles régulièrement et finement dentées en scie, foliole à base symétrique - base à cannelures profondes

Sium latifolium L. (fig. $122, \mathrm{pl} .10$ )

$8(1)$ : feuilles divisées en folioles indistinctes

9(12): feuilles toutes d'un même type

$10(11)$ : divisions relativement larges en coin, racines renflées dès le collet en tubercules fasciculés $(20 \mathrm{~cm}$ de long)

Oenanthe crocata L. (fig. 123 , pl. 10) $11(10)$ : divisions filiformes - base de la tige progressivement renflée mais non tuberculeuse

Oenanthe phellandrium (L.) Lmk (fig. 124, pl. 10)

$12(9)$ : feuilles de 2 types - les supérieures à divisions longuement linéaires, les inférieures :

13(14) : à divisions en coin, racines renflées sur leur trajet en tubercules

Oenanthe pimpinelloides L. (fig. 125, pl. 10)

14(13) : à divisions lancéolées étroites

15(16) : stolons - racines renflées en fuseaux fasciculés - pétioles creuses

Denanthe fistulosa L. (fig. 126, pl. 10)

16(15) : racines renflées en massues fasciculées - pas de stolons - pétioles pleins

Oenanthe globulosa L. (fig. 127, pl. 10)

\section{Famille des CRUCIFERES}

$1(4)$ : feuilles toutes de même type

2(3) : feuille composée

$3(2)$ : feuille entière

Nasturtium officinale R. Br. (fig. 128, pl. 10)

Subularia aquatica L. (fig. 129, pl. 10)

$4(1)$ : feuilles de 2 types, les radicales composées pétiolées - les caulinaires entières, sessiles, lancéolées, dentées

Roripa amphibia (fig. 130, 131, pl. 10).

\section{Famille des COMPOSEES}

$1(8)$ : feuilles cordiformes velues, dentées, nervures saillantes sur la face inférieure 2(3) : contour polygonal, dents grandes séparant les côtés - face inférieure blanchâtre

3(2) : contour plus régulier et arrondi Tussilago farfara L. (fig. 132, pl. 10)

4(7) : sommet arrondi obtu - face inférieure pubescente - feuilles très grandes $(1 \mathrm{~m} \times 50 \mathrm{~cm})$ 
5(6) : échancrure bordée par une nervure épaisse - pétiole creusé d'une gouttière et bordé d'ailes sur toute sa longueur - fleur rougeâtre

Petasites officinalis Moench. (fig. 133, pl. 10)

6(5) : échancrure non limitée par une nervure - pétiole aplati sur le côté, sans ailes - fleurs jaunes

Petasites albus (L.) Moench (fig. 134, pl. 10)

$7(4)$ : sommet plus ou moins pointu - contour triangulaire - feuille blanche en dessous - pétiole aplati non ailé - fleurs rosées

Petasites niveus Baumg. (fig. 135. pl. 11)

$8(1)$ : feuilles lancéolées, simples ou composées

9(16) : feuilles composées de folioles rapprochées semblant diverger à partir d'un même point

$10(11)$ : folioles très étroites, presque linéaires - dents à peine marquées

$11(10)$ : folioles lancéolées, ovales

Bidens heterophylla Ortega

12(13): feuilles divisées en 5 folioles (à la base)

B. frondosa L. (fig. 136, pl. 11)

13(12): feuilles divisées en 3 folioles

14(15) : tige verdâtre - feuille vert jaunâtre

15(14) : tige rougeâtre - feuille vert foncé

B. radiata Thuillier (fig. $137, \mathrm{pl} .11$ )

16(9) : feuilles simples entières, soudées 2 a 2 inférieurement

17(18) : feuille vert jaunâtre sans pétiole

B. tripartita L.

$18(17)$ : feuille vert sombre amenuisée en large pétiole au $1 / 3$ inférieur

B. cernua L. (fig. 138, pl. 11)

B. connata

(fig. 139, pl. 11)

\section{Famille des HALORRHAGIDACEES}

$1(2)$ : fleurs alternes par des bractées au sommet et par des feuilles laciniées à la base de l'inflorescence

2(1) : fleurs verticillées

3(4) : en épis munis de bractées seules

4(3) : échelonnées à l'aisselle des feuilles laciniées

Myriophyllum alterniflorum DC. (fig. 141, pl. 11)

Myriophyllum spicatum L. (fig. 142, pl. 11)

Myriophyllum verticillatum L

(fig. 143, pl. 11)

\section{Famille des ELATINACEES}

$1(2)$ : feuilles verticillées, ovales, petites, sessiles, tige robuste dressée

Elatine alsinastrum $\mathrm{L}$

2(1): feuilles opposées, plus ou moins courtement pétiolées, tige grêle, couchée

(fig. 144, pl. 11)

3(6) : 3 étamines, feuilles linéaires oblongues à pétioles plus courts que le limbe - fleurs minuscules à l'aisselle des feuilles

(fig. 145, 146, pl. 11)

4(5) : fleurs sessiles

$5(4)$ : fleurs pédicellées $(2-2,5 \mathrm{~mm})$

6(3): 6 ou 8 étamines sur 2 rangs, feuilles ovales-lancéolées, fleurs pédicellées

E. triandra Schk

$7(8)$ : sépales, pétales, style 3 , fleurs solitaires à l'aisselle des feuilles

E. hexandra (Lapierre)

8(7) : sépales, pétales, style 4 , étamines 8

DC. (fig. 147, pl. 11)

$9(10)$ : graine droite ou à peine arquée, capsule à 4 valves

E. major A. Br. (fig. 148, pl. 11)

$10(9)$ : graine courbée en fer à cheval à branches inégales, capsule à 3 valves

E. hydropiper L. (fig. 149, pl. 11).

\section{Famille des POLYGonACEES}

1(4): feuilles très grandes (40 a $100 \times 25 \mathrm{~cm}$ )

$2(3)$ : feuilles radicales cordiformes très grandes $(40 \times 20 \mathrm{~cm})$. les supérieures sessiles, légèrement ondulées

Rumex aquaticus L. (fig. 151, pl. 12)

$3(2)$ : feuilles allongées $(1 \mathrm{~m} \times 0,25)$ sensiblement rétrécies aux deux extrémités, décurrentes sur le pétiole

Rumex hydrolapathum Huds. (fig. 152, pl. 12)

$4(1)$ : feuilles plus petites $(20 \mathrm{~cm}$ de longueur)

$5(6)$ : base de la feuille arrondie

Polygonum amphibium L. (fig. 153, pl. 12)

6(5) : base de la feuille rétrécie

$7(10)$ : sommet de la gaine longuement cilié

$8(9)$ : inflorescence en épi compact

(fig. 154, pl. 12)

9(8) : inflorescence en épi : grêle et discontinu

Polygonum persicaria L. (fig. 155, pl. 12)

$10(7)$ : sommet de la gaine pas ou à peine cilié

Polygonum mite Schrank (fig. 156, pl. 12)

$11(12)$ : inflorescence en épi compact - plante à saveur fade

(fig. 158, pl. 12)

$12(11)$ : inflorescence en épi grêle ou discontinu - plante à saveur poivrée

P. lapathifolium L.

(fig. 157, pl. 12)

P. hydropiper L.

(fig. 159, pl. 12). 


\section{Famille des CARYOPHYLLACÉS}

$1(2)$ : tige quadrangulaire, feuille lancéolée, ciliée à la base, stipulée, plante basse en touffe de vase $(10-40 \mathrm{~cm})$ Stellaria uliginosa Murr. (fig. 166, pl. 13)

2(1): tige ronde

$3(4)$ : tige grêle rougeâtre, couchée, feuilles stipulées $(5-20 \mathrm{~cm})$

IIlecebrum verticillatum L. (fig. 167, pl. 13)

4(3) : tige verte grimpante, plante vert clair pubescente au sommet - feuilles non stipulées $(30-60 \mathrm{~cm})$ Malachium aquaticum (L.) Fries (fig. 168, pl. 13).

\section{Famille des CALLITRICHACEES}

$1(4)$ : feuilles plus larges à la base qu'au sommet, toutes submergées, jamais en rosette, transparentes 2(3) : extrémité de la feuille échancrée en $V$

3(2) : extrémité de la feuille échancrée en $U$

Callitriche truncata Guss. (fig. 161, pl. 12)

$4(1)$ : feuilles amincies à la base, les supérieures généralement en rosette, non transparentes

$5(6)$ : plante robuste, feuilles de la tige régulières, feuille en rosette spatulée - échancrure en forme de croissant - eaux courantes

C. hamulata Kütz. (fig. 163, pl. 12)

6(5) : plante fragile des eaux stagnantes peu profondes - échancrure irrégulière

$7(8)$ : feuilles inférieures elliptiques, celles de la rosette elliptiques, circulaires

C. stagnalis Scop. (fig. 164, pl. 12)

$8(7)$ : feuilles des rosettes nombreuses, largement rhomboïdales

$$
\text { C. obtusangula Le Gall }
$$

(fig. $165 \mathrm{~A}$, pl. 12 ; fig. $165 \mathrm{~B}$, pl. 13) 


\section{Planche I PTERIDOPHYTES}
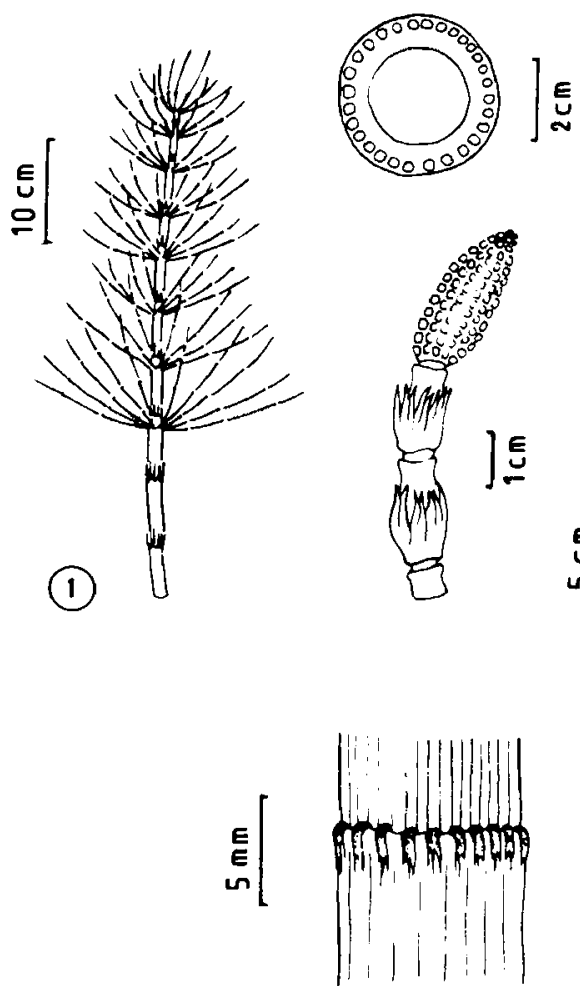

(4)

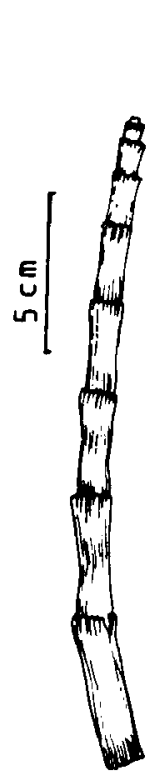

(2)
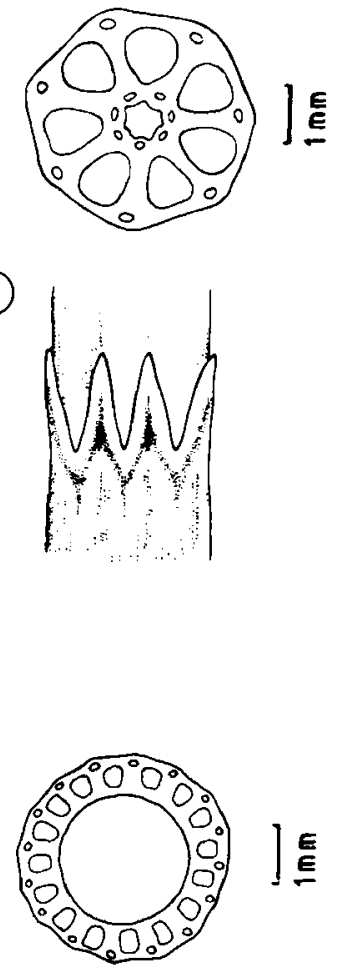

(3)
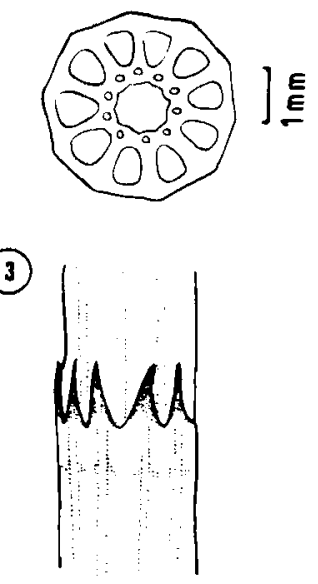
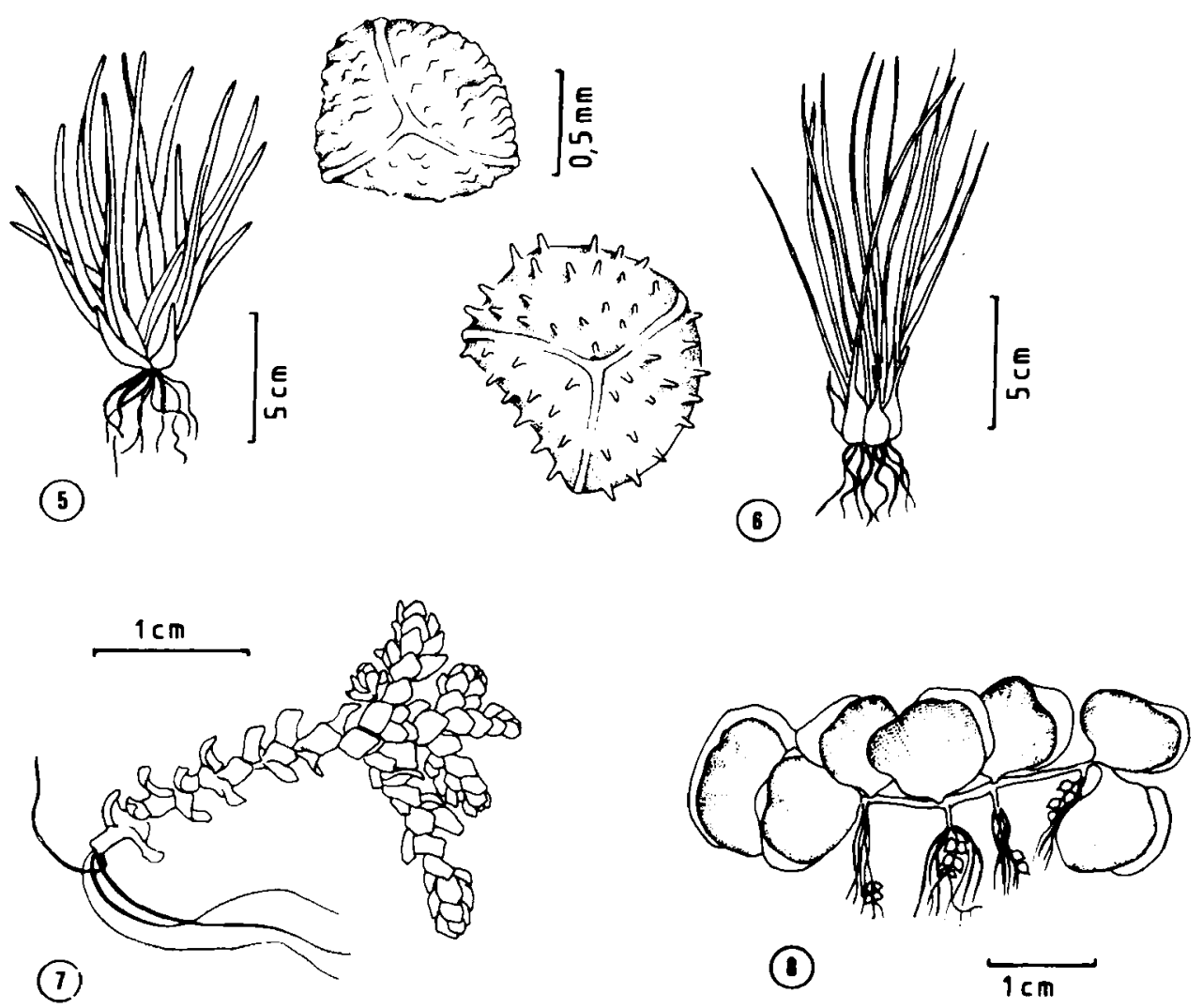
Planche II PTERIDOPHYTES

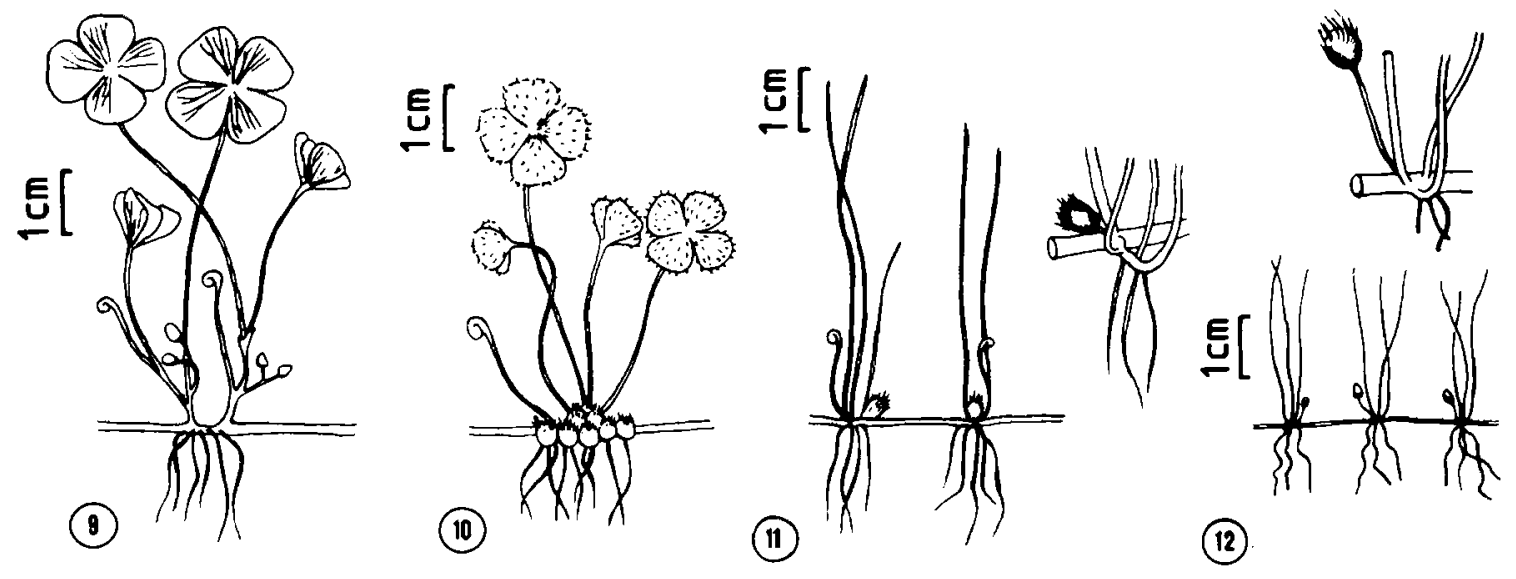

MONOCOTYLEDONES

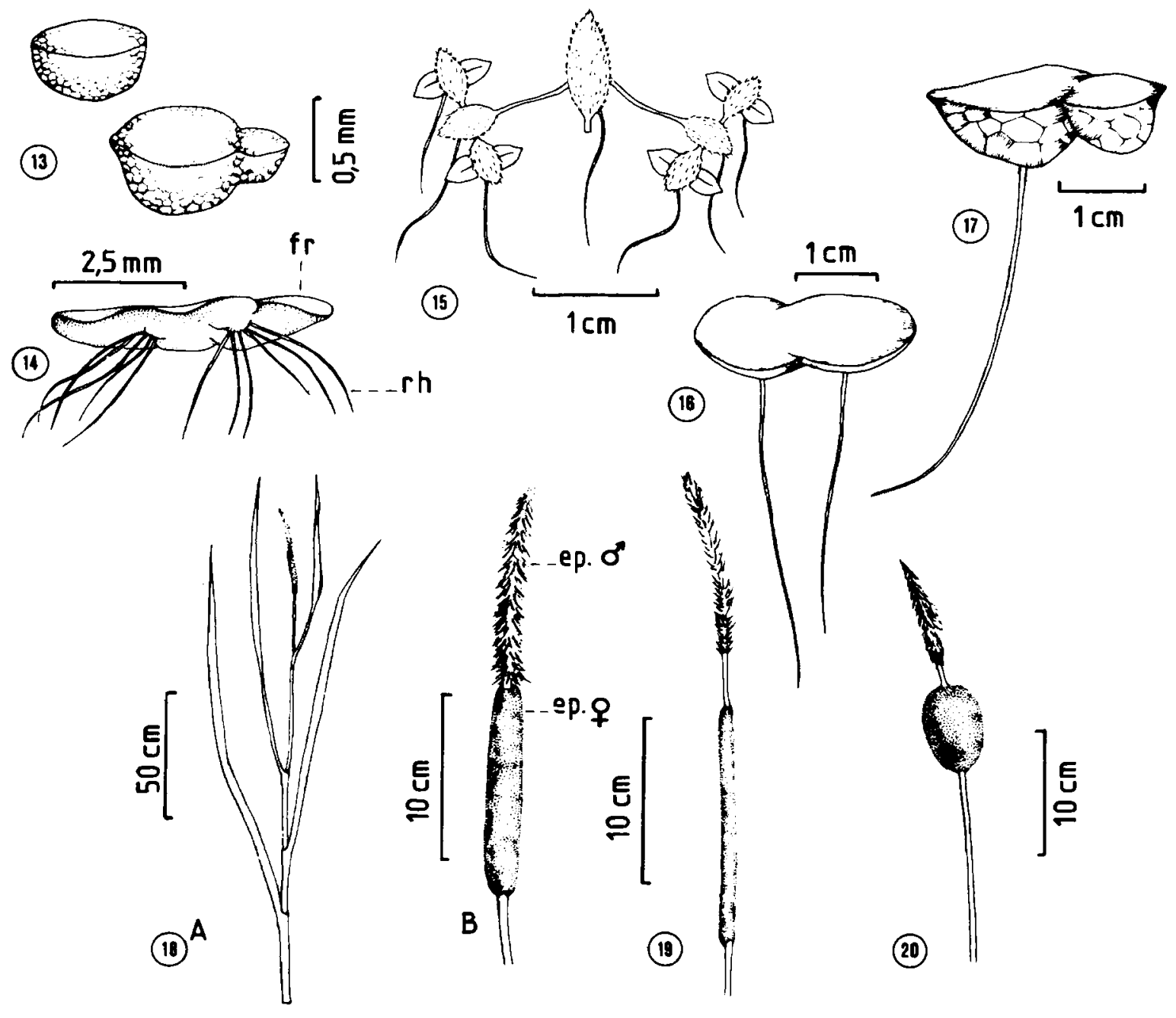




\section{Planche III MONOCOTYLEDONES}
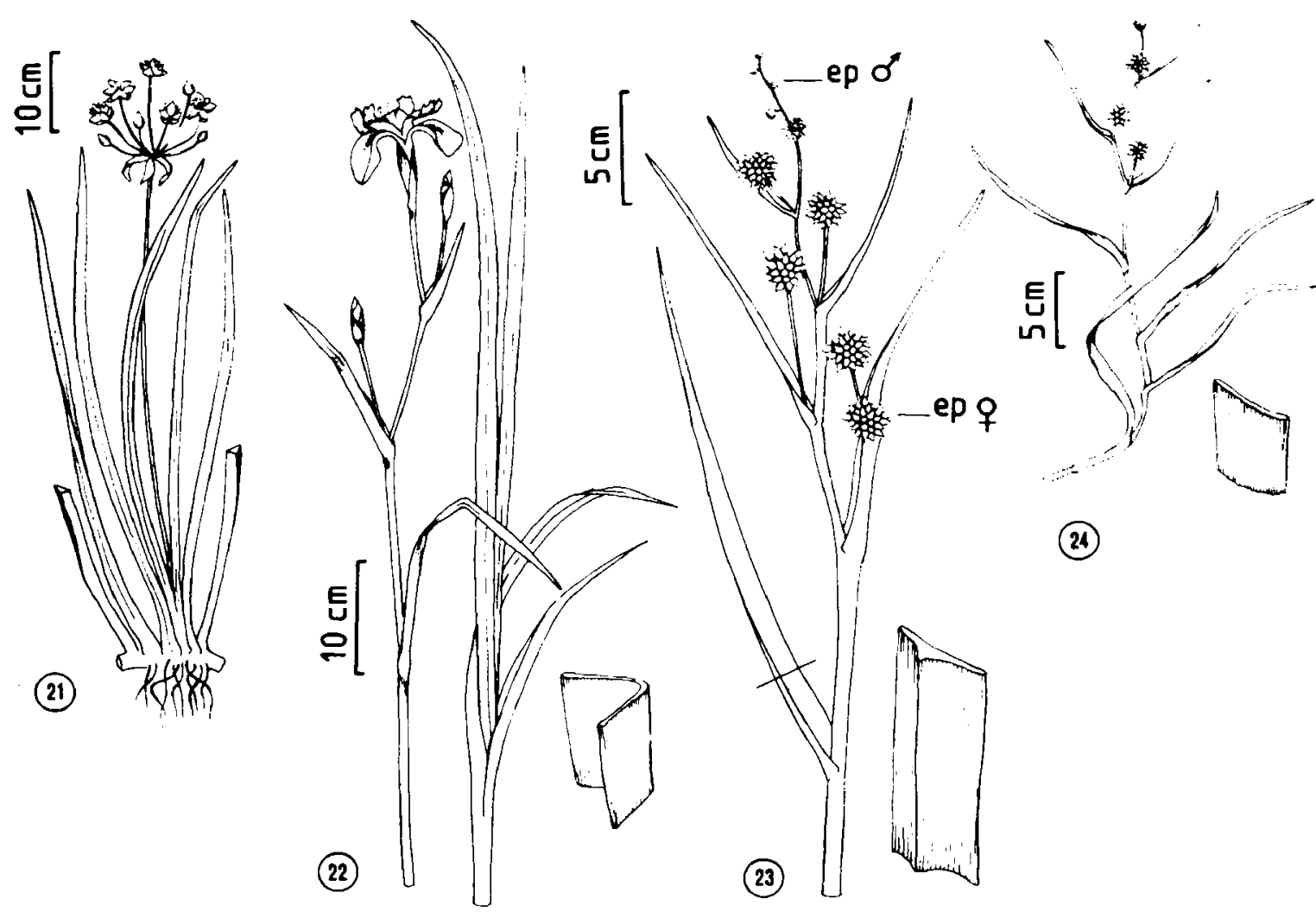

(24)
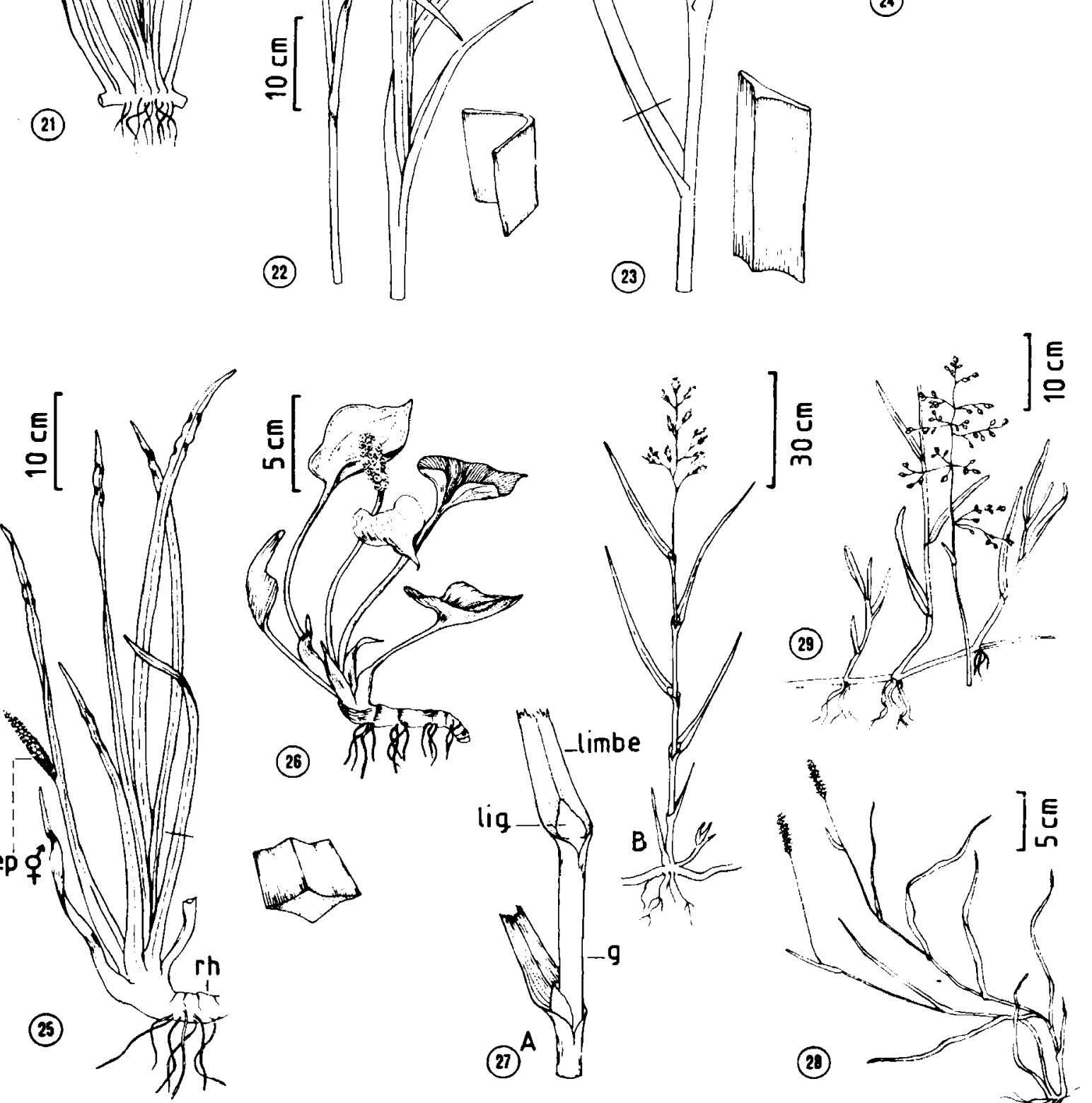

189 


\section{Planche IV MONOCOTYLEDONES}

(30)

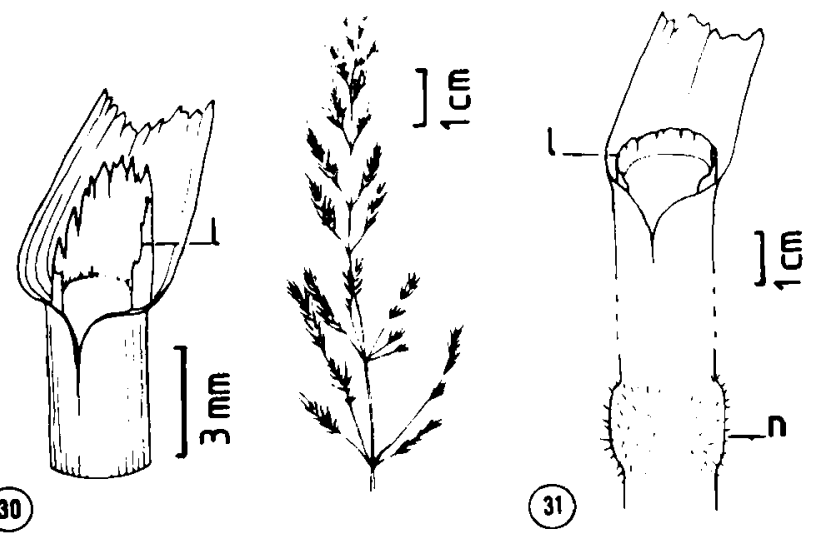

(33)

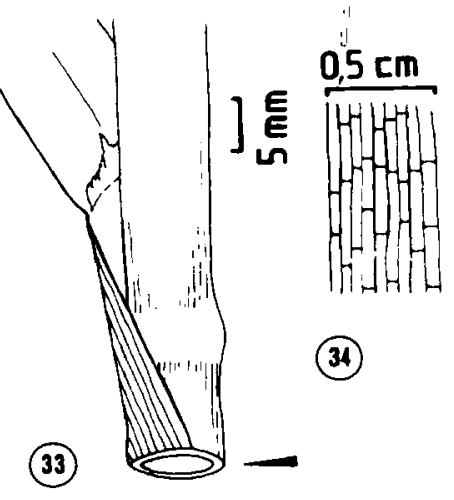

(35)

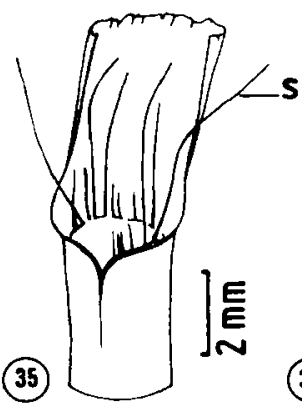

(31)

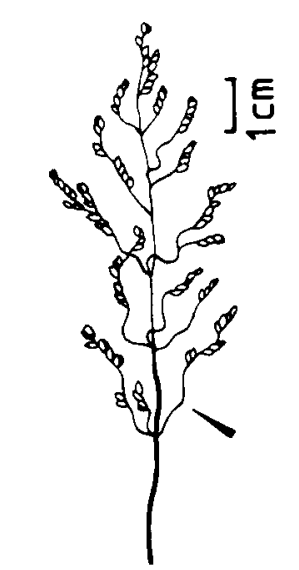

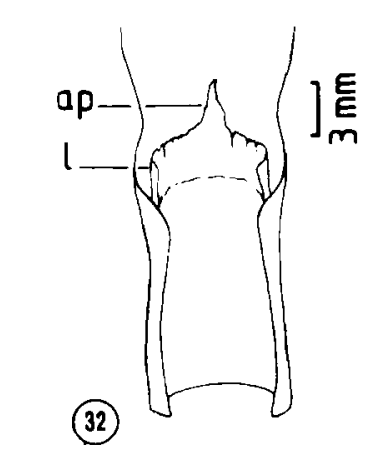
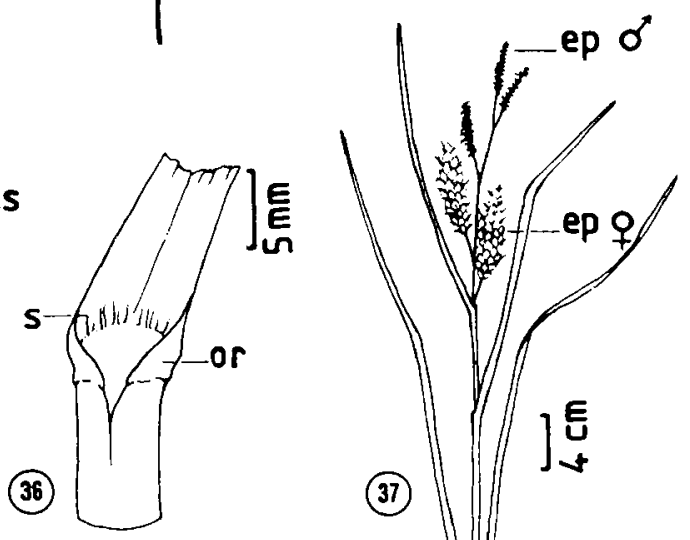

(38)

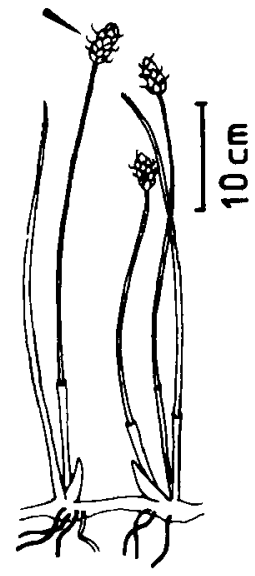

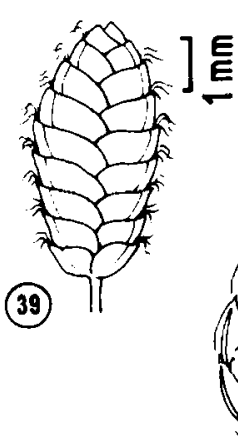

(39)

(40)

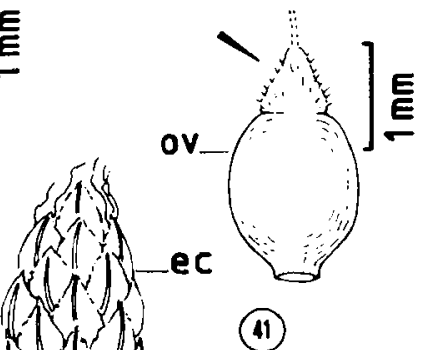

(4)

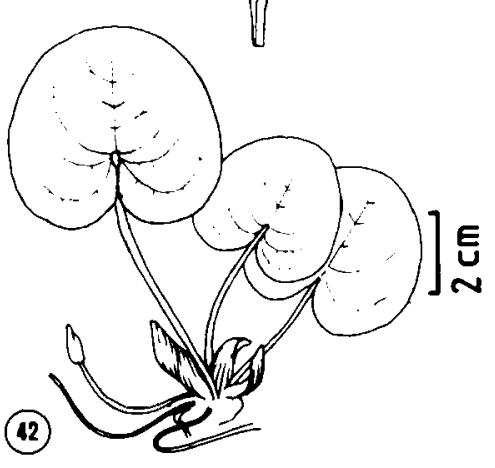

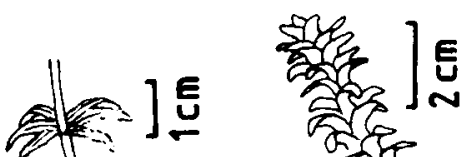

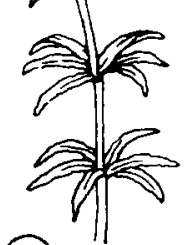

(43)

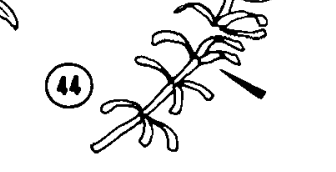

(45)
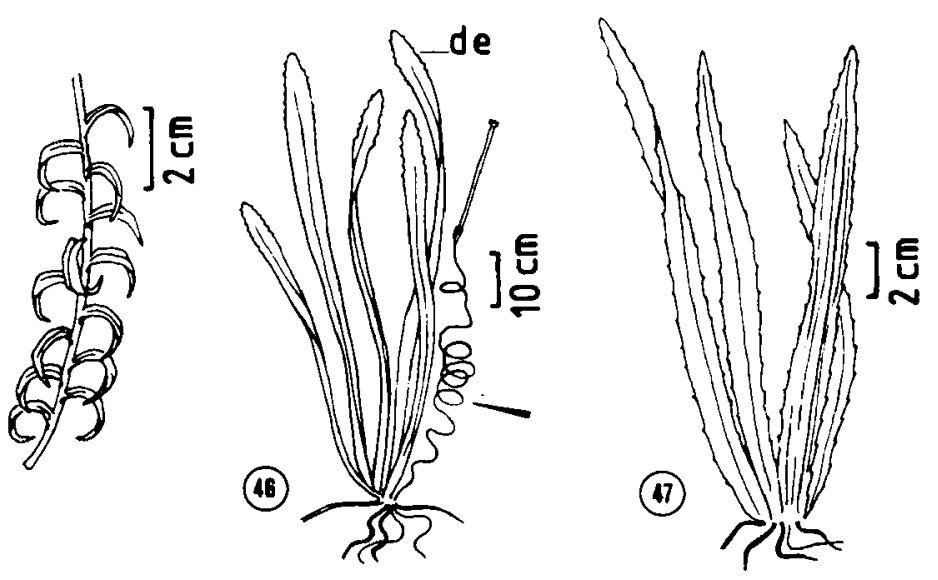

noiror 


\section{Planche V MONOCOTYLEDONES}
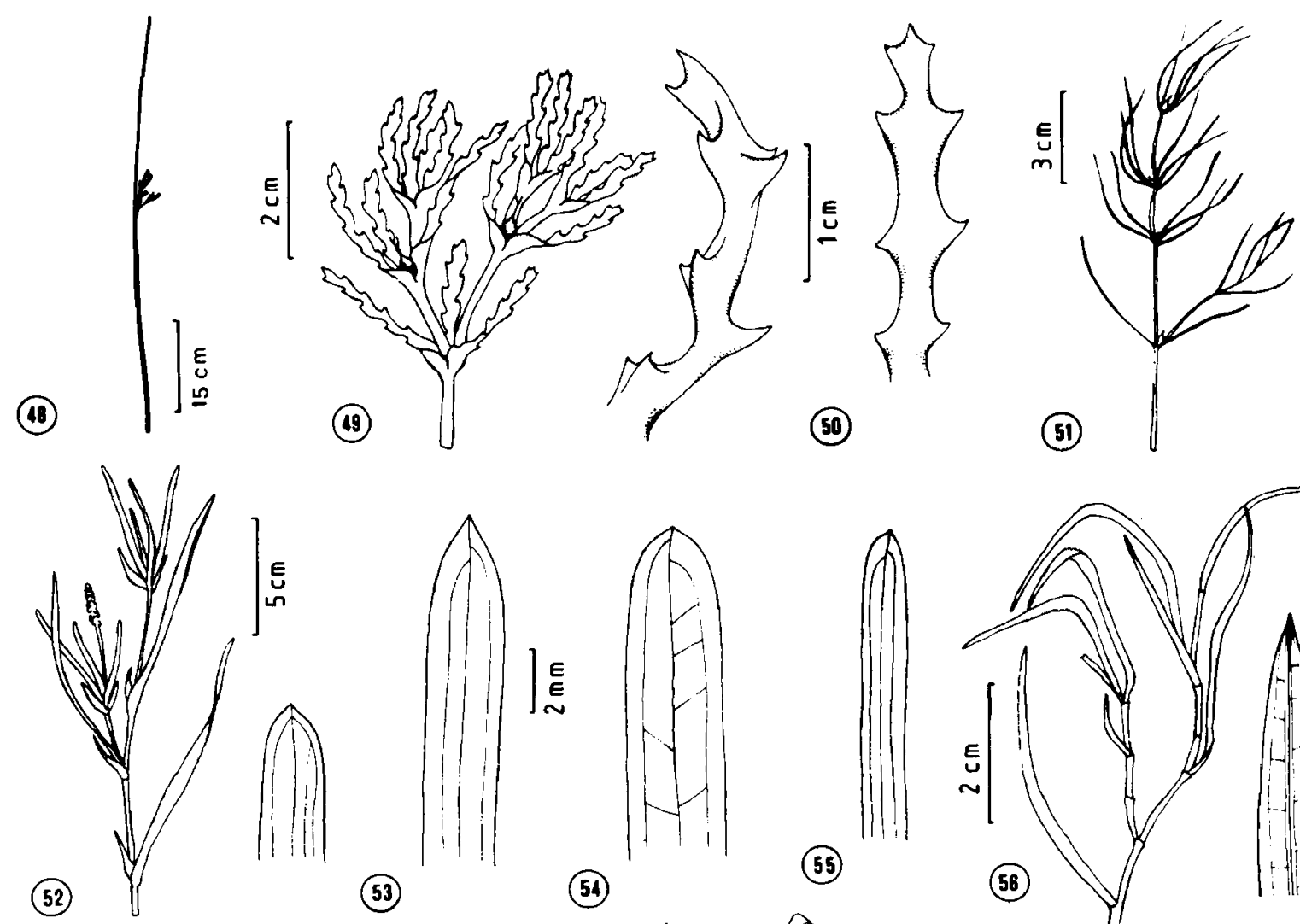

(53)

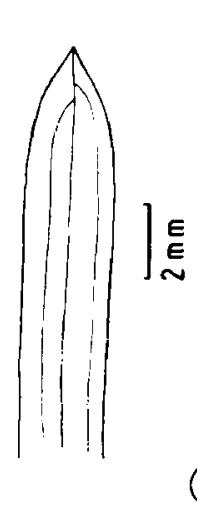

(54)

(55)
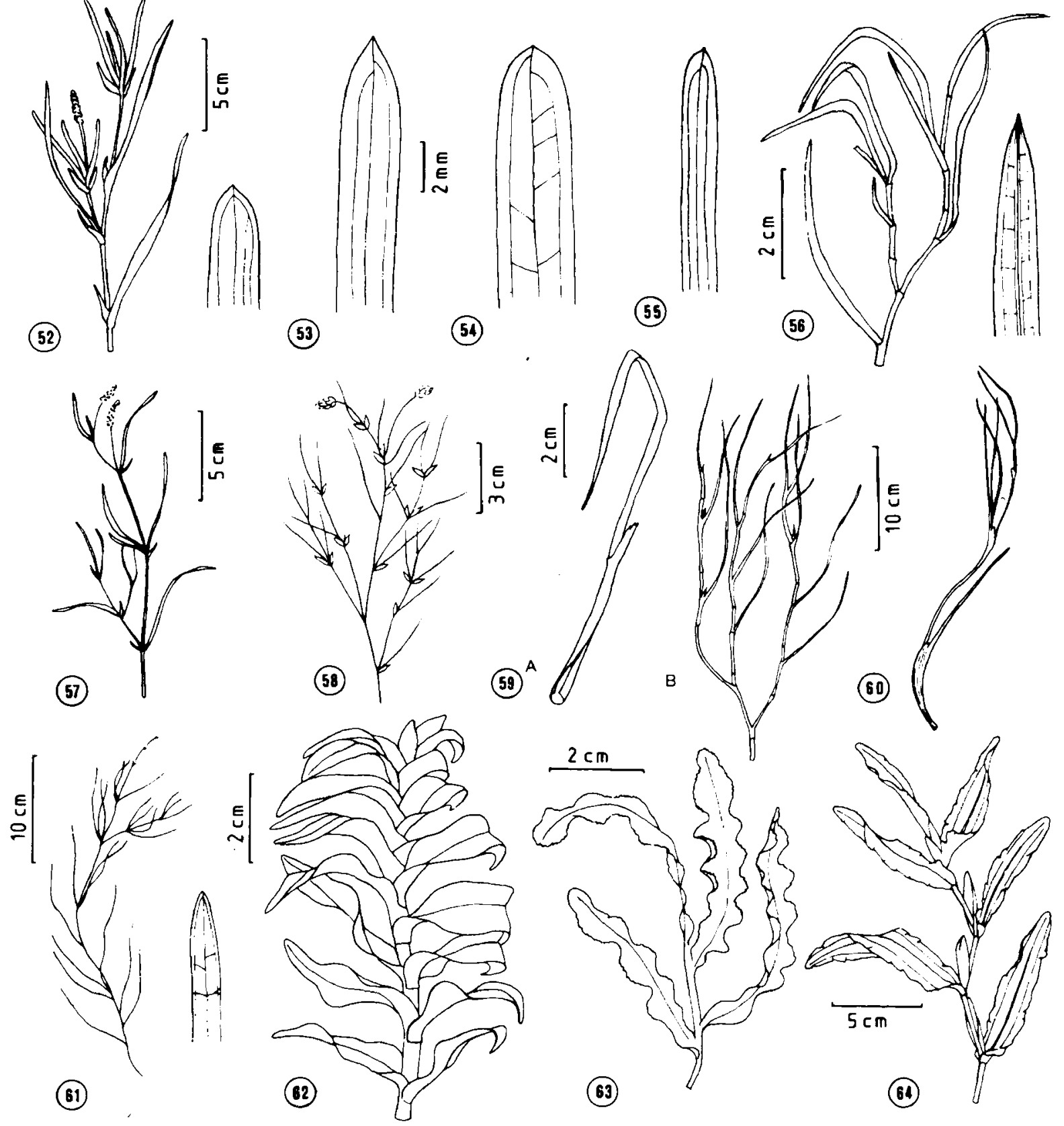


\section{Planche VI MONOCOTYLEDONES}
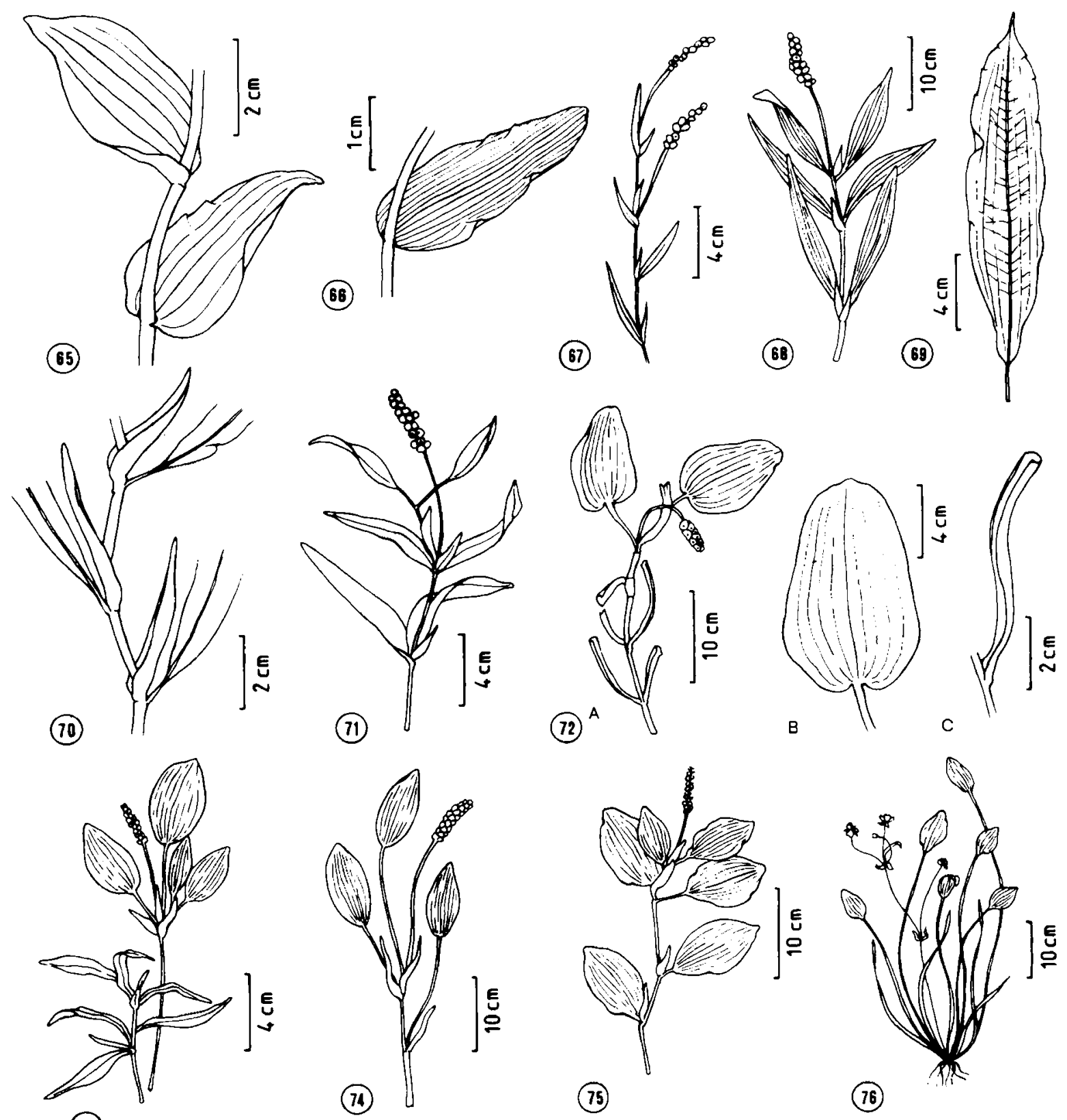

(73)
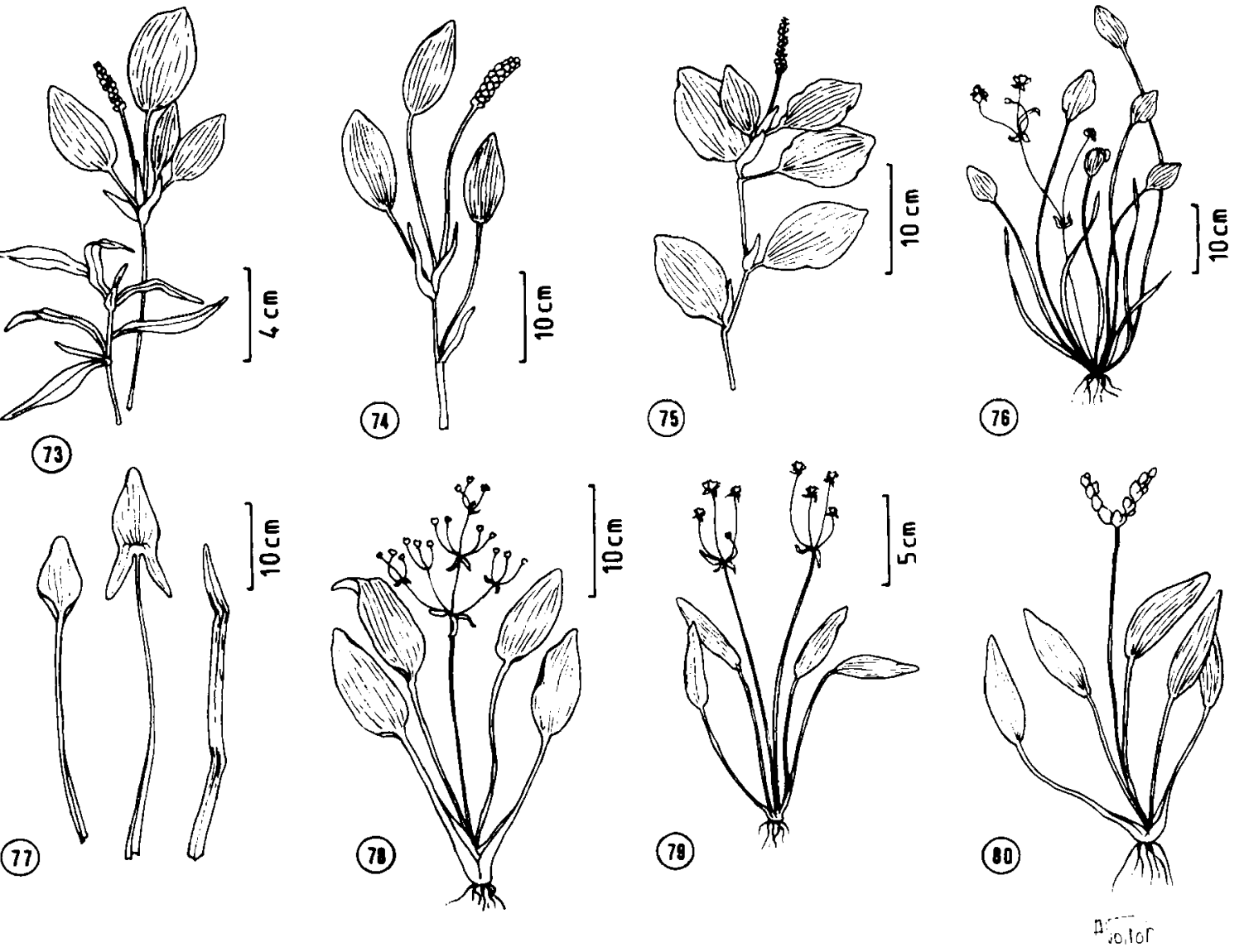


\section{Planche VII DICOTYLEDONES}
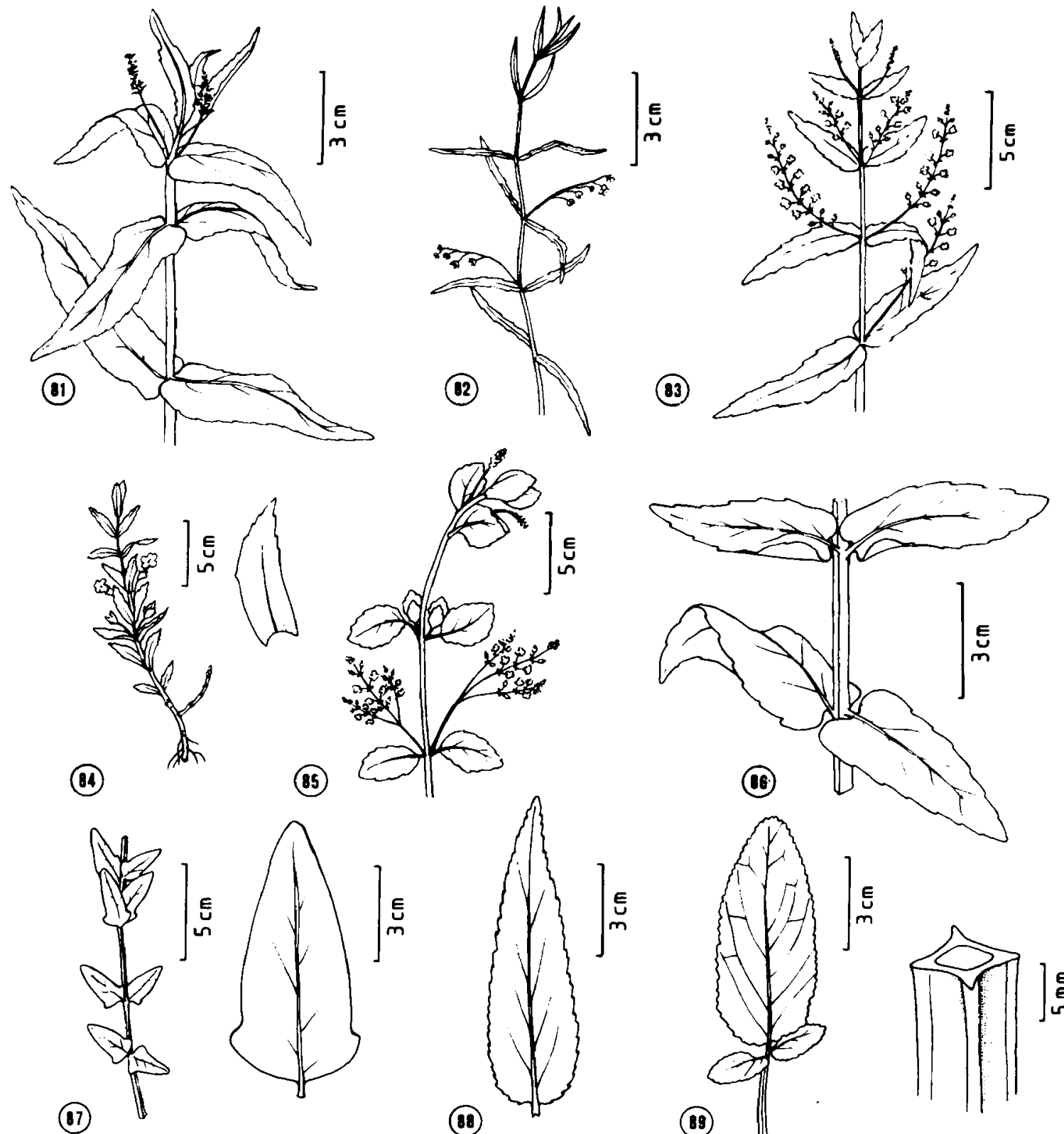

(i5)
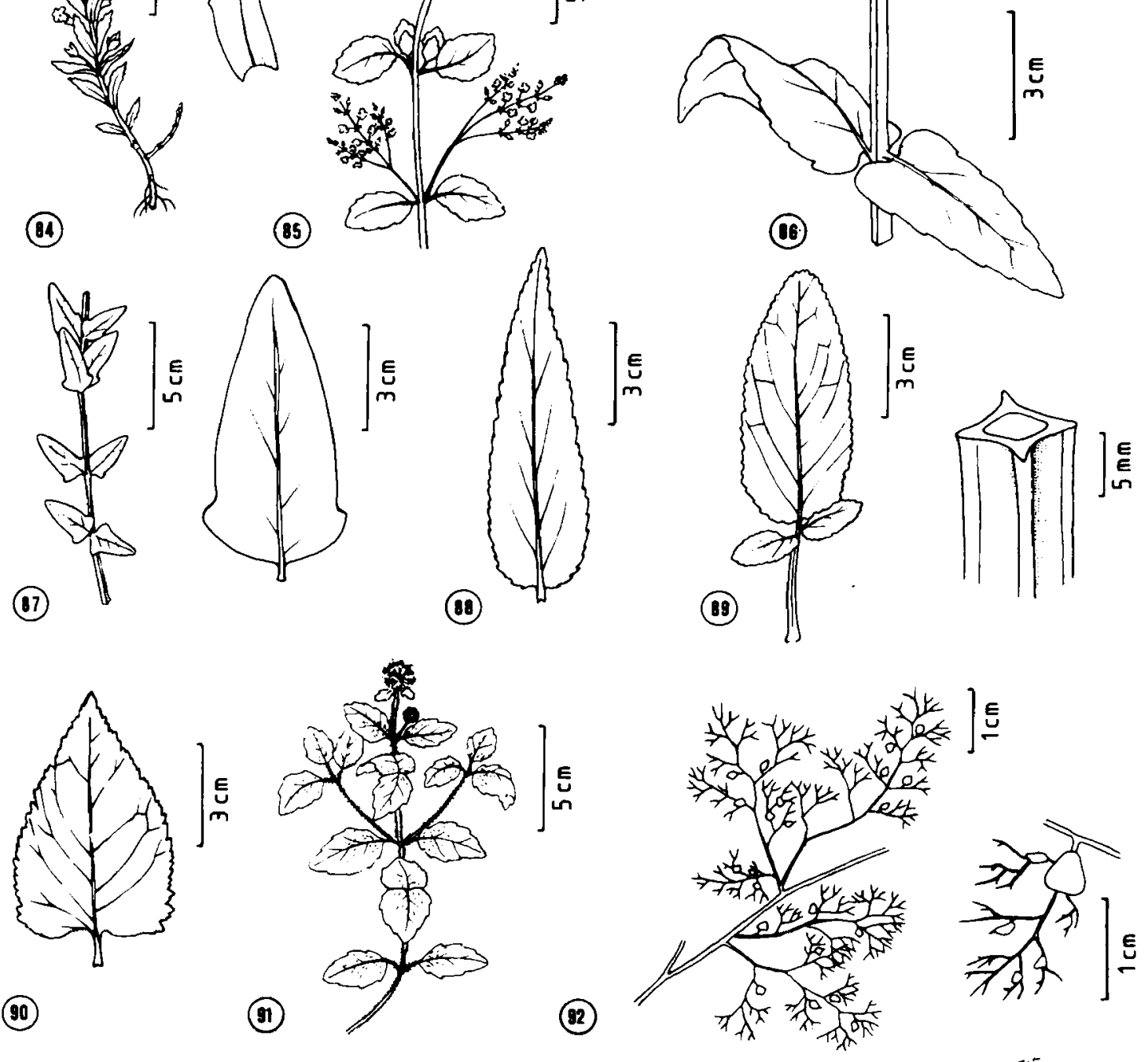

Fisirer 


\section{Planche VIII DICOTYLEDONES}
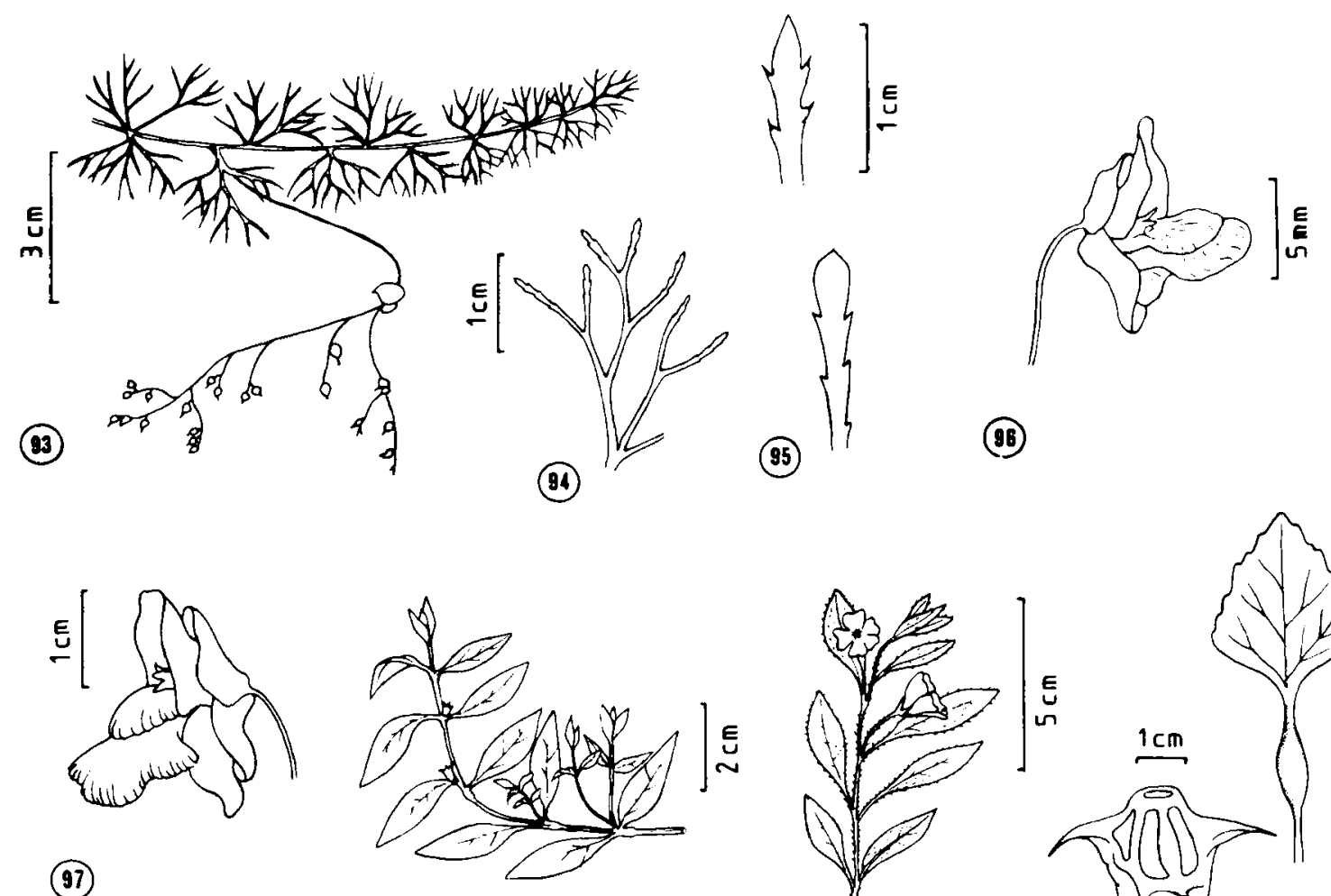

(98)

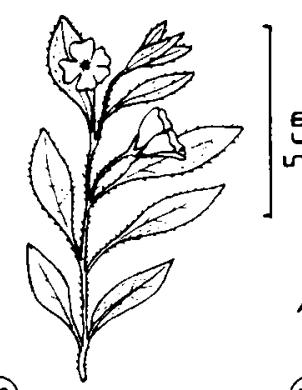

(98)

(97)
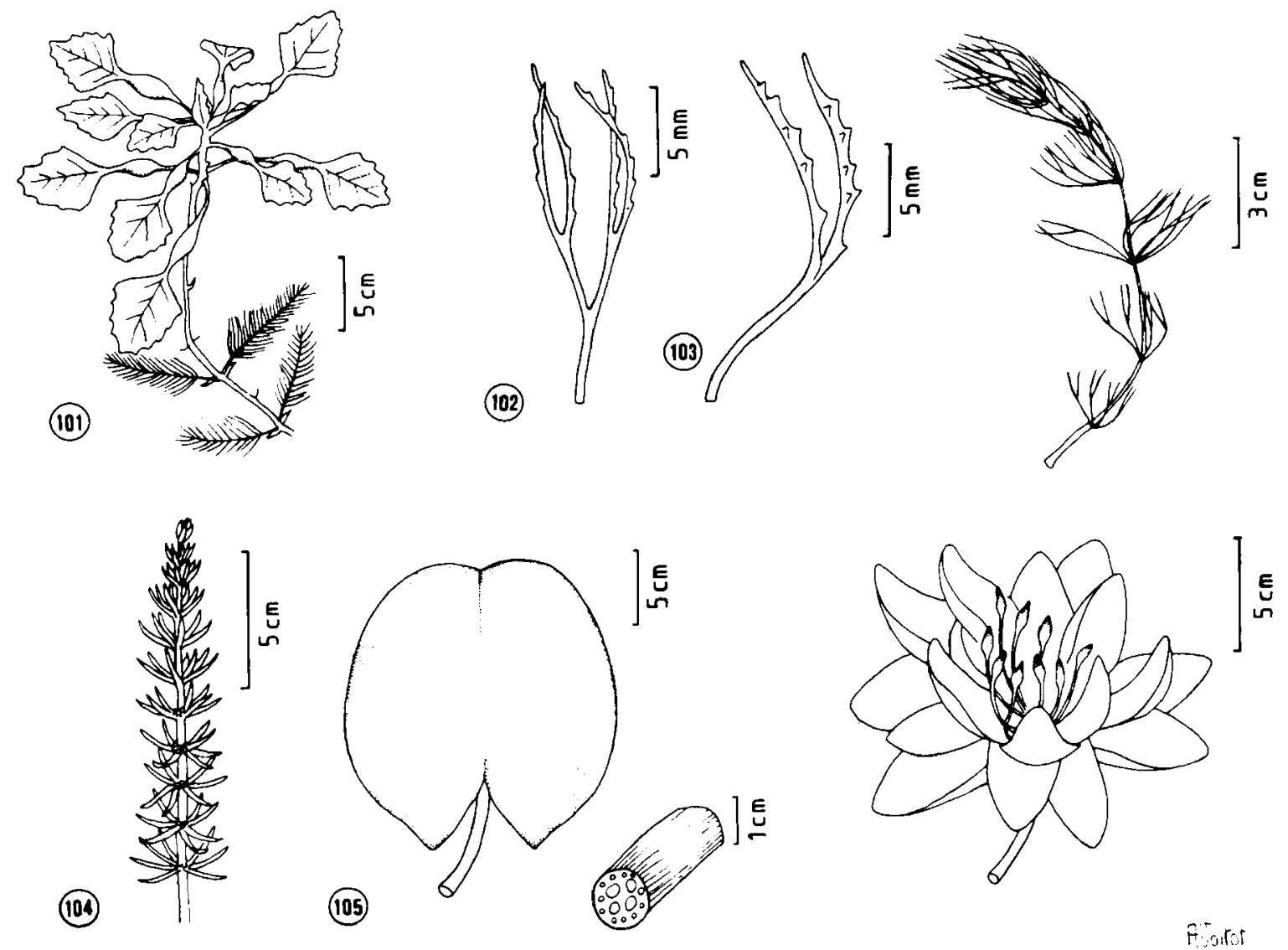


\section{Planche IX DICOTYLEDONES}
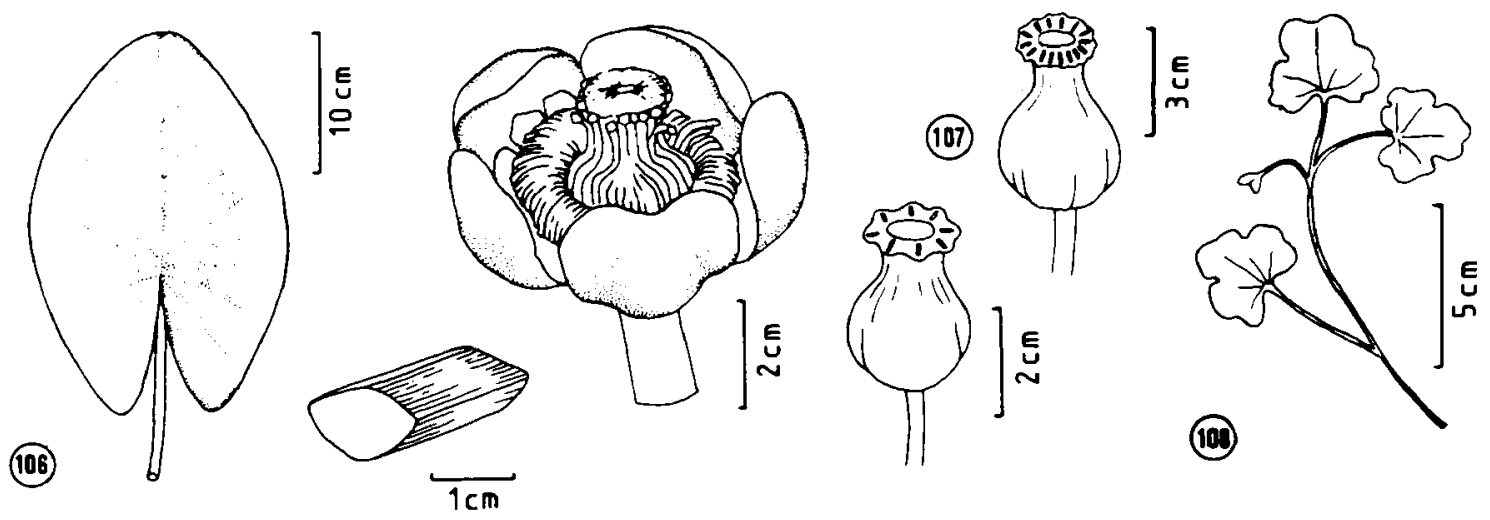

(109)
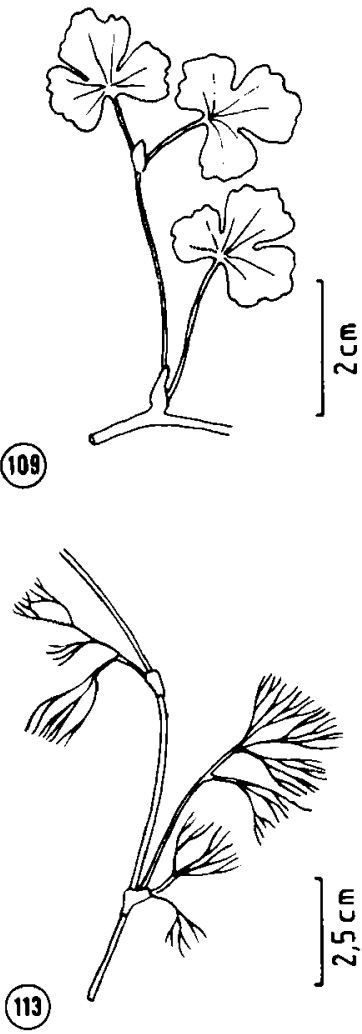

(114)

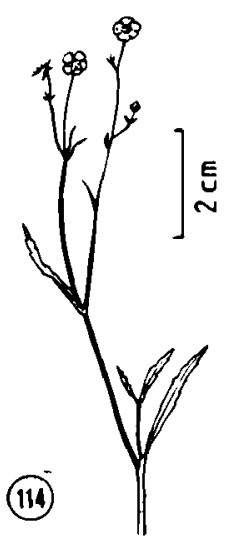

(111)

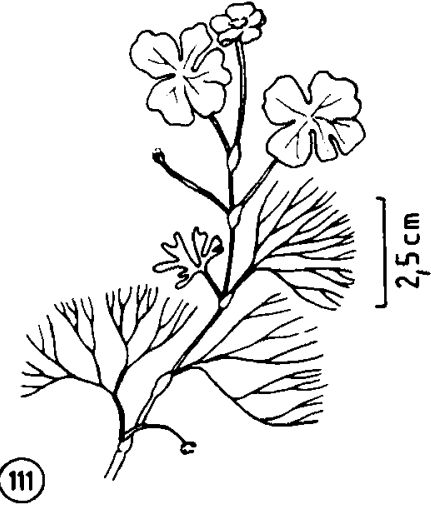

(112)

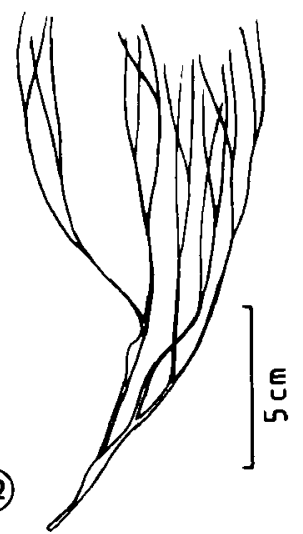

(115)

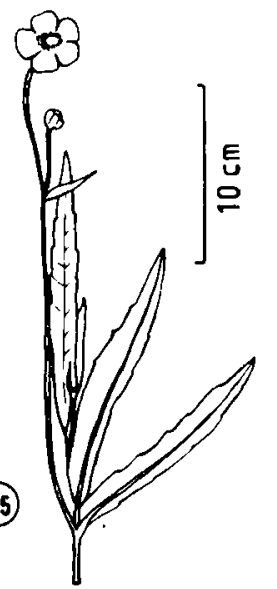

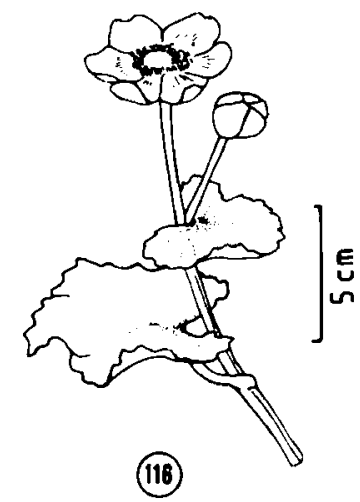

(116)

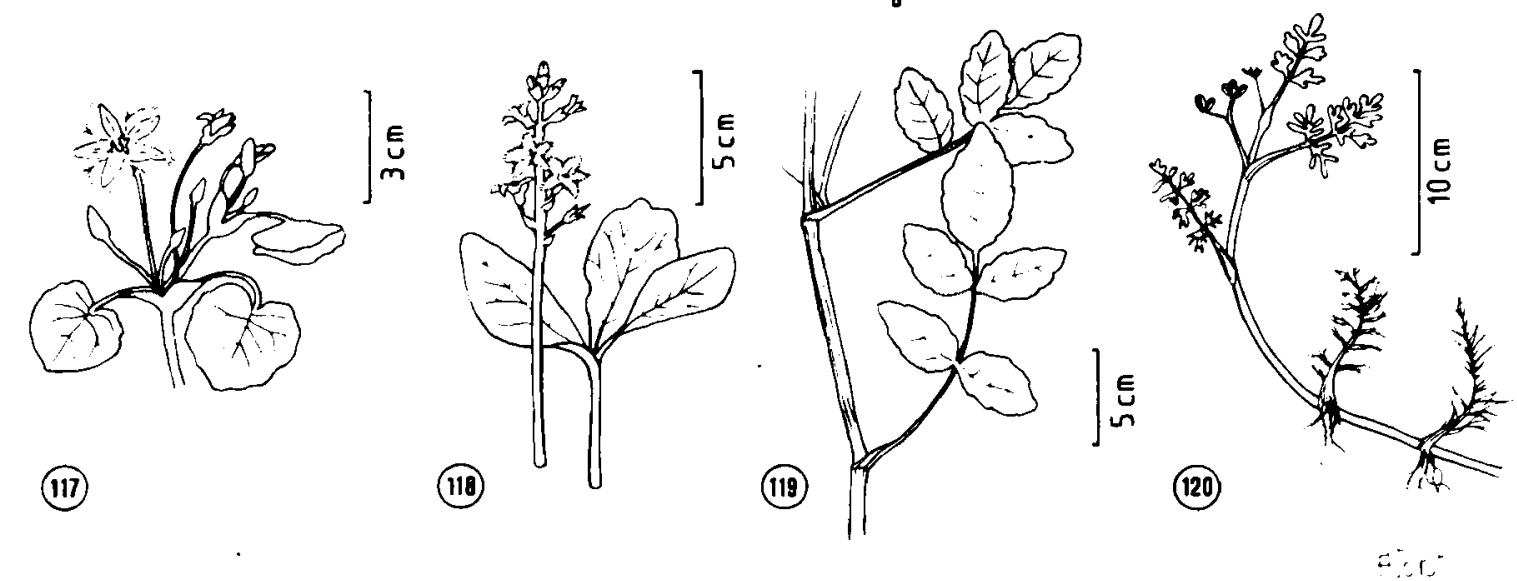




\section{Planche $X$ DICOTYLEDONES}
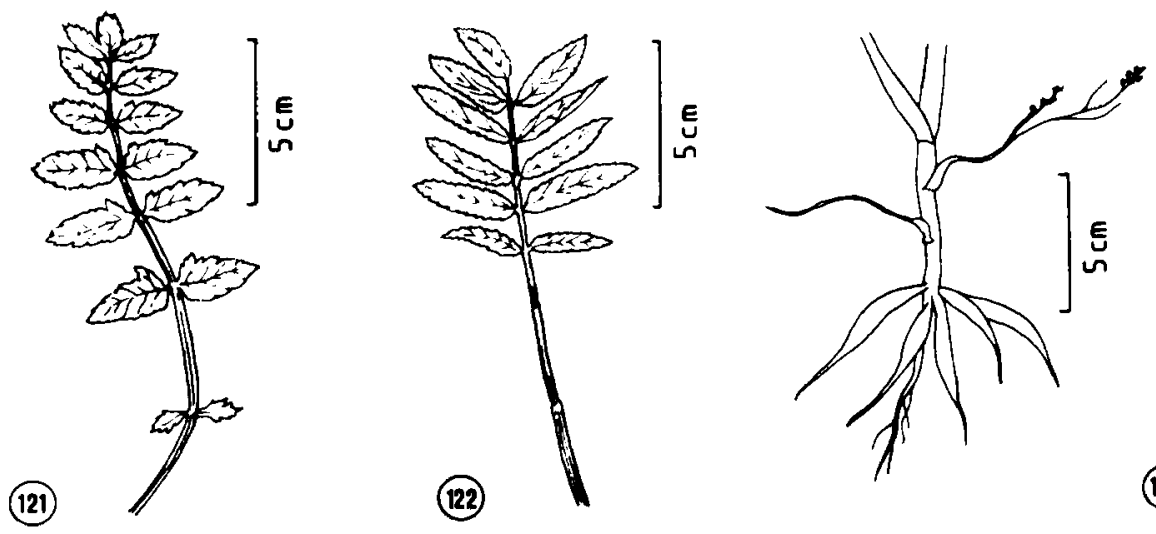

(123)

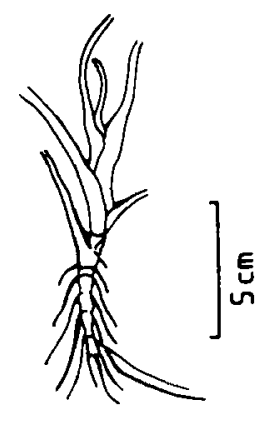

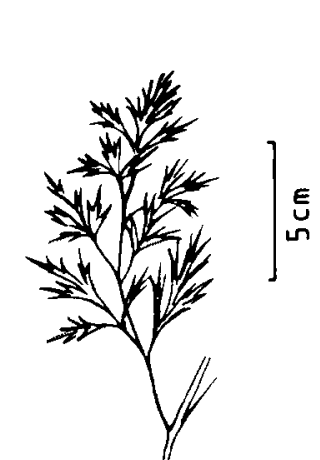

(124)

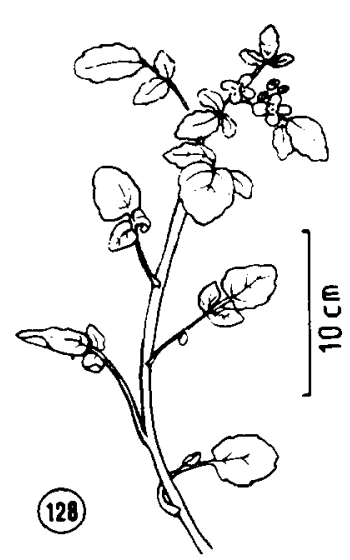

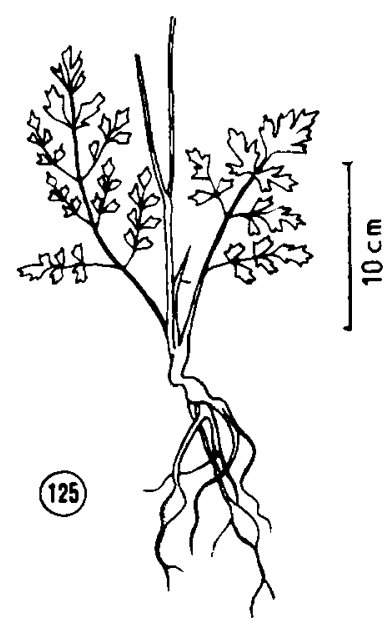

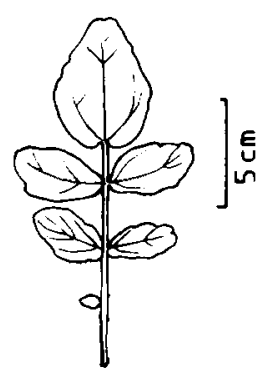

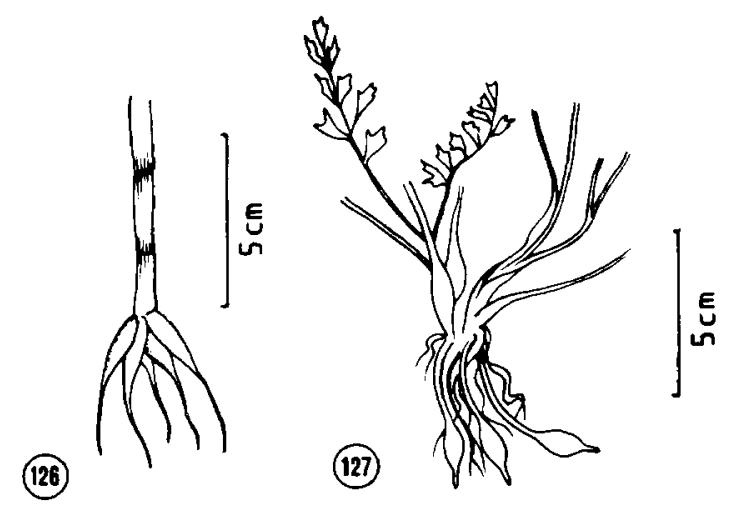

(129)
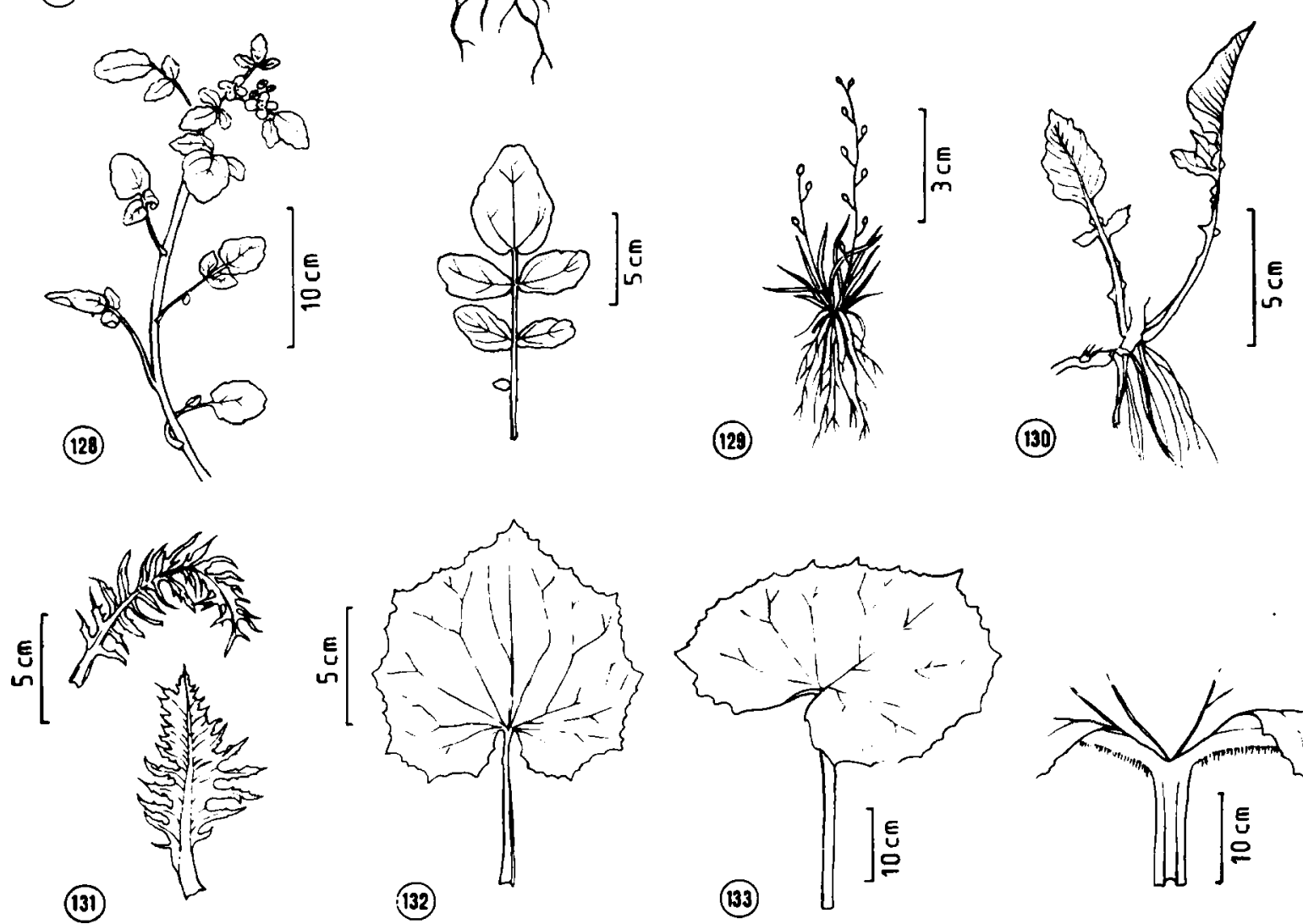

(132)
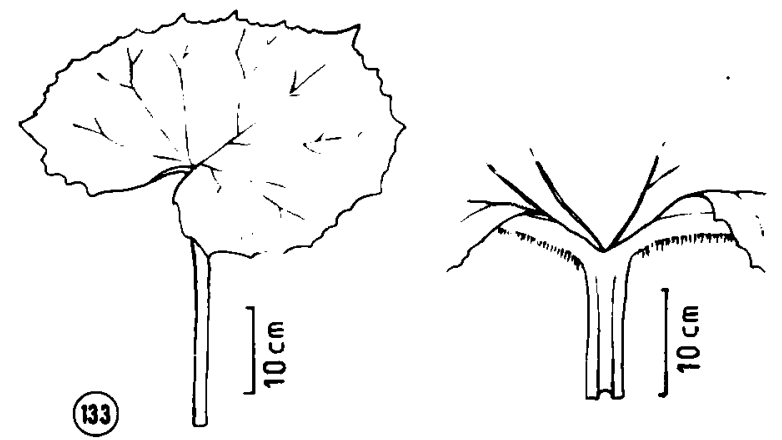


\section{Planche XI DICOTYLEDONES}

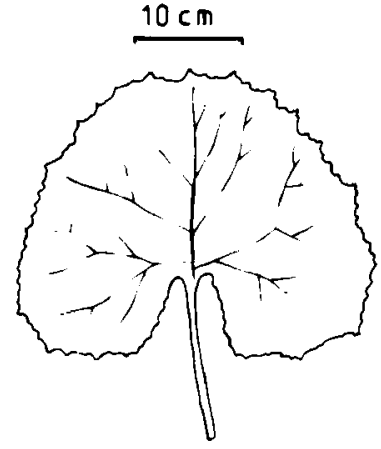

(134)

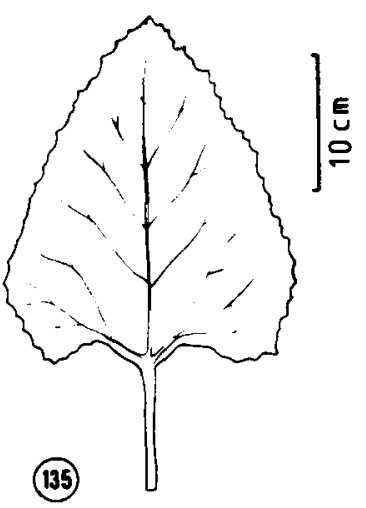

(135)
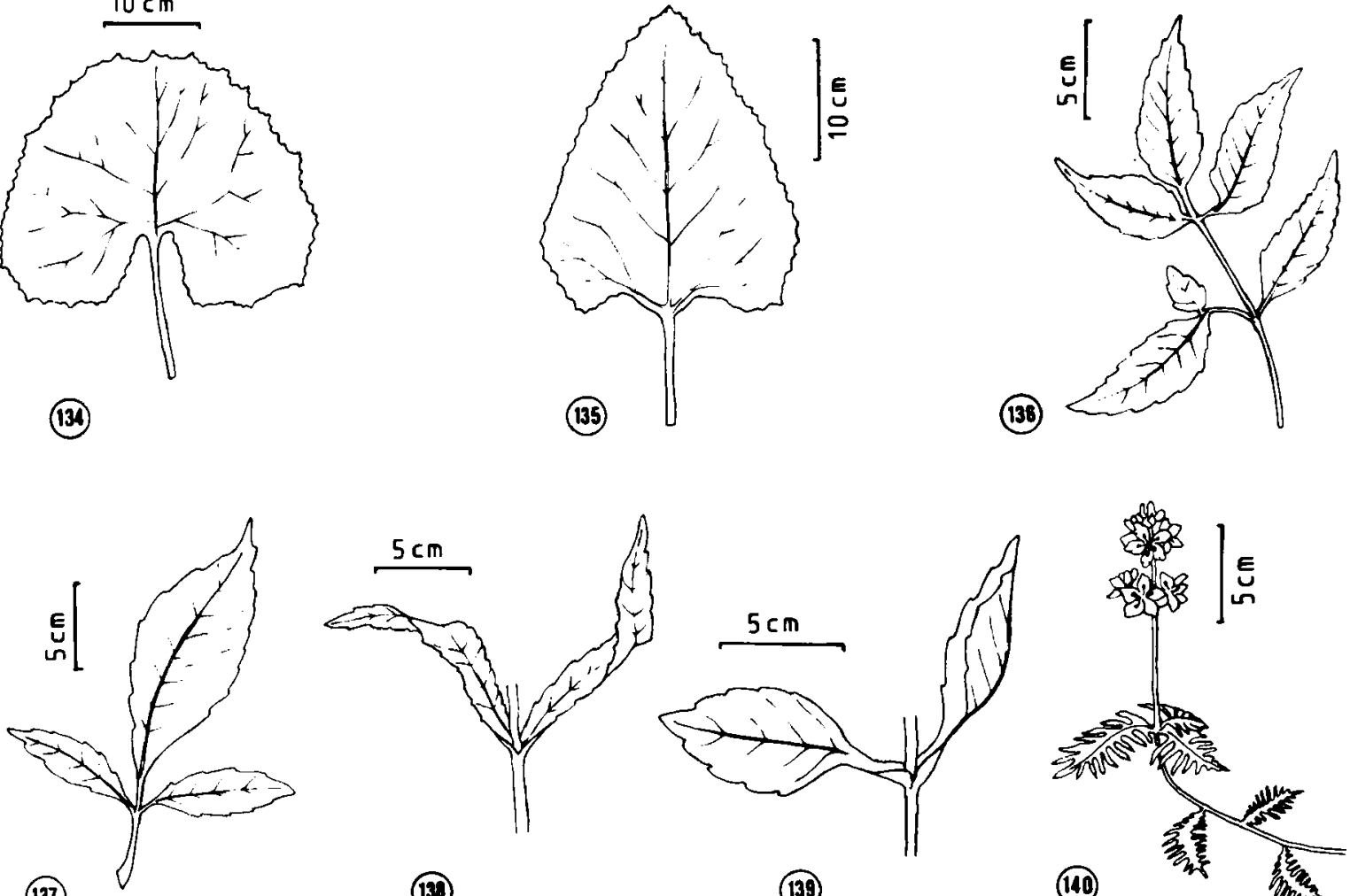

(130)

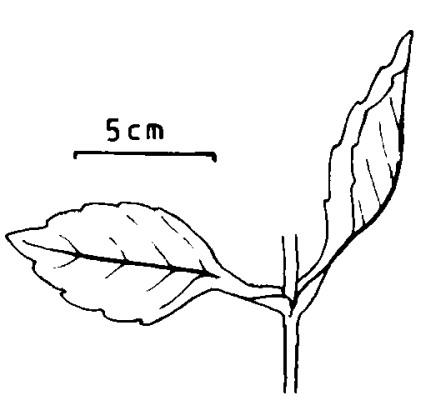

(199)

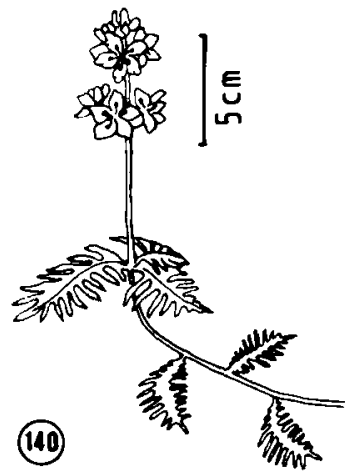

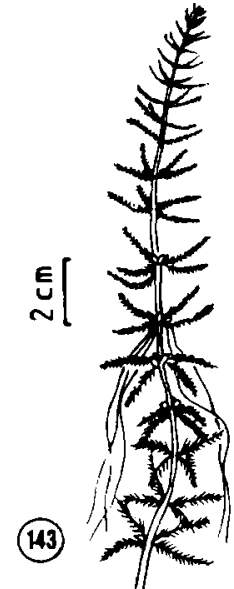

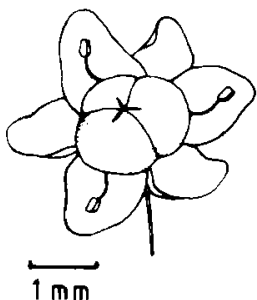

(146)

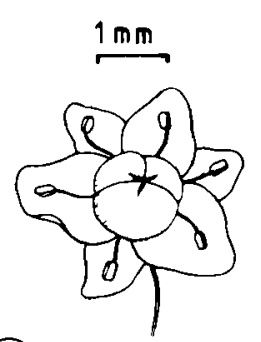

(147)
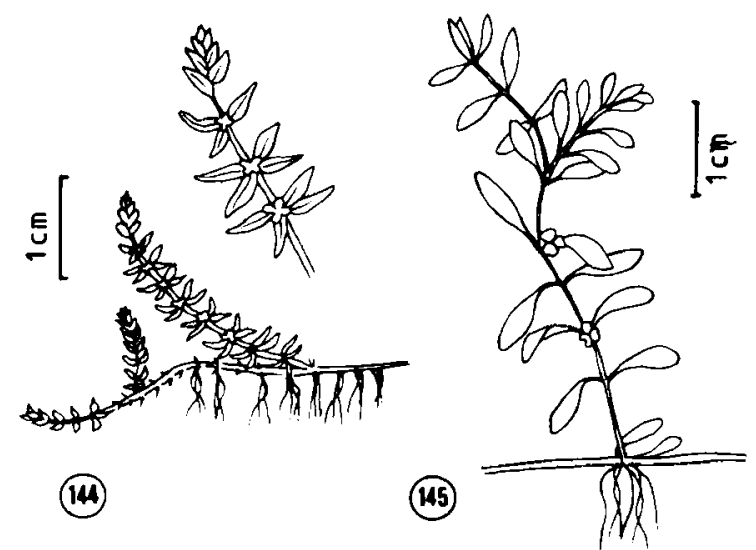

(148)

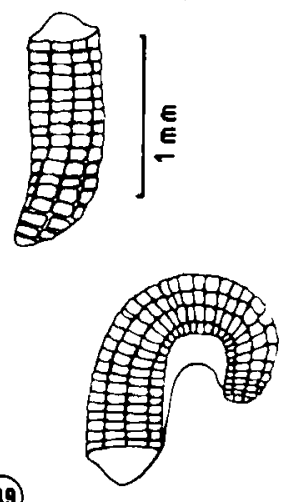




\section{Planche XII DICOTYLEDONES}
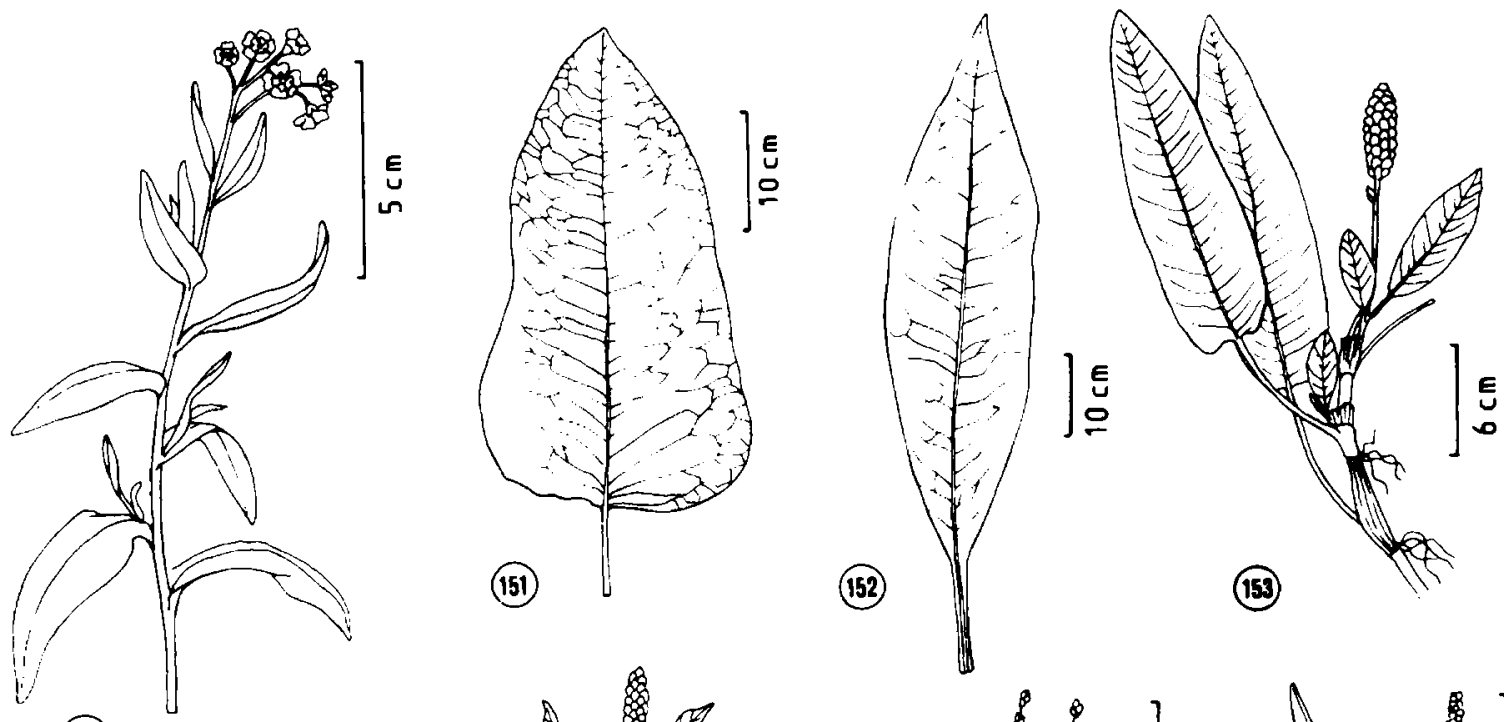

(150)

(154)
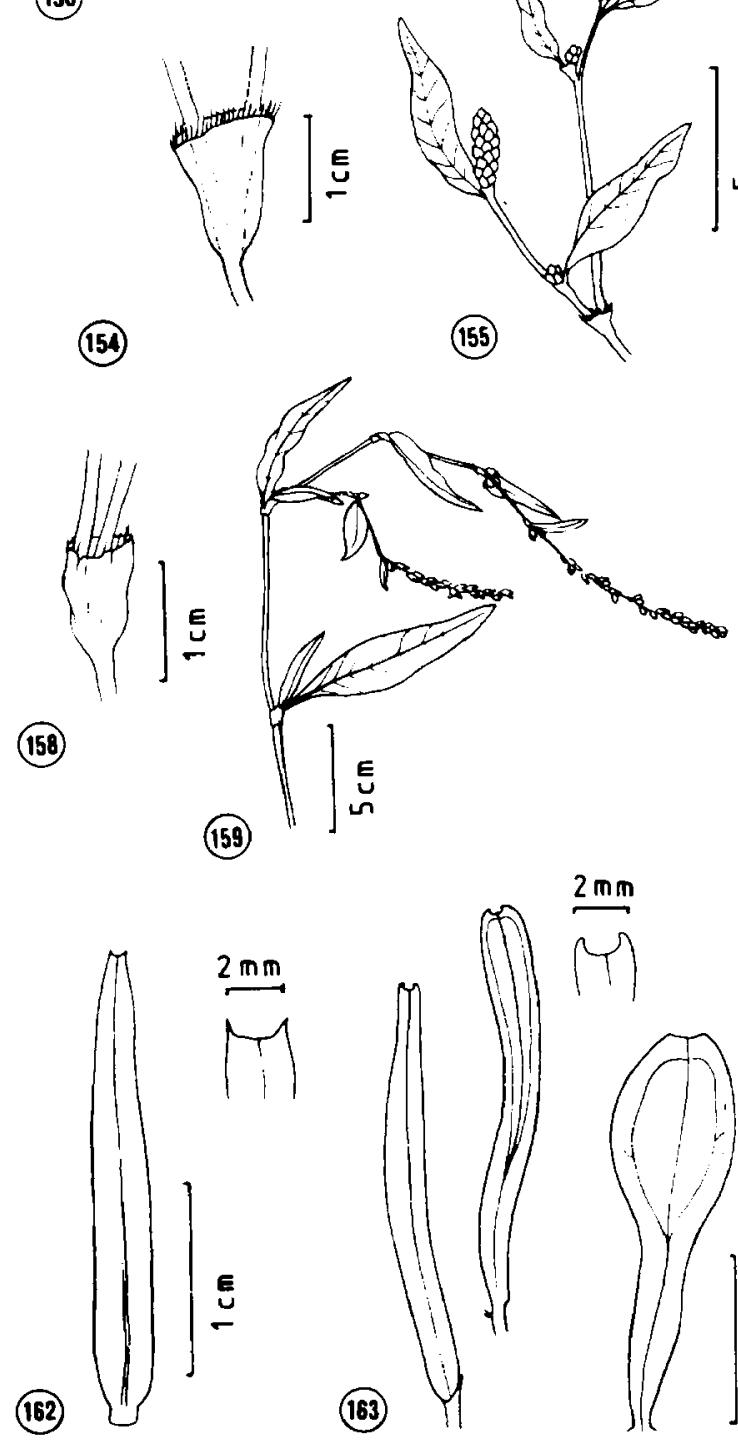<smiles>C1CCCCC1</smiles>

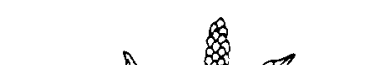

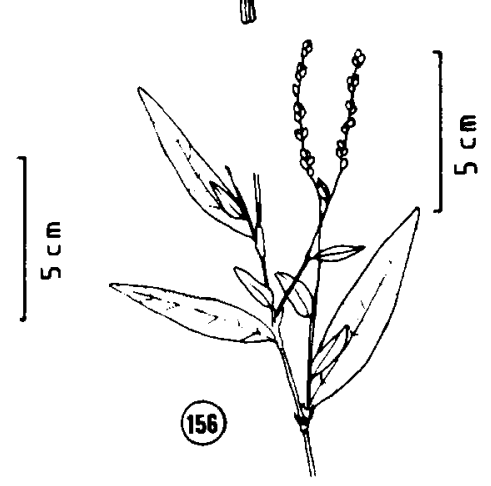

(156)

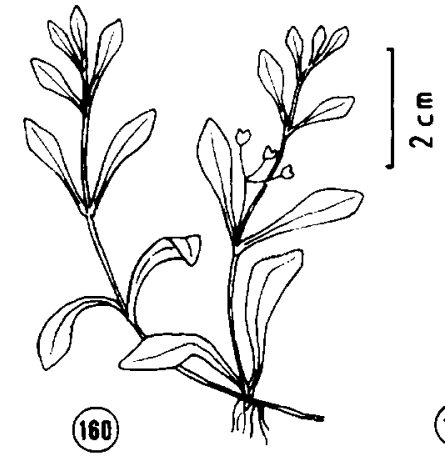

(157)

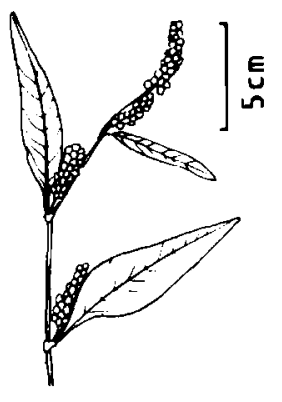

(161)

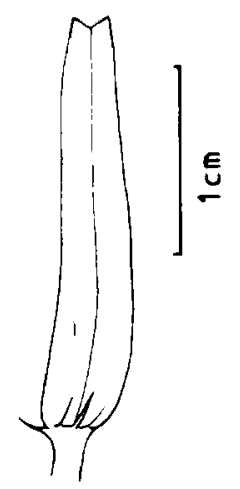

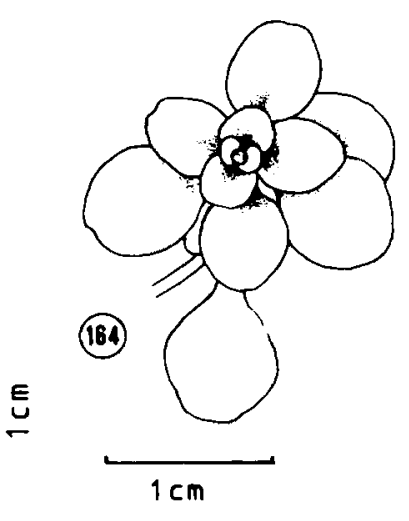
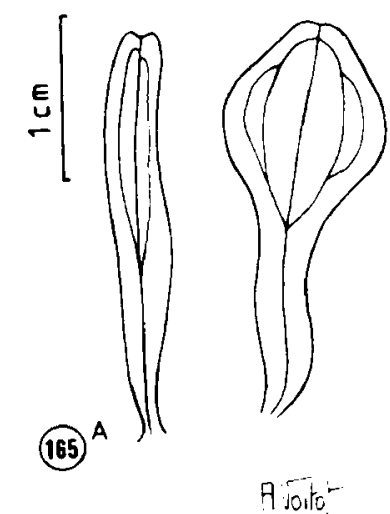
Planche XIII DICOTYLEDONES

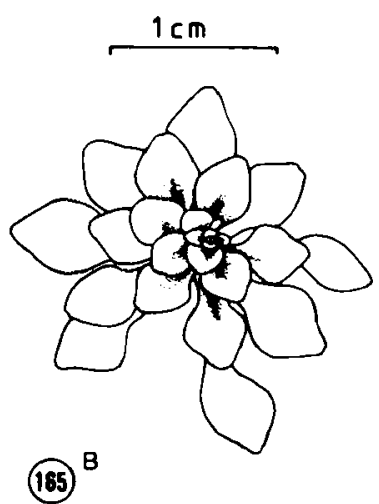

(165) $^{\mathrm{B}}$

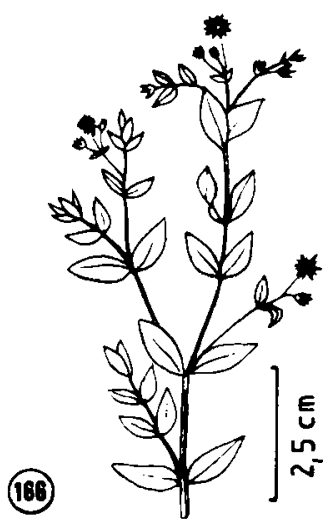

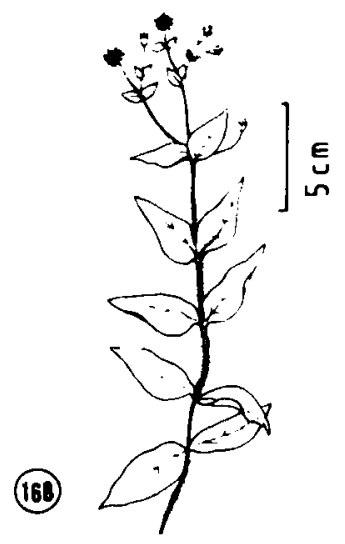




\section{GLOSSAIRE}

ACICULAIRE : en forme d'aiguille.

ACUMINE : terminé en pointe effilée.

ADVENTIVES (racines) : naissant directement le long de la tige.

AILE : membrane mince plus ou moins large bordant certains organes.

AISSELLE (d'une feuille) : point où elle se détache de la tige ou du rameau.

ALTERNES (fevilles) : insérées à des hauteurs différentes sur la tige.

ANASTOMOSEES (nervures) : réunies entre elles en réseau.

APICULE : dont le sommet se rétrécit brusquement en une pointe courte et fine

AUTROTOPHIE : capacité d'opérer des synthèses vitales aux dépens de molécules simples (oxygène, azote, carbone, gaz carbonique, sels minéraux).

AXILLAIRE : placé à l'aisselle.

BIFIDE : fendu en deux jusque vers son milieu.

BILOBE : partagé en deux lobes.

BRACTEE : organe en forme de très petite feuille, mais différent des feuilles par sa forme et sa couleur, et accompagnant les pédoncules ou les fleurs.

BULBE : souche renflée et courte, charnue et écailleuse, par exemple celle du Lis.

BULBILLE : très petit bulbe accompagnant les fleurs ou les feuilles, par exemple les fleurs de l'Ail.

CALICE : enveloppe extérieure de la fleur, ordinairement de couleur verte, et formée de sépales indépendants ou plus ou moins soudés entre eux.

CANALICULE : creusé d'un petit sillon en forme de gouttière.

CAPILLAIRE : fin comme des cheveux.

CARENE : partie d'un organe ayant la forme d'une carène de vaisseau.

CAULINAIRE : porté par la tige.

EMBRASSANTE (feuille) : entourant partiellement la tige.

EPERON : tube prolongeant par dessous la fleur un pétale ou un sépale.

EPI : série de fleurs très rapprochées et sessiles ou presque à l'extrémité d'une tige ou d'un rameau, par exemple l'épi de blé. L'épi est composé d'épillets chez les Graminées.

EPILLET : élément de l'épi ou de la panicule des Graminées formé d'une ou plusieurs fleurs comprises entre deux bractées dites glumes. Exemple : chacun des menus épis qui tremblent au vent de la Brize ou Amourette est un épillet.

ETAMINE : organe mâle de la fleur, inséré entre la corolle et l'ovaire, et composé d'un filet, ordinairement grêle, qui porte ordinairement 2 sacs ou loges dont l'ensemble constitue l'anthère. Ces loges contiennent le pollen.

FILIFORME : fin comme un fil.

FOLIOLE : division d'une feuille composée.

FRONDE : "feuille" des Fougères portant les fructifications

FUSIFORME : en fuseau, c'est-à-dire renflé au centre et rétréci vers les deux extrémités.

GAINE : enveloppe cylindrique entourant la tige et ordinairement soudée à la base de certaines feuilles, par exemple des Graminées.

GENOUILLE : formant un angle brusque en forme de genou.

GLABRE : sans poils.

GLANDE : réservoirs, souvent en forme de minuscule tête d'épingle, contenant des liquides secrétés par des cellules spéciales.

HERMAPHRODITE (fleur) : contenant étamines et pistil.

HETEROTROPHE : se dit de tout être vivant qui ne peut effectuer par lui-mème la synthèse de tous ses constituants et doit de ce fait utiliser les matières organiques élaborées. 
INFLORESCENCE : disposition des fleurs sur une même plante, ensemble de ces fleurs.

LANCEOLE : en forme de fer de lance, c'est-à-dire rétréci du milieu aux deux extrémités. LEPIDOPTERES : ordre d'insectes ayant quatre ailes couvertes d'une poussière écailleuse tels que les papillons.

LIGULE : expansion membraneuse à la jonction de la tige et du limbe, parfois remplacée par des poils, prolongeant la gaine et embrassant la tige

LIMBE : partie élargie de la feuille.

LINEAIRE : étroit et allongé.

MUCRON : pointe raide très courte terminant brusquement une feuille, un sépale, une bractée.

NERVURE : prolongement et ramifications dans le limbe du pétiole d'une feuille, épaississement longitudinal d'un sépale, d'une bractée, d'une silique.

ORBICULAIRE : arrondi en forme de cercle.

PALMATILOBE : feuille palmée dont les divisions sont arrondies.

PEDONCULE : sorte de petit rameau portant une ou plusieurs fleurs; ne pas confondre avec pétiole.

PENNE : folioles disposés de chaque côté d'un pétiole commun comme les barbes d'une plume.

PETALE : élément de la corolle.

PHOTOSYNTHESE : mécanisme physiologique complexe grâce auquel les êtres vivants sont capables de fixer le gaz carbonique et de le transformer en matière vivante en utilisant comme source d'énergie les radiations lumineuses.

PUBESCENT : garni de poils fins peu serrés, mous et courts.

RADICAL : qui naît de la racine ou de la souche.

RADICANT : couché et émettant çà et là des racines.

RENIFORME : en forme de rein ou de haricot.

RHIZOME : tige souterraine allongée et horizontale ou oblique émettant des tiges et des racines.

ROSETTE : feuilles étalées en cercle autour de la souche, par exemple dans le Pissenlit.

SAGITTEE (feuille) : en fer de flèche.

SCISSIPARITE : forme de multiplication végétative par laquelle l'organisme se divise en de ux parties identiques.

SEPALE : élément du calice.

SINUEE (feuille) : à bords sinueux formant des angles arrondis peu profonds.

STIPULES : appendices foliacés généralement pairs situés de part et d'autre de la tige au niveau des ramifications des feuilles.

STOLON : rejet rampant et muni cà et là de racines, à la façon des "filets" du fraisier.

TRICHOPTERES : ordre d'insectes dont les larves aquatiques vivent à l'intérieur de fourreaux composés de débris végétaux ou miriéraux.

TUBERCULEUX : renflé en tubercule; (graine) couverte de petites granulations.

VASCULAIRES : dont le tissu comporte des vaisseaux et non seulement des cellules.

VERTICILLE : ensemble d'organes disposés en cercle autour d'un axe

VIVACE : plante vivant de nombreuses années.

ZYGOTE : produit de la fécondation des gamètes mâles et femelles 


\section{BIBLIOGRAPHIE SOMMAIRE}

A.C.T.A. - 1973. Le milieu aquatique. Connaissance, entretien, desherbage. 3 fascicules. Imprimerie Couesnon, Thomery, $178 \mathrm{p}, 30 \mathrm{pl}$.

BONNIER G., DELAYENS G., 1974. Flore complète portative de la France et de la Suisse. Librairie générale de l'enseignement éd., Paris, $425 \mathrm{p}$.

CARPENTER S.R., ADAMS M.S., 1977. The macrophyte tissue nutrient pool of a hardwater eutrophic lake : implications for macrophyte harvesting. Aquat. Bot., 3, 239-255.

COSTE H., 1937. Flore de la France. 3 volumes. Paris.

DAWSON F.H., 1978. Aquatic plant management in semi-natural streams. The role of marginal vegetation. J. Environ. Manag., 6, 213-221.

DAWSON F.H., 1978. Seasonal effects of aquatic growth on the flow of water in a small stream. In : European weed Research Society, 5th Int. Symposium on aquatic weeds, 5-8.09.78, $71-78$.

DAWSON F.H., CASTELLANO E., LADLE M., 1978. Concept of species succession in relation to river vegetation and management. Verh. Int. Verein. Limnol., 20, 1429-1434.

FOURNIER P., 1961. Les quatre flores de France. Ed. P. Lechevalier, Paris, 1105 p.

GAUDET J.J., 1974. The normal role of vegetation in water. In : Aquatic vegetation its use and control. Mitchell ed., 24-37, UNESCO.

HUTCHINSON G.E., 1975. A treatise on Limnology. III. Limnological Botany. Wiley. Interscience. New-York, $660 \mathrm{p}$.

JUGET J. et ROSTAN J.C., 1973. Influence des herbiers à Trapa natans sur la dynamique d'un étang en période estivale. Annales Limnol. 9 (1), $11-24$.

MCLINTOCK D., FITTER R.S.R., FAVARGER S. et Cl., 1964. Guide des plantes à fleurs de I'Europe occidentale. Delachaux Niestlé, Neuchâtel, $325 \mathrm{p}$

PHILLIPS G.L., EMINSON D., MOSS 8., 1978. A mechanism to account for macrophyte decline in progressively eutrophicated freshwaters. Aquat. Bot., 4 (2), 103-126.

RICH P., 1970. Utilization of benthic detritus in a marl lake. Ph. D. Thesis, Michigan State University, $187 \mathrm{p}$

SCULTHORPE C.D., 1967. The biology of aquatic vascular plants. London Edward Arnold Ltd, $610 \mathrm{p}$. SYMOËNS J.J., HOOPER S.S., COMPERE P., 1982. Studies on aquatic vascular plants. Bruxelles, 424 p.

WESTLAKE D.F., 1961. Aquatic macrophytes and the oxygen balance of running waters. Verh. Intern. Verein. Limnol., 14, 499-503.

WESTLAKE D.F., 1963. Comparisons of plant productivity. Biol. Rev., 38, 385-425.

WETZEL R.G., 1964. A comparative study of the primary productivity of higher aquatic plants, periphyton and phytoplankton in a large shallow lake. Int. Revue ges. Hydrobiol., 49, 1-61.

WETZEL R.G., 1969. Excretion of dissolved organic compounds by aquatic macrophytes. Bioscience, $19,539-540$.

WETZEL R.G. et HOUGH R.A., 1973. Productivity and role of aquatic macrophytes in lakes. An assessment. Polskie Archiv. Hydrobiol., 20 (1), 9-19. 